\title{
Physical activity : implications for human energy metabolism
}

Citation for published version (APA):

Meijer, G. A. L. (1990). Physical activity : implications for human energy metabolism. [Doctoral Thesis, Maastricht University]. Rijksuniversiteit Limburg. https://doi.org/10.26481/dis.19900216gm

Document status and date:

Published: 01/01/1990

DOI:

10.26481/dis.19900216gm

Document Version:

Publisher's PDF, also known as Version of record

\section{Please check the document version of this publication:}

- A submitted manuscript is the version of the article upon submission and before peer-review. There can be important differences between the submitted version and the official published version of record.

People interested in the research are advised to contact the author for the final version of the publication, or visit the DOI to the publisher's website.

- The final author version and the galley proof are versions of the publication after peer review.

- The final published version features the final layout of the paper including the volume, issue and page numbers.

Link to publication

\footnotetext{
General rights rights.

- You may freely distribute the URL identifying the publication in the public portal. please follow below link for the End User Agreement:

www.umlib.nl/taverne-license

Take down policy

If you believe that this document breaches copyright please contact us at:

repository@maastrichtuniversity.nl

providing details and we will investigate your claim.
}

Copyright and moral rights for the publications made accessible in the public portal are retained by the authors and/or other copyright owners and it is a condition of accessing publications that users recognise and abide by the legal requirements associated with these

- Users may download and print one copy of any publication from the public portal for the purpose of private study or research.

- You may not further distribute the material or use it for any profit-making activity or commercial gain

If the publication is distributed under the terms of Article $25 \mathrm{fa}$ of the Dutch Copyright Act, indicated by the "Taverne" license above, 


\title{
PHYSICAL ACTIVITY
}

\author{
Implications for human \\ energy metabolism
}




\title{
PHYSICAL ACTIVITY
}

\author{
Implications for human \\ energy metabolism
}

\section{PROEFSCHRIFT}

ter verkrijging van de graad van doctor aan de Rijksuniversiteit Limburg te Maastricht, op gezag van de Rector Magnificus, Prof. Dr. F.I.M. Bonke, volgens het besluit van het College van Dekanen,

in het openbaar te verdedigen op vrijdag 16 februari 1990 om 16.00 uur

door

\section{Gerwin Alexander Leo Meijer}

geboren te Emmen 
promotores:

Prof. Dr. F. ten Hoor

Prof. Dr. Ir. W.H.M. Saris

co-promotor:

Dr. K.R. Westerterp

beoordelingscommissie: Prof. Dr, Ir. J.D. Janssen (voorzitter)

Prof. Dr, RA. Binkhorst

Prof. Dr. Tj. de Boorder

Prof. Dr. J.M. Greep

Prof. Dr. H.C.G. Kemper

Prof. Dr. A. Tremblay

\section{CJP-GEGEVENS KONINKLIJKE BIBLIOTHEEK, DEN HAAG}

Meijer, Gerwin Alexander Leo

Physical activity : implications for human energy

metabolism / Gerwin Alexander Leo Meijer; [ill. from the author]. - Maastricht: Datawyse. - III.

Proefschrift Minastricht. - Met lit. opg. - Met

samenvatting in het Nederlands.

ISBN 90-5291-018-9

SISO 599.7 UDC 612(043.3)

Trefw: lichamelijke aktiviteit / stofwisseling /

accelerometer.

Vormgeving: Gerwin Meijer

Omslag: Guus van Rooy

Omslagfoto: Paul Rutten

Fotografie: $\quad$ Audio Visuele Dienst, RL Maastricht

Druk: Datawyse Maastricht / Krips Repro Meppel 
ter nagedachtenis aan mijn vader" aan Inge en Jannes 


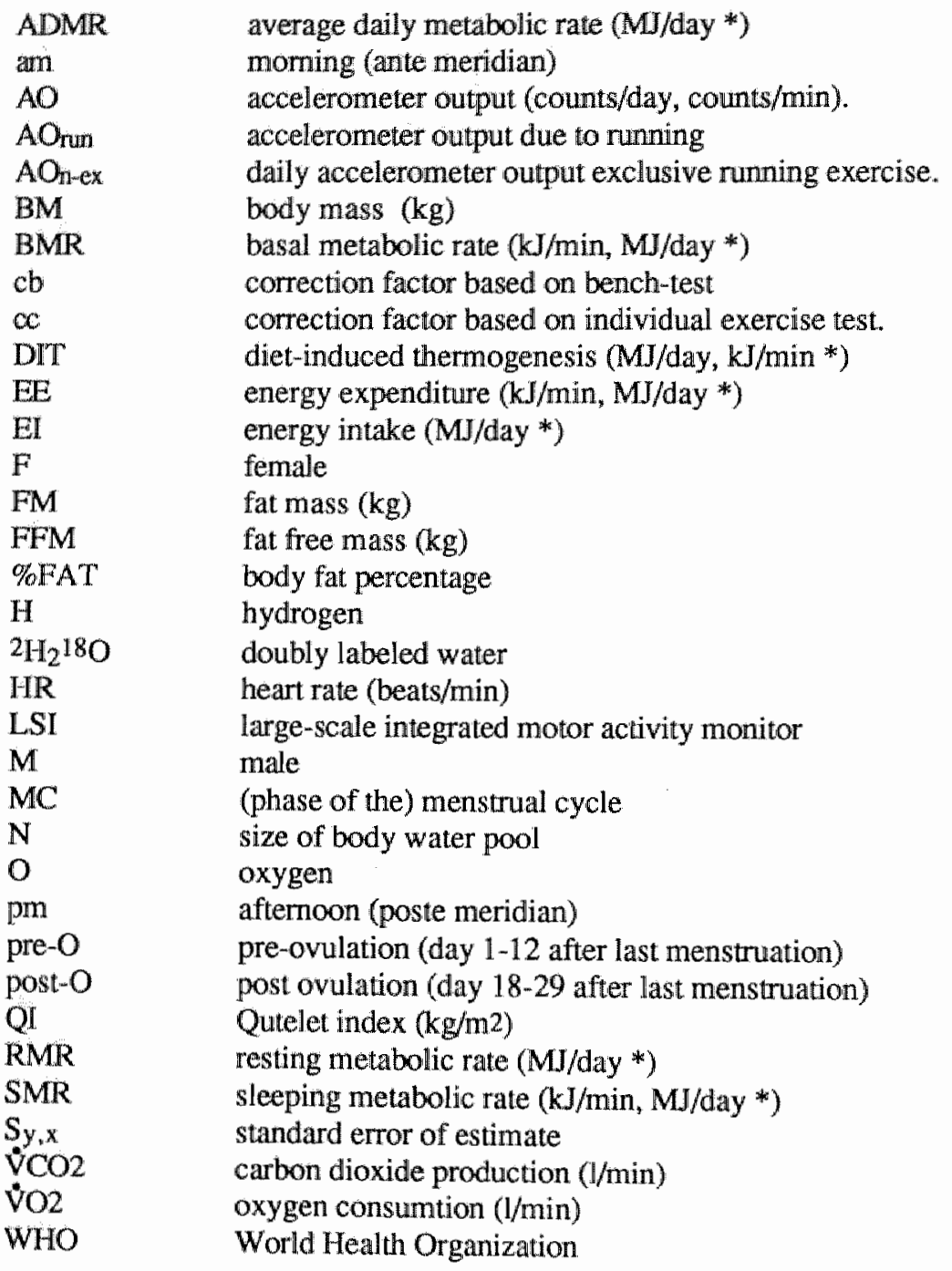

*) All measures of metabolism and energy expenditure are either expressed in $\mathrm{kJ} / \mathrm{min}$ or in $\mathrm{MJ} / \mathrm{day}$, as is usual in the field of human nutrition 


\section{Contents}

Chapter 1 Introduction and outline of the thesis

Chapter 2 Methods to assess physical activity with special reference to motion sensors and accelerometers

Chapter 3 Assessment of energy expenditure by recording heart rate and body acceleration

Chapter 4 Validity of the accelerometer in the field; a comparison with the doubly labeled water technique

Chapter 5 Physical activity and energy expenditure in lean and obese adult human subjects

Chapter 6 The effect of a 5-month endurance-training program on physical activity: evidence for a sex-difference in the metabolic response to exercise

Chapter 7 Body composition and sleeping metabolic rate in response to a 5-month endurance-training program in adults

Chapter 8 Sleeping metabolic rate in relation to body composition and the menstrual cycle

Chapter 9 General Discussion

Summary

Samenvatting

Dankwoord

Curriculum vitae 


\section{Chapter 1}

\section{Introduction and outline of the thesis}

Physical activity is a part of our behaviour which is very complex in its nature and appearance. Behavioural, psychological, physiological and physical aspects may be recognized when studying it (1-3). This thesis will focus on physical activity of human beings regarding body movement and the energy expenditure resulting from it.

Average daily metabolic rate (ADMR) is usually divided into three major compartments: a) resting metabolic rate (RMR), the level of metabolic rate necessary for maintaining the basal functions of the body ; b) diet induced thermogenesis (DIT), also called thermic effect of feeding, representing the energy cost of food processing; and c) energy expenditure due to physical activity. From these three energy compartments, physical activity is beyond doubt the most facultative component contributing to ADMR. This is nicely illustrated in a figure conceived by Ravussin (4) (Fig. 1.1). Here energy expenditure due to physical activity is suggested to vary largely. Whether physical activity may show such large variation is difficult to answer. It requires a technique capable of measuring physical activity under free living conditions with a reasonable accuracy. Up till now, information on this is only available from studies in laboratory settings like

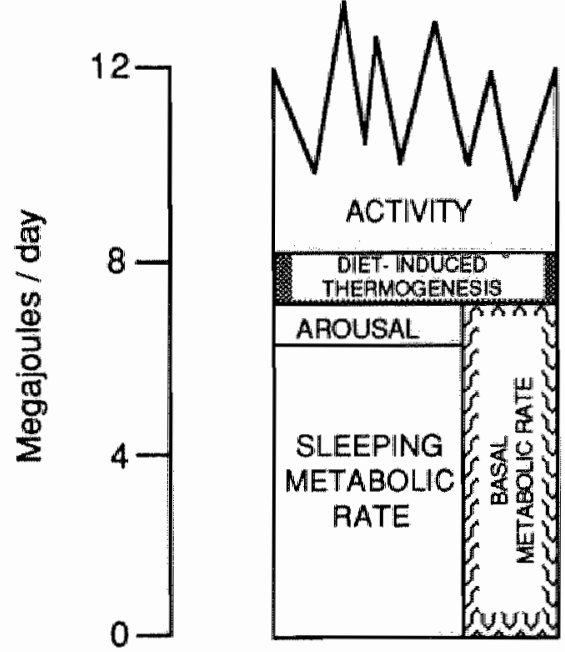

Fig. 1.1 Major compartments contributing to average daily metabolic rate. 
metabolic wards or respiration chambers. There, variation in physical activity is usually very small (5-8). However, in these settings the physical activity level is usually low due to the restrictive nature of the environment.

It has been suggested that a low physical activity level may play a role in the onset of obesity $(9,10)$ and is associated with an increased risk for cardiovascular diseases (11). Consequently, stimulation of physical activity is promoted (12). However, little is known on the impact of physical activity on energy metabolism and other physiological processes. Therefore the study of physical activity of free living subjects is inevitable. The urge of a reliable technique for the assessment of physical activity under these circumstances rises from this conclusion. Apart from reliable, such a technique should be socially acceptable and not interfere with the activity pattern of the subjects.

Most authors agree on the complexity of assessment of physical activity under free living conditions (1,3,13-15). Techniques used for assessment of physical activity mostly fail on one or more of the demands mentioned above. Recently, two new techniques have been introduced for measurement of energy expenditure and physical activity of free living subjects: the doubly labeled water technique and electronic accelerometers.

\section{Measurement of physical activity}

The doubly labeled water technique was developed by Lifson and Mc. Clintock (16) initially for the measurement of energy expenditure in small animals. Administration of water of which both the oxygen and the hydrogen atom are labeled using the stable isotopes $2 \mathrm{H}$ and $18 \mathrm{O}$ leads to labeling of the water pool and the carbondioxide pool of the body. The disappearance rate of $18 \mathrm{O}\left(\mathrm{k}_{\mathrm{O}}\right)$ from the body reflects the rate of water flux through the body plus the rate of $\mathrm{CO}_{2}$-production. The disappearance rate of $2 \mathrm{H}\left(\mathrm{k}_{\mathrm{H}}\right)$ reflects water flux only. Thus, carbondioxide production $\left(\mathrm{C}_{2}\right)$ may be calculated from:

$$
\mathrm{rCO}_{2}=1 / 2 \mathrm{~N} *\left(\mathrm{kO}_{\mathrm{O}}-\mathrm{k}_{\mathrm{H}}\right)
$$

where $\mathrm{N}$ is the size of the body water pool. The factor $1 / 2$ adjusts for the two $\mathrm{H}$ atoms versus one $\mathrm{O}$ in water. This equation underwent some modifications as corrections had to be made for fractionation of water and $\mathrm{CO}_{2}$ which leave the body as gases (17).

The isotopes are administered simply by drinking a glass of the doubly labeled water. After approximately 4 hours the isotopes are completely mixed with body water and carbondioxide, after which they disappear logarithmically. Disappearance rate may be assessed by measuring the isotope concentrations in urine. Using an estimate for the respiratory quotient derived from the average food-quotient total energy expenditure between time of first and last urine sampling can be calculated. In humans, time between the initial and the final sample usually extends from 1 to 3 weeks (18). Reviewing 35 validation studies conducted during the last 30 years Speakman concludes the reliability of the method to be within 7\% (19). It should be stressed this method results in a measure of ADMR. Assessment of energy expenditure due to physical activity can only be established indirectly by subtracting RMR and DIT. These energy compartments may be estimated or separately assessed in the laboratory. Alternatively, the activity level can be 
calculated as ADMR as a multiple of basal metabolic rate (BMR) (20).

In this thesis three measures are used which refer to metabolic rate in a resting statew

SMR Sleeping metabolic rate: metabolic rate of a subject measured from 3.00 $6.00 \mathrm{~h}$ during an overnight sleep in a respiration chamber, at least $9 \mathrm{~h}$ after the last meal, and $36 \mathrm{~h}$ after heavy exercise like training.

BMR Basal metabolic rate: metabolic rate of a lying subject just after waking up, completely inactive, and in a fasting state. In this thesis BMR is always calculated using the equations of Harris and Benedict (21).

RMR Resting metabolic rate: metabolic rate of an inactive subject (sitting, lying, sleeping) at any time of the day mostly but not necessarily in a fasting state.

BMR is usually slightly higher $(\sim 5 \%)$ than SMR (22). In this thesis we subtract SMR from ADMR for calculation of the energy compartment due to activity. DIT is assumed to be a constant fraction of ADMR, thus adding little in the variation of ADMR-SMR.

A direct measure of physical activity may be obtained using an accelerometer. This instrument records both intensity and duration of body movement (23). Reliability of mechanical accelerometers (actometers) however is poor $(1,24,25)$. Electronic accelerometers have only recently been introduced (26). Results show that the method is valid. However, little is known about the reliability and accuracy of the method (14).

Summarizing, both techniques are highly socially acceptable and show little interference with spontaneous activity of the subject. The doubly labeled water technique is probably the best technique available at the moment for assessment of energy expenditure under free living conditions (3,13-15). Accelerometers give more direct information on intensity and duration of physical activity.

\section{Physical activity and abesity}

Storage of surplus energy in body fat is a growing problem in our Western society where food supply is merely unlimited, and energy expenditure is decreasing due to mechanization. Obesity is characterized by an excess of body fat mass (27). It is associated with increased risks for hypertension, diabetes, hypercholesterolemia, and cardiovascular diseases $(28,29)$. Using the Quetelet index $\left(\mathrm{QI}=\right.$ body mass $(\mathrm{kg}) /$ height $^{2}$ $(\mathrm{m}) ;(30)$ ) Seidell et al. (31) showed $34 \%$ of women and $24 \%$ of men of the Dutch population to be moderately obese $(25<\mathrm{QI}<30)$ while $4 \%$ of women and $6 \%$ of men were severely obese $(\mathrm{QI}>30)$.

The role of physical activity in obesity is unclear $(10,27)$. Several authors found obese people to be less active than lean people $(9,32,33)$. Decreased physical activity may result in a positive energy balance since food intake in obese and lean subjects is mostly found to be equal $(34,35)$. However, in most recent studies on physical activity in lean and obese people no differences were found $(36,37)$. Neither have the obese been shown to be more efficient in their efficiency of food processing $(38,39)$, DIT $(40,41)$, or RMR 
$(7,8)$ when the outcome is adjusted for their higher BM or FFM. Thus all data suggest that no metabolic disorder is associated with obesity, and overeating may be the most probable cause. However, as mentioned above measurement of physical activity under free living conditions is cumbersome. In an extensive review on physical activity in the obese Thompson et al (10) found 9 studies in which the obese were less active than nonobese, while in 7 studies no difference was reported. In these 16 studies a variety of methods was used to assess physical activity. When these methods are categorized, it appears that from 8 studies using teacher ratings, activity diaries and observational- and recall techniques, 6 report the obese to be less active, while from 8 studies using pedometers, actometers, heart rate monitors or other movement recorders, only three do so. Thus the different findings on physical activity in the obese compared to lean subjects may be due to errors in the assessment of physical activity.

\section{Physical activity and energy metabolism}

Of all the three energy compartments RMR, DIT and physical activity, both intra- and inter-individual variation is highest in physical activity. It is the only energy compartment which may be changed consciously. Energy expenditure may increase or fall depending on what we plan and want to do. Physical activity has been shown to increase activity of the sympathetic nervous system (42) as a result of which other processes that act on energy balance may be stimulated or inhibited $(43,44)$. Numerous studies have shown post-exercise RMR to be increased (45-47). However, others failed to show a postexercise increase in RMR $(43,48,49)$. The post-exercise increment in RMR does not seem to be adaptive as it increases expenditure to a further extent. Short-term effects as restorage of muscle glycogen and clearing the oxygen debt may be mainly obligatory (50). Nevertheless, a long term increase in RMR as a response to increased physical activity does not seem logical from a biological point of view. Yet data from crosssectional studies suggest that RMR may be increased in subjects with a high habitual activity level (51-53). It is unclear whether this increase reflects differences in body composition only. A long-term effect of physical activity on RMR would have large implications for the treatment of obesity. Adding exercise to a slimming diet would not only raise expenditure due to the added exercise itself but might also inhibit the fall in RMR which usually accompanies caloric restriction.

The effect of physical activity on DIT is highly controversial. Some authors showed post-exercise DIT to be decreased $(54,55)$. However, in a respiration chamber study using most accurate techniques to measure and manipulate energy balance, Saris et al. found no effect of exercise on RMR and DIT during overfeeding (56). Nevertheless DIT may be expected to be prone to effects of exercise as it is believed to consist of an obligatory and a facultative component of which the latter responds to activity of the sympathetic nervous system (57).

Last but not least physical activity may be a self-stimulating process. Elite athletes are known to be exercise-dependent, and people who raise their activity level often report an 
increased feeling of well being. Heavy sustained exercise may cause the release of endorphins in the brain, as a result of which addiction to exercise may occur (58). Alternatively, Thompson (59) suggests adaptive responses to exercise might reduce physiological arousal to the pre-training level. Thus subsequently higher exercise levels are necessary to maintain the established feeling of well being.

Summarizing, physical activity may be voluntarily changed and changes in physical activity level may affect other energy compartments. Therefore the overall effect on energy balance may be larger or smaller than expected on the basis of the energy cost of activity itself. The effects on energy balance may be due to changes in body composition (i.e. FFM) only and may also be mediated by the sympathetic nervous system. Further investigation of these relationships in normal healthy subjects is needed.

\section{Outline of the study}

Summarizing, from literature the following major conclusions can be drawn:

1 Physical activity is positively related to different aspects of health. As physical activity in our society may be expected to decrease due to mechanization, stimulation of leisure time activities may prove useful for prevention of various diseases, and in the treatment of obesity.

2 Measurement of physical activity under free living conditions is cumbersome and the reliability of different techniques used in the past is questionable. The recently introduced doubly labeled water technique is accurate, but does not measure physical activity directly. The accelerometer may prove to be a satisfying instrument for the assessment of physical activity. Its accuracy and reliability need to be examined.

3 The role of physical activity as causing factor of obesity is unclear. Reexamination of physical activity levels in obese and lean subjects using the new techniques mentioned above may lead to new insights.

4 Physical activity is the only energy compartment we can change consciously. The effects of increasing physical activity on energy metabolism and body composition are controversial.

In the present thesis each of these issues will be addressed. The next three chapters deal with the validity and reliability of an accelerometer developed in our department under laboratory and outdoor conditions. Chapter 5 reports on a comparison of habitual physical activity in obese and lean subjects, using both the accelerometer and the doubly labeled water technique. Furthermore, a study was conducted to measure the effects of a 20 week endurance-training program on energy metabolism in normal healthy subjects with an initially low activity level. Habitual physical activity, average daily metabolic rate, sleeping metabolic rate, exercise performance, and body composition were assessed 
before and 8 and 20 weeks after start of the training program. Food intake was ad libitum. The results are described in Chapters 6 and 7 . In Chapter 8 material of both studies was combined to examine more closely the relationship between body composition, the menstrual cycle, and sleeping metabolic rate.

\section{References}

1 Tryon,WW. Behavioral assessment in behovioral medicinie. New York, Springer, 1985.

2 Caspersen, CC, KE Powell, and GM Christenson. Physical activity, exercise and physical fitness: Defininions and distinctions for health-related research. Publ Healith Rep 100, 126-131, 1985.

3 LaPorte, RE, HJ Montoye, and CJ Caspersen. Assessment of physical activity in epidemiological research : problem and prospects. Publ Health Rep 100, 1311-146, 1985.

4 Ravussin, $\mathrm{E}$, and $\mathrm{C}$ Bogardus. Relationships of genetics, age, and physical finess to daily energy expenditure. Am J Clin Nutr 49, 968-975, 1989.

5 Garby $\mathrm{I}_{-,} \mathrm{O}$ Lammert, and E Nielsen. Energy expenditure over 24 hours on low physical activity programmes in human subjects. Hum Nutr: Clin Nutr 40C, 141-150,1985.

6 Schulx, $X, F$ Froidevau $x_{v}$ and $E$ Jequier. Estimation of 24 h energy expenditure by a poriable accelerometer. Proc Nutr Soc 47, 23A, 1988.

7 Webb. P. Energy expenditure and fat-free mass in men and women. Am J Clin Nutr 34, 1816$1826,1981$.

8 Rawussin, $\mathbb{E}_{\mathrm{w}} \mathrm{B}$ Burnand, Y Schutz, and $\mathrm{E}$ Jéquier. Twenty-four hour energy expenditure and resting metabolic rate in obese, moderately obese, and control subjects. Am J Clin Nutr 35, 566-573, 1982.

9 Bloom, WL and MF Eidex. Inactivity as a major factor in adult obesity. Metabolism 16, 679-684, 1967.

10 Thompson, JK, GJ Jarvie, BB Lahey and KJ Cureton. Exercise and obesity: Etiology, physiology, and intervention. Psychol Bull 91, 55-79, 1982.

11 Brown, $\mathrm{KS}$, and $\mathrm{P}$ Milvy. A critique of several epidemiological studies of physical activity and its relationship to aging, health and mortality. Ann NY Acad Sci 301, 703-713, 1977.

12 Paffenbarger, RS, and RT Hyde. Exercise in the prevention of coronary heart disease. Prev Med 13, $3-22,1984$.

13 Montoye, HJ and HL Taylor. Measurement of physical activity in population studies : A review. Hum Biol 56, 195-216, 1984.

14 Saris, WHM. Habiual physical activity in children: methodology and findings in health and diserise. Med Sci Sports Exerc 18, 253-263, 1986.

15 Acheson, KJ, IT Campbell, OG Edholm, DS Miller, and MJ Stock. The measurement of daily energy expenditure a an evaluation of some techtiques. Am J Clin Nutr 33, 1155-1164, 1980.

16 Lifson, $\mathrm{N}$, and R McClintock. Theory of the we of the turnover rates of body water for measuring energy and material balance. J Theor Biol 12,46-74, 1966.

17 Schoeller, DA, E Ravussin, Y Schutz, KJ Acheson, P Baertschi, and E Jéquier. Energy expendiuure by doubly labeled water: validation in humans and proposed calculation. Am I Ploysiol 250, R823R830, 1986.

18 Westerterp, KR, WHM Saris, M van Es and F ten Hoor. Use of the doubly labeled water technique in humans during heavy sustained exercise. J Appl Physiol 61(6), 2162-2167, 1986.

19 Speakman, JR. The doubly labelled water techniqu: principles, problems and a paradox. Statistics in Medicine 1989 (in press).

20 World Health Organization. Energy and protein requirements, report of a joint FAO/WHONUNO expert consultation. Technical Report Series 724, Geneva, 1985: 71-79.

21 Harris, IA and FG Benedict. A biametric study of basal metabolism in man. Carnegie Institution of Washington, 1919.

22 Goldberg, GR, AM Prentice, HL Davies, and PR Murgatroyd. Overmight and basal metabolic rates in men and women. Eur J Clin Nutr 42, 137-144, 1988. 
23 Servais, SB, JG Webster, and HI Montoye. Estimating hwow energy expendinure using an accelerometer dewice. J Clin Eng 9, 159-170, 1984 .

24 Kemper, HCG and R Verschuur. Validity and reliability of pedometers in habinal activity research. Eur J Appl Physiol 37, 71-82, 1977.

25 Morrell, EM and FJ Keefe. The actometer: an evaluation of instrament applicability for chromic pain patients. Pain $32,265-270,1988$.

26 Montoye, HJ, R Washbum, S Servais, A Ertl, JG Webster, and F Nagle. Estimation of energy expenditure by a portable accelerometer. Med Sci Sports Exerc 15, 403-407, 1983.

27 Garrow, JS. Energy bolance and obesity in man. Amsterdam, North Holland Publishing Conpany, 1974.

28 Burton, BT, WR Foster, J Hirsch, TB Van Itallie. Healh implications of obesity: an NH consensus developmewt conference. Int J Obes 9, 155-169, 1985.

29 Royal College of Physicians. Obesity. A report of the royal college of physicians, reprinted from J Royal Coll Phys 17, 1983.

30 Quetelet, LAJ. Anuropométrie ou mesure des différentes facultés de l'homme. Brussels; Muquatdt, 1871.

31. Seidell, JC, CPGM de Groot, JLA van Sonsbeek, P Deurenberg, and JGAJ Hautvast, Associations of moderate and severe overweighr with self-reported illness and medical care in Duch adults. Am J Publ Health 76, 2644-269, 1986.

32 Dorris, RJ, AJ Stunkard. Physical activity: performance and atuitudes of a group of obese women. Am J Med Sci 223, 622-628, 1957.

33 Chirico, AM, AJ Stunkard. Physical activity and human obesity. N Engl I Med 263, 935-940, 1960.

34 Widdowson, EM. A study of english diets by the individual merhod. Part I: Men. Hyg 36, 269. $292,1936$.

35 George, V, A Tremblay, JP Despres, C LeBlanc, L Perusse and C Bouchard. Evidence for the existence of small eaters and large eaters of similar fat-free mass and activity level. Int J Obes 13 , 43-53, 1989.

36. Tryon, WW. Activity as a funcrion of body weight. Am J Clin Nutr 46, 451-455, 1987.

37 Prentice, AM, AE Black, WA Coward, et al. High levels of energy expenditure in obese women. Brit Med J 292, 983-987, 1986.

38 Webb, $\mathrm{P}$, and T Abrams. Loss of fat stores and reduction in sedentary energy expenditure from undereating. Hum Nutr: Clin Nutr 37C, $271-282,1983$.

39 Boer, de JO, AJH van Es, JMA van Raaij, and JGAJ Hautvast. Energy requirements and energy expenditure of lean and overweight women, measured by indirect calorimetry. Am J Clin Nutr 46, 13-21, 1987.

40 Felig, P, J Cunningham, M Levitt, R Hendller, E Nadel. Energy expenditure in obesity in fasting and posiprandial state. Am J Physiol. 244, E45-51, 1983.

41 Weststrate, JA, P Deurenberg, and JGAJ Hautwast. Natwre and magnisude of inter-individuet differences in resting meiabolic rate and diet-induced thermogenesis in lean and obese indiwduals. PhD. Thesis, Wageningen, The Netherlands, 1989, pp. 140-159,

$42 \mathrm{Kjor}, \mathrm{M}$. Epinephrine and some other hormonal responses to exercise in man: with special reference to physical Iraining. Int J Sports Med 10, 2-15, 1989.

43 Pochiman, ET, A Tremblay, A Nadeau, J Dussault, G Thériault, and C Bouchard. Heredity and changes in hormones and metabolic rates with short-term training. Am J Physiol 250, E 711 . E717, 1986.

44 Acheson, KI, E Ravussin, DA Schoeller, L, Christin, L Bourquin, P Baertschi, E Danfortli, and E Jequier. Two-week stimulation or blockade of the sympathetic nervous system in man. Influence on body weight, body composition, and twenty four-hour energy expenditure. Metabolism 37. 91 98,1988 .

45 Bielinski, $\mathrm{R}, \mathrm{Y}$ Schulz, and $\mathrm{E}$ Jequier. Energy metabolism during the postexercise recovery in man. Am IClin Nutr $42,69-82,1985$.

46. Maehlum, S, M Grandmontagne, EA Newsholme, and OM Sejersted. Magnitude and duration of excess postexercise oxygen consumption in healihy young subjects. Metabolism 35, 425-429., 1986. 
47 Bathi, R, I Ingnes, O Vaage, OM Sejersted, and EA Newsholme. Effeci of duration of exercise on ercess postexercise 02 consumption. I Appl Physiol 62,485490, 1987.

48 Firedman-Akabas, S, E Colt, HR Kissileff, FX Pi-Sunyer. Lack of sustained increase in VO2 following exercise in fit and unfit subjects. Am J Clin Nutr 41, 545-549, 1985.

49 Bingharn, SA, GR Goldberg; WA Coward, AM Prentice, and JH Cummings. The effect of exercise and improved physical fitness on basal metabolic rate. Brit J Nutr $61,155-173,1989$.

50 Gaesiser, GA, and GA Brooks. Metabolic basis of excess post-exercise oxygen consumption: a review. Med Sci Sports Exerc 16, 29-43, 1984

51 Owen, $O E, \mathbb{E}$ Kavle, RS Owen et al. A reappraisal of caloric requirements in thealthy women. Am J Clin Nutr $44,1-19,1986$.

52 Tremblay, A, E Fontaine, and A Nadeau. Contribution of postexercise incremem in glucose siorage 10 variations in glucose-induced thermogenesis in endurance athletes. Can I Physiol Pharmacol 63. $1165-1169,1985$.

53 Westerterp, KR, GAL Meijer, WHM Saris , PB Soeters, Y Winants, and F ten Hoor. Physical activity and sleeping metabolic rate.(submitted for publication).

54 Tremblay, A, J Côtc, and J LeBlanc. Diminished dietary thermogenesis in exercise-irained human \$ubjects. Eur I Appl Physiol 52, 1-4, 1983.

55 Segal, KR, B Gutin, AM Nyman, and FX Pi-Sunyer. Thermic Effect of food at rest, during exercise, and after exercise in lean and obese men of similar body weight. I Clin Invest 76, 1107 $1112,1985$.

56 Saris, WHM, KR Westerterp, and F ten Hoor. The prolonged effect of exercise on energy balance during over-feeding. Proc 5th Int Congres Obesity, Jerusalem, Sept. 14-19, 1986, pp. 64.

57 Sims, EA. Energy balance in human beings: the problems of plenitude. Vitam Horm 43, 1-101, 1986.

58 Bortz, WM, P Angwin, IN Mefford, MR Boarder, N Noyce, and JD Barchas. Catecholamines, dopamine and endorphin levels during extreme exercise. $\mathrm{N}$ Engl J Med 305, 466-467, 1981.

59 Thompson, $\mathrm{KJ}$, and P Blanton. Energy conservation and exercise dependence. a sympathetic arousal hypothesis. Med Sci Sports Exerc 19, 91-99, 1987. 


\title{
Chapter 2
}

\section{Methods to assess physical activity with special reference to motion sensors and accelerometers}

\author{
G.A.L. Meijer, K.R. Westerterp, F. Verhoeven, H. Koper, and F. ten Hoor
}

submitted for publication

\section{Abstract}

Motion sensors may be applied for the assessment of physical activity. This paper reviews the evolution of these instruments from the mechanical pedometer to the electronic accelerometer. We conclude that for accurate assessment of physical activity under free living conditions the recently introduced accelerometer looks most promising, although little information was available regarding the reliability of these instruments.

Subsequently, reliability of an accelerometer with at three directional sensor was examined. Intra-instrument variation in a bench test was less than $8 \%$ during 4 measurements over a week. Inter-instrument variation during treadmill experiments while subjects wore two accelerometers at the same time was on average $22 \%$ and was not improved after adjustment for differences found in the bench test. Reproducibility in the treadmill experiment was approximately $24 \%, 15 \%$ and $5 \%$ at $3 \mathrm{~km} / \mathrm{h}, 5 \mathrm{~km} / \mathrm{h}$ and $7 \mathrm{~km} / \mathrm{h}$, respectively. Bench testing revealed that the sensitivity of a piezo-electric element is prone to shifts, probably due to mechanical, electro-magnetic and/or temperature shock, which may be encountered during outdoor application. However, the relevance of the bench test in this study may be questioned, as results did not correspond with the findings in subjects. This needs further investigation. 
The development and use of accelerometers for monitoring physical activity: a review

Physical activity, being an important part of human behaviour, may be related to various aspects of health and disease. The study of these relationships is difficult and cumbersome mostly due to the complex nature of physical activity and the resulting difficulties in measuring it. For a long time, observational techniques were the only reliable methods to get an impression of physical activity. However, this approach is costly, not free of the subjective judgement of the observer and not of any use if larger groups must be studied. Therefore there is a need for a more practical and objective method to measure physical activity in clinical settings, epidemiological research and behavioural studies. Together with heart rate monitoring the development of motion sensors was an attempt to produce such an objective technique. This chapter gives a short review of the development of motion sensors, from mechanical devices up to more recently developed electronic accelerometers, after which the rationale and the reliability of the latter techniques will be dealt with.

\section{Mechanical motion sensors}

One of the earliest mechanical motion sensors is the pedometer, a stepcounter that consists of an arm balanced by a delicate spring. It is worn at the ankle or at the waist and in each step the impulse of the foot when landing will result in swinging of the balanced arm which through a series of gears is registered in a counting mechanism (Fig. 2.1 a). The pedometer may be calibrated for stride length of the subject to convert steps into distance walked $(1,2)$. Strictly spoken the pedometer is not an accelerometer since it does not reflect the intensity of the movement. Hence, differences in energy expenditure are not accurately assessed (3). Also the validity and reliability are rather poor $(3,4,5,6,7)$.

The actometer, as proposed by Schulman and Reisman (8) is a modified wristwatch of which the escape mechanism has been removed, whereby any rotation of the rotor will be directly transduced to the hands (Fig. 2.1 b). Activity can be interpreted from the resulting time displayed on the watch. This device reflects the amount and intensity of body movement and shows a fairly good correlation with energy expenditure in a variety of circumstances $(3,9,10)$. Despite a good reproducibility when used during standardized movements $(3,8,11,12)$ and a good test-retest reproducibility $(r=0.67)(13)$, the actometer shows a very large inter-instrument variability which makes individual calibration essential $(3,10,14)$. 


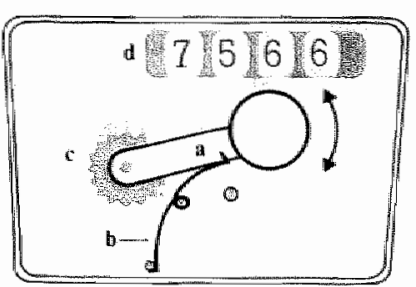

Fig. 2.1 a Schematic drawing of a pedometer. ( $a=$ arm, $b=$ spring, $c=$ gearing, $d=$ counter, arrow indicates movement of the arm).
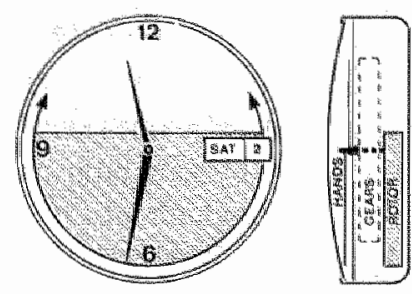

Fig. 2.1 b The actometer.

\section{Electronic motion sensors}

The current generation of motion sensors is the electronic counterpart of the mechanical devices described above. Their evolution is the logical consequence of the development of integrated circuits during the last decade resulting in devices small enough to be socially acceptable. The first descriptions of electronic devices using the principle of measuring accelerations date from the early seventies $(15,16,17,18)$. They were used to assess body movement in psychiatric patients $(18,19)$ or to assess the increase in physical activity coinciding with the estrus in cattle (20). Based upon the type of sensor that is used two types of instruments can be recognized.

The first type is the large-scale integrated motor activity monitor (LSI) $(19,21,22)$. The sensor of the LSI consists of a cylinder with a ball of mercury. Inclination or declination of the sensor results in closing a switch by the mercury ball, which is registered in a counter. Montoye (23) reports test-retest coefficients of 0.44 to 0.98 for a mercury switch on the wrist and of 0.10 to 0.85 when the switch is worn on the waist in 4 subjects performing 14 standardized activities. Principle and accuracy of measurement of the LSI are comparable with those of the pedometer.

The second type of electronic movement counters are real accelerometers. Although different types of sensors have been proposed $(17,18,24,25,26)$ they all make use of the characteristics of piezo-electrical ceramics, the major property of which is that they evoke a charge when deformed in a special direction. The magnitude of the resulting voltage is directly related to the extension of the deformation. Deformation of the ceramic plate can be mechanically amplified by attaching a small mass to it $(24,26)$, or by the mass of the plate itself when it is clamped into a cantilever position $(17,18,25)$. Servais et al. showed that the instrument is valid in that it measures body acceleration very accurately compared to the output of a force platform (25). Also high correlation coefficients $(0.74-0.92)$ have been reported between accelerometer readings and energy expenditure measured by indirect calorimetry under different circumstances $(24,26,27)$. Unfortunately, up till now, 
there is very little information available on the reliability of the technique. Nevertheless, it is obvious that, of all portable movement counters, the electronic accelerometers are the most promising ones due to their accuracy in measuring accelerations, the ease of calibration by gain adjustment, and the still growing possibilities of data storage on a single chip which will extend the length of time a subject can be studied as well as diminish the time resolution to shorter intervals.

\section{A rationale for the use of accelerometers to assess physical activity and estimate energy expenditure}

\section{Physical activity, movement of the body}

Where the rationale for application of direct and indirect calorimetry lies in the laws of thermodynamics, the rationale for the use of accellerometers to measure physical activity lies in the mechanical laws of Newton. It can be stated that the goal one is aiming at when using an accelerometer is to assess movements of the body in order to get a quantitative measure of physical activity. Before outlining the rationale of movement counters for measuring physical activity we need a definition of physical activity in terms of body movement and its energetic consequences. It is clear that all physical activity is due to muscle contraction and will lead to energy output in heat loss and external work. This work may have dynamic properties, as in movement of the body, or static properties as in weight bearing. All body movements will have their concurring accelerations and decelerations. A large amount of empirical data shows a linear relationship between the integral of body acceleration and energy expenditure or oxygen uptake (28-31). Therefore it seems reasonable that the measure of the integral of the absolute value of body acceleration serves as a good estimate of energy expenditure.

However it is too simple to state that physical activity is equivalent to movement (32,33). Neglecting the energy expenditure due to static work may have a large impact on the conclusions drawn from studies on physical activity, in particular when comparing subjects of different body mass (34) " or when comparing subjects which may be expected to differ mainly in the amount of static work they perform (35). The extra cost of weight bearing that occurs in the obese can be stressed by taking body mass in consideration when interpreting accelerometer readings in terms of energy expenditure, as is usually done by expressing the caloric equivalent of the accelerometer readings per $\mathrm{kg}$ body mass $(23,26)$. However, static work due to lifting objects or climbing stairs cannot be expected to be accurately quantified by measuring body movement. One has to make the assumption that static work will only be of a small magnitude in the context of normal daily physical activity, and it should always be considered whether this assumption is 
valid for the population studied. Nevertheless, most researchers seem to agree on the validity of this assumption, when suggesting that dynamic activities such as walking are the major contributors to physical activity in normal daily life $(4,6)$.

\section{Site of attachment}

If one would like to assess all body accelerations due to muscular activity the subject would end up as a "christmas tree" full of accelerometers. In normal practice only one accelerometer is used, either attached to one of the limbs, or to the waist. The main question to be answered here is: where on the human body should the accelerometer be attached in order to obtain the most accurate estimate of energy expenditure? Tryon (12) refers to this as the "site of attachment issue". From a theoretical point of view, regarding the mechanical laws, it seems clear that the sensor should be attached to the trunk, since this part of the body represents most of the body mass. It is for this reason that Cavagna et al. $(36,37)$ placed the accelerometer on the back, at the lumbosacral level as close as possible to the center of gravity of the body, when studying external work in walking and running. Nevertheless, one might argue that attachment to one of the limbs should be favored as this would more closely assess walking habits (4). Although the swinging of the leg in walking and running will be clearly measured in this way, the attachment to the back seems superior, since: 1 ) it has been shown that body accelerations as a result of walking are very well detectable at this site (38-41), and can be measured with a high reproducibility (42) and 2) it is not necessary to choose between the dominant or the nondominant leg, considering the asymmetry of muscle forces that appear in normal human gait (43).

However, when attaching the accelerometer on the back or on the waist the assumption has to be made that the larger movements of the body (e.g. walking, running, jumping) have the greatest impact on daily activity level and that influence of the smaller movements of the limbs (fidgeting) is negligible. Avons et al. (10) report on a complex technique using heart rate as well as three actometers, one at the wrist, one at the waist and one on the leg. In five out of 12 subjects the wrist readings significantly improved the model of only one leg reading, compared with indirect calorimetry in a respiration chamber. Yet it is unclear whether these five subjects were fidgeting more than the others. Avons concludes that if one sensor should be used it certainly would have to be on the leg, but this conclusion is probably due to the fact that he used an actometer, an instrument which is most sensitive to rotation (swinging). In a study with children Saris et al. (4) did not find a relation between actometer results from the wrist and daily physical activity based on observation score. This in contrast to the results obtained from ankle readings (actometer) or waist readings (pedometer). 
Reliability of the accelerometer

The accelerometer used in this study

Previously we described an accelerometer based upon a three directional sensor (26). Data were stored using a portable tape recorder. Disadvantages were that tapes had to be changed every $24 \mathrm{~h}$ and that the size of the recorder was quite large which discouraged subjects to wear it for more than a few days. In an attempt to challenge these problems we developed a new small data acquisition unit with a solid state memory (Fig. 2.2.a and b). The sensor is built in in a plastic housing which has two wide slits by means of which it can be easily attached to a waist belt. The sensor weighs about $25 \mathrm{~g}$ and is connected to a small unit ( $4 \times 6 \times 8 \mathrm{~cm} / 350 \mathrm{~g})$ which carries the equipment for data acquisition and data storage as well as a rechargable battery unit.

A block diagram of the the data acquisition unit is given in Fig. 2.3. The signal of the acceleration sensor first passes a low pass filter of $30 \mathrm{~Hz}$ to disable signals with higher frequencies - which cannot be expected to arise from body movement - from further processing. After filtering, the signal is amplified, rectified, and integrated. Calibration of the instrument is possible through adjusting the gain of the integrator. A 1 min time pulse from the built in timer triggers the conversion of the analogue value of the integral to an 8 bit value, which is stored in memory, after which the integrator is reset. Thus data are expressed in counts/min. Power consumption of the device is less than $1 \mathrm{~mA}$. Recharging of the four nickel-cadmium cells is necessary only once every three weeks. However, batteries were recharged before every 7-day measurement period.

The sensor of this new accelerometer is exactly the same as the one previously described (26; see Fig. 3.1). It is sensitive in three directions and accelerations from any direction will add up to one signal. The most important differences with the formerly used cassette recorder technique lie in the acquisition and storage of the data. Due to the 8-bit $\mathrm{AD}$ converter the maximum scaling of the data is 256 counts/min. Since the integrator tends to have an offset of $\sim 25$ counts/min the effective range is from 0 to approximately 230 counts/min. The solid state memory consists of a $16 \mathrm{Kbyte}$ random access memory which enables monitoring during 11 days with a time resolution of $1 \mathrm{~min}$. Afterwards data can be read out by means of a serial interface connected to the 25 pin D-connector of the device and may be further processed on any personal computer system. 


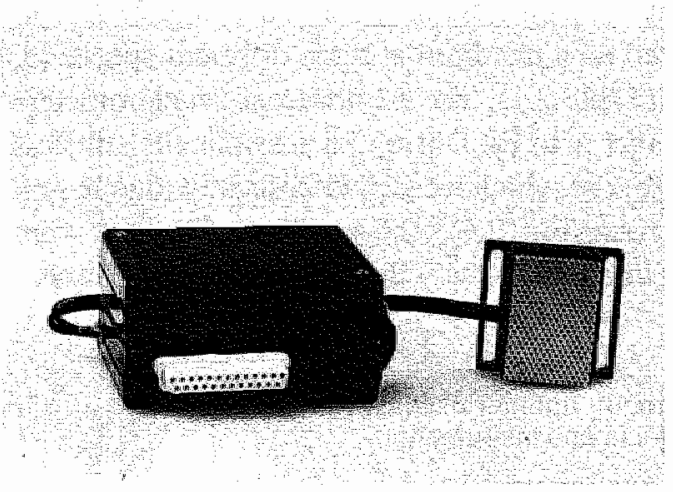

Fig. 2.2.a The accelerometer used in this study. Data acquisition unit (left), sensor (right).

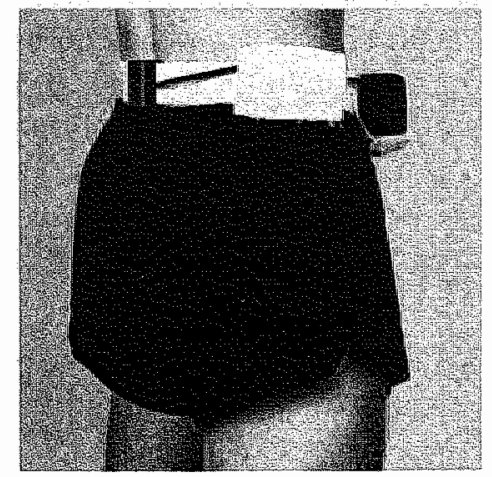

Fig. 2.2.b Subject wearing a belt carrying the accelerometer.The sensor is applied at the back.

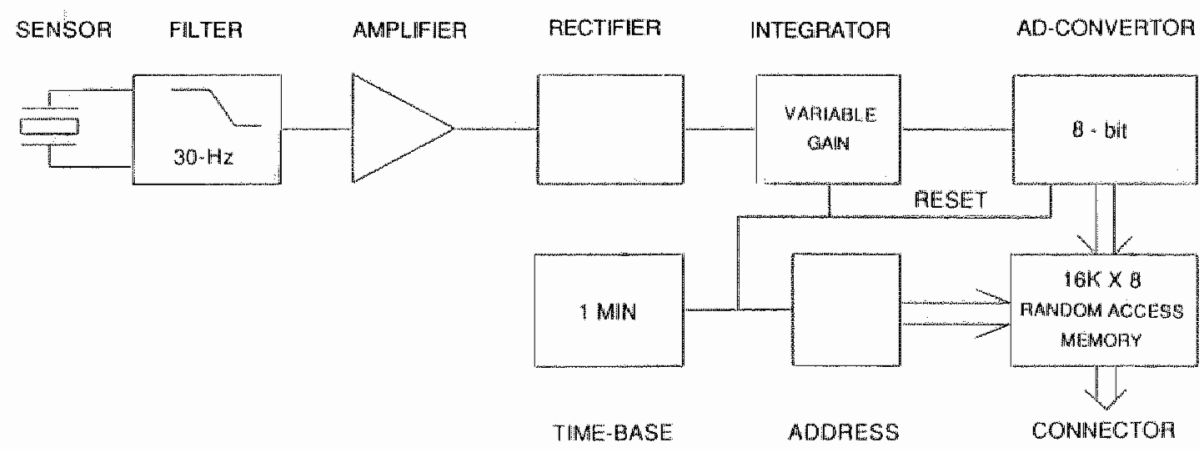

Fig. 2.3 Block diagram of the portable accelerometer with solid state memory. 


\section{Experimental design}

In order to cover questions conceming the reproducibility of the instrument as well as concerning the inter-instrument and inter-individual variation, a latin square type of protocoll was designed in which four healthy subjects ( 2 males, 2 females; age $22 \pm 1 \mathrm{yr}$, length $179 \pm 6 \mathrm{~cm}$, weight $66 \pm 9 \mathrm{~kg}$ ) walked on a treadmill at three different speeds (3, 5 , and $7 \mathrm{~km} / \mathrm{h}$ ) for five min at each speed (Table 2.1). The 12 different accelerometers used in this study were diwided in six sets (set A to F). During all sessions the subjects wore one set of two accelerometers the sensors of which were placed closely together on the same waist belt at the lower part of the back (Fig. 2.4). The sessions with set A were repeated in a second trial one week after the first trial to study the reproducibility in time.

Table 2.1 Design of the experiment; number of trials with different combinations of subjects and instruments

\begin{tabular}{ccccccc}
\hline $\begin{array}{c}\text { device set } \\
\text { device no. }\end{array}$ & $5 \& 11$ & $9 \& 12$ & $1 \& 3$ & $4 \& 7$ & $13 \& 14$ & $10 \& 8$ \\
subject & & & & & & \\
1 & 2 & 1 & 1 & & & \\
2 & 2 & & 1 & 1 & & \\
3 & 2 & & & 1 & 1 & 1 \\
4 & 2 & & & & 1 & 1 \\
\hline
\end{tabular}

\section{Bench test}

All devices were tested in a standardized way (bench test). A speaker connected to a frequency oscillator with variable amplitude settings was used to produce up and down movements. The accelerometer shows a linear response both to frequency and amplitude of the movement (Fig $2.5 \mathrm{a}$ and b). Therefore one frequency and amplitude setting may serve for calibration purposes. The response to a movement with a frequency of $5 \mathrm{~Hz}$ and an amplitude of $0.6 \mathrm{~mm}$ was chosen, as these values lie close to those that may be expected on the lower part of the back $(41,44)$; they result in an output of approximately $75 \%$ of the maximum output of the device. Correction factors were calculated converting the output of the accelerometer to 150 counts/min.

One day before and after the treadmill sessions the accelerometers were calibrated using this bench test. Thus four trials were conducted, two trials within $48 \mathrm{~h}$ being repeated after one week. Analysis of the treadmill sessions were conducted both on the uncorrected data and the corrected data to study the effectiveness of these corrections.

To study the accuracy and reproducibility of the instrument, percentage differences between first and second trial were calculated for each different speed, individual and instrument. Also an analysis of variance (Anova) was conducted on the data of set A to reveal inter-individual differences. 
The coefficient of variation (CV) of the 1 min readings during each five min of exercise was calculated as a measure of within measurement reproducibility.

Fig. 2.4 Application of the two sensors in the treadmill experiment
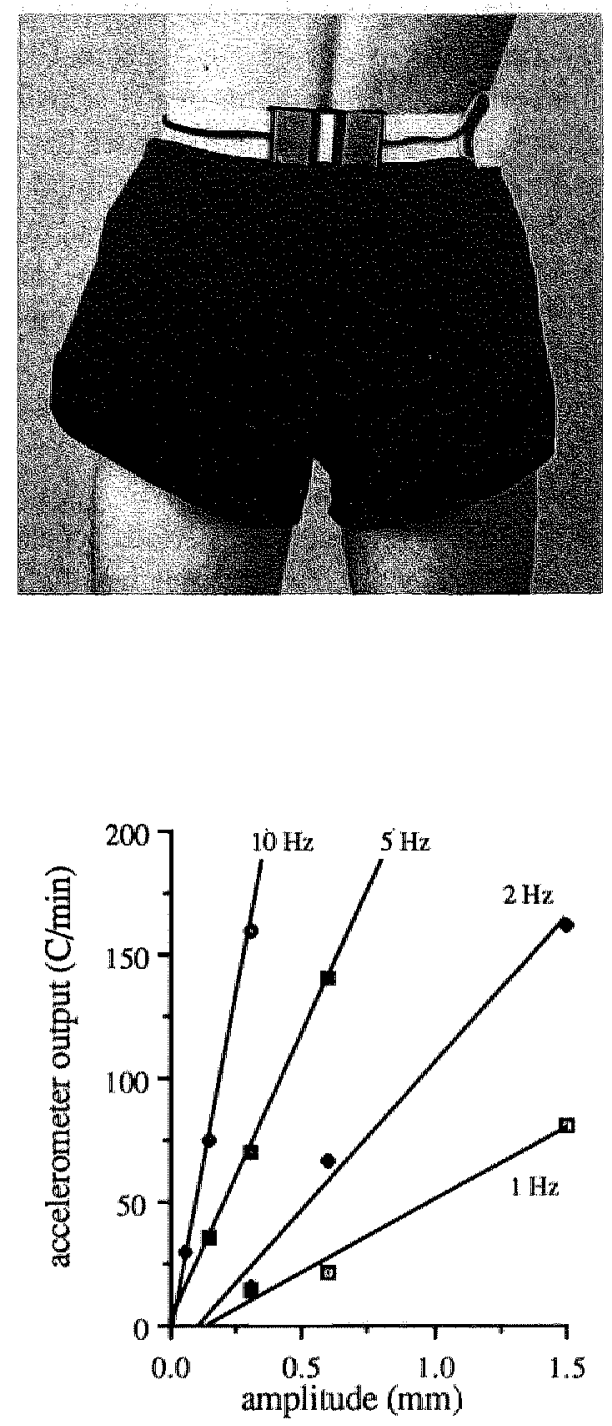

Fig. 2.5 $b$ Response of the accelerometer to different amplitudes at fixed frequencies. 
Results

\section{Bench test}

The results of set $\mathrm{D}$ (devices no. $4 \& 7$ ) were excluded from analysis. Device no. 7 was excluded because of having a response of only $10 \%$ compared to the other instruments, the response of device no. 4 decreased over $30 \%$ during the week of measurement indicating malfunctioning of the sensor-unit. Within $48 \mathrm{~h}$ response to the bench test shows a mean percentage difference for ail instruments of -0.1 and $-6.5 \%$ in the first and second week respectively. The mean CV over 4 trials is $7.6 \%$ (Table 2.2). All instruments have CVs less than $10 \%$; most of them come close to the ideal response of 150 counts/min as a consequence of which correction factors were small.

The mean response of the instruments decreased from 143.5 counts/min during the first trial to 125.7 counts/min during the last trial. This decrease is due to the properties of piezo-electric ceramics, and will be discussed in greater detail later on in this paper.

\section{Treadmill experiment}

Within the $5 \mathrm{~min}$ exercise periods accelerometer output showed little variance. The SD averaged over 22 observations was between 1 and 2.2 counts/min (Table 2.3). In the individual cases the SD of accelerometer output never exceeded 7 counts $/ \mathrm{min}$. The mean coefficient of variation is less then $5 \%$ and decreases with increasing walking speed. The results show that the output of the accelerometer reflects walking speed in an exponential way. 
Table 2.2 Response of 10 accelerometers durng the bench test. Mean, SD and CV are calculated over 4 trials.

\begin{tabular}{|c|c|c|c|c|c|c|c|c|c|c|c|}
\hline \multirow{2}{*}{$\begin{array}{c}\text { device } \\
\text { no. }\end{array}$} & \multicolumn{2}{|r|}{ trial } & \multicolumn{2}{|c|}{ difference } & \multicolumn{2}{|r|}{ trial } & \multicolumn{2}{|c|}{ difference } & \multirow{2}{*}{$\begin{array}{l}\text { mean } \\
\text { (cpm) }\end{array}$} & \multirow{2}{*}{$\begin{array}{l}\mathrm{SD} \\
(\mathrm{cpm})\end{array}$} & \multirow{2}{*}{$\begin{array}{c}\mathrm{CV} \\
\%\end{array}$} \\
\hline & $\begin{array}{r}1 \\
\text { (cpm) }\end{array}$ & $\begin{array}{r}2 \\
(\mathrm{cpm})\end{array}$ & $(\mathrm{cpm})$ & $\%$ & $\begin{array}{r}3 \\
(\mathrm{cpm})\end{array}$ & $\begin{array}{r}4 \\
(\mathrm{cpm})\end{array}$ & (cpm) & $\%$ & & & \\
\hline $\begin{array}{r}1 \\
3 \\
5 \\
8 \\
9 \\
10 \\
11 \\
12 \\
13 \\
14\end{array}$ & $\begin{array}{r}55 \\
177 \\
144 \\
155 \\
164 \\
159 \\
139 \\
139 \\
157 \\
146\end{array}$ & $\begin{array}{r}56 \\
161 \\
154 \\
142 \\
158 \\
158 \\
135 \\
152 \\
167 \\
148\end{array}$ & $\begin{array}{r}1 \\
-16 \\
10 \\
-13 \\
-6 \\
-1 \\
-4 \\
13 \\
10 \\
2\end{array}$ & $\begin{array}{r}1.8 \\
-9.5 \\
6.7 \\
-8.8 \\
-3.7 \\
-0.6 \\
-2.9 \\
8.9 \\
6.2 \\
1.4\end{array}$ & $\begin{array}{r}65 \\
159 \\
127 \\
134 \\
152 \\
146 \\
123 \\
146 \\
149 \\
135\end{array}$ & $\begin{array}{r}57 \\
155 \\
133 \\
123 \\
132 \\
138 \\
115 \\
141 \\
133 \\
130\end{array}$ & $\begin{array}{r}-8 \\
-4 \\
6 \\
-11 \\
-20 \\
-8 \\
-8 \\
-5 \\
-16 \\
-5\end{array}$ & $\begin{array}{r}-13.1 \\
-2.6 \\
-4.6 \\
-8.6 \\
-14.1 \\
-5.6 \\
-6.7 \\
-3.5 \\
-11.4 \\
-3.8\end{array}$ & $\begin{array}{r}58.3 \\
163.0 \\
139.5 \\
138.5 \\
151.5 \\
150.3 \\
128.0 \\
144.5 \\
151.5 \\
139.8\end{array}$ & $\begin{array}{r}4.6 \\
9.7 \\
12.0 \\
13.5 \\
13.9 \\
10.1 \\
11.0 \\
5.8 \\
14.4 \\
8.7\end{array}$ & $\begin{array}{l}9 \\
9 \\
6 \\
8 \\
4 \\
9 \\
6\end{array}$ \\
\hline $\begin{array}{l}\text { mean } \\
\mathrm{SD}\end{array}$ & $\begin{array}{r}143.5 \\
33.3\end{array}$ & $\begin{array}{r}143.1 \\
32.0\end{array}$ & $\begin{array}{r}-0.4 \\
9.7\end{array}$ & $\begin{array}{r}-0.1 \\
6.3\end{array}$ & $\begin{array}{r}133.6 \\
26.7\end{array}$ & $\begin{array}{r}125.7 \\
26.4\end{array}$ & $\begin{array}{r}-7.9 \\
7.1\end{array}$ & $\begin{array}{r}-6.5 \\
5.6\end{array}$ & & & $\begin{array}{l}7.6 \\
1.8\end{array}$ \\
\hline
\end{tabular}

(cpm) $=$ counts/min

Time between trial 1 and 2 and between trial 3 and 4 was $48 \mathrm{~h}$; the interval between trials $1 / 2$ and the trials $3 / 4$ was one week.

Table 2.3 Average of 22 observations (all subjects, all accelerometers) of mean accelerometer output (AO), standard devilation and coefficient of variation at different walking speeds.

\begin{tabular}{lrrr}
\hline & \multicolumn{3}{c}{ walking speed (km/h) } \\
\cline { 2 - 4 } & 3 & 5 & 7 \\
mean AO (cpm) & 26.5 & 62.8 & 128.2 \\
range & $13.8-36.8$ & $29.4-86.3$ & $63.3-182.0$ \\
mean SD (cpm) & 1.1 & $0.0-6.6$ & $0.8-5.0$ \\
range & $0.5-3.3$ & 2.5 & 1.8 \\
$\begin{array}{l}\text { mean CV (\%) } \\
\text { range }\end{array}$ & $1.6-9.9$ & $0.0-8.3$ & $0.7-3.8$ \\
\hline
\end{tabular}

$\mathrm{cpm}=\mathrm{counts} / \mathrm{mim}$ 
Table 2.4 presents the test-retest data of the treadmill experiment for the four subjects and the two devices of set A. It appears that the mean percentage difference between first and second trial is about $20 \%$ at the speed of $3 \mathrm{~km} / \mathrm{h}$ and is less than $10 \%$ at the speed of $7 \mathrm{~km} / \mathrm{h}$. Differences between subjects as interpreted from the CV over subjects is only slightly larger than the error of repeated measurement. Nevertheless a 3 factor repeated measure Anova revealed that significant differences could be found between walking speed (F 124.0, p<0.0001) and subjects (F 4.6, p<0.05), whereas the repeated measure showed no significant difference ( $F 0.46, p>0.5$ ).

Correction factors calculated from Table 2.2 are 1.01 and 1.15 for device no.5 and 1.09 and 1.26 for device no.11 for the first and second experiment respectively. Applying these correction factors to the data did not improve the reproducibility, although subjects were better discriminated in the Anova (F 11.0, p<0.001).

Neglecting the rather poor result at $3 \mathrm{~km} / \mathrm{h}$ - since this walking speed is of little relevance in normal daily life - it can be concluded that the reproducibility of the accelerometer is within $18 \%$. This would imply a correlation coefficient of $\mathrm{r}=0.91$. The regression coefficient between the results of trial 2 versus trial 1 (Table 2.4) is 0.98 . The standard error of estimate is 11.2 counts being about $14 \%$ of the mean $(X, Y)$ (Fig.2 6).

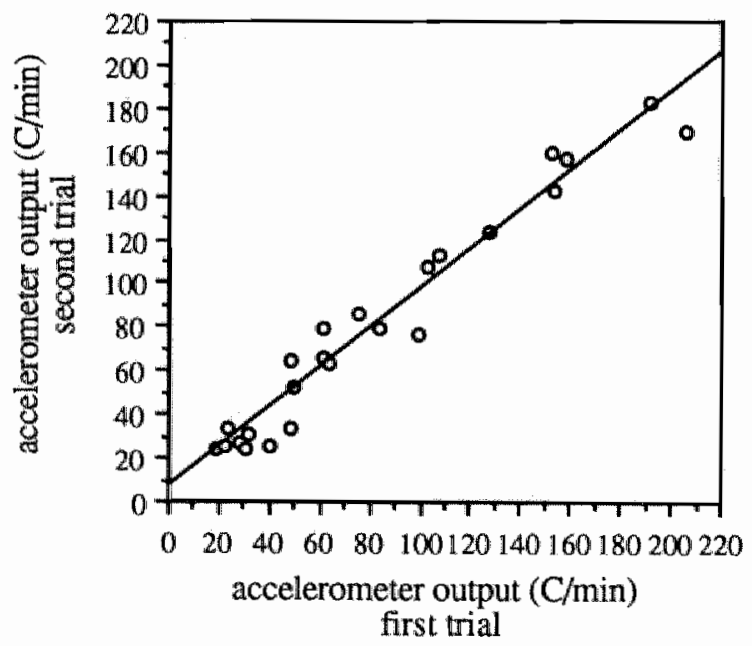

Fig. 2.6 Scattergram of the accelerometer output from trial $2 v$. trial 1 of the test-retest experiment on the treadmill $\left(n=24, r=0.98, S_{y, x}=11.2, p<0.001\right)$. 
Table 2.4 Test-retest results of accelerometers 5 and 11 obtained in treadmill experiments in 4 subjects with an interval of one week.

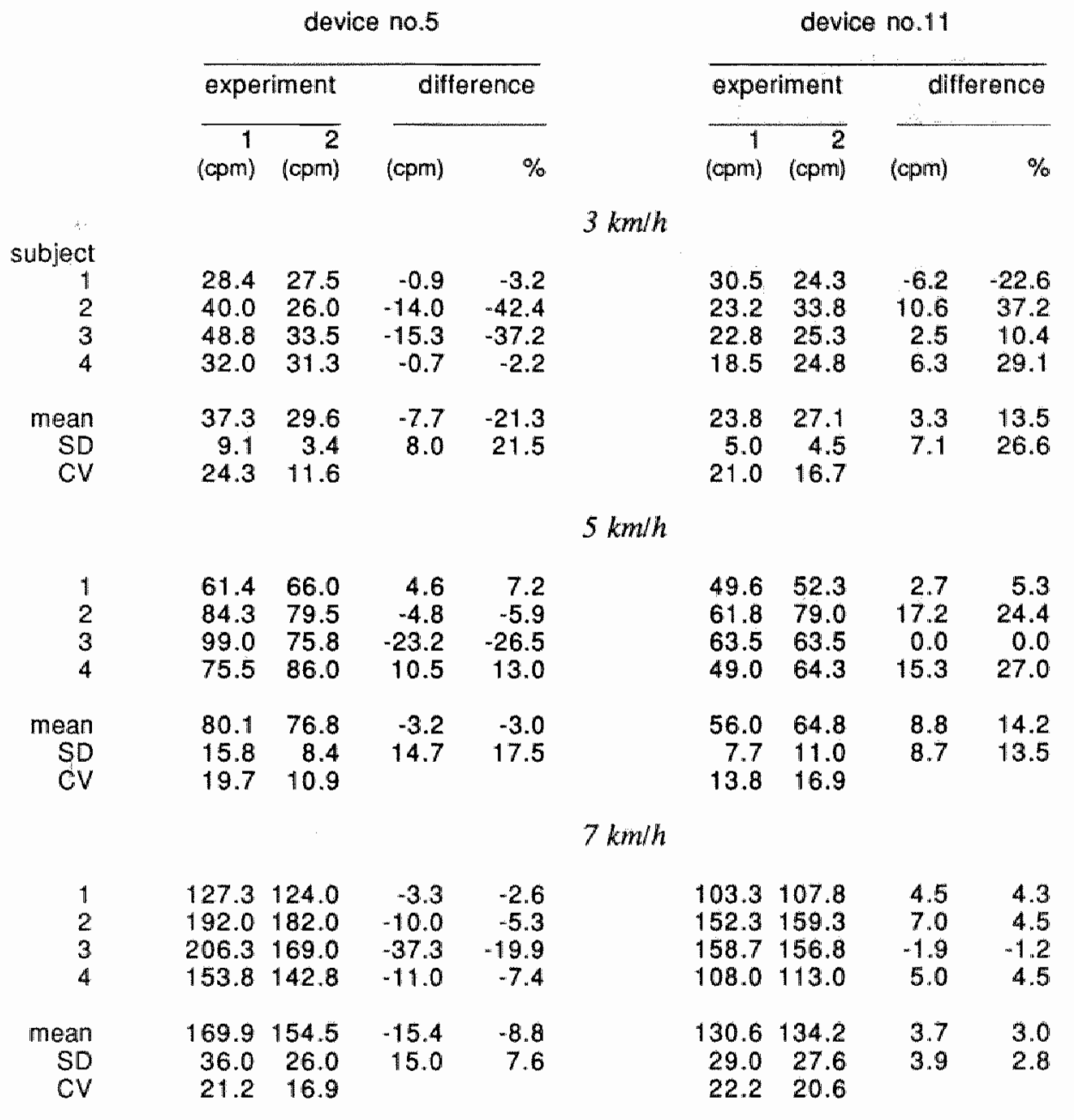

$(\mathrm{cpm})=$ counts/min 


\section{Inter-instrument variation}

The inter-instrument variation has been studied looking at the output of two instruments worn together under similar circumstances. Table 2.5 shows the results of this comparison between instruments $x$ and $y$ within set $A-F$ (see Table 2.1). It is remarkable that the sign of the difference between two instruments within the same set is not constant but varies from subject to subject. The percentage difference between two instruments usually is less then $30 \%$. The difference in set $\mathrm{C}$ is much higher (due to the low response of device no.1) and exceeded mean \pm 2 times SD for all sets. Therefore set $C$ was excluded from this analysis. The SD of the percentage difference is approximately $22 \%$ independently of walking speed. Appliance of the correction factors based upon differences in the bench test does not decrease inter-instrument variation.

\section{Variation in response of accelerometers in time}

The decline in response to the mechanical calibration after one week which was found in almost all instruments, led us to reanalyze all calibration data collected during the last year. It was known that the response of a particular instrument could vary largely, although no explanation for this effect could be found. Most instruments were very frequently used in field measurements, and calibrated during the short periods they were in the laboratory. At the time of the treadmill test-retest experiments, however, they were all in the laboratory and had not been used for two weeks.

To see whether the decreasing trend in response which appears in Table 2.2 extends over a longer period of time, all calibration data per instrument were plotted against the number of days after the last field experiment. These plots revealed a decline in response in all instruments which usually appeared to be logarithmic. A typical example is shown in Fig. 2.7. The rate of loss of sensitivity averaged about $15 \%$ in the first week.

Secondly all calibration points of each particular device were plotted against time before or after a field measurement period (Fig. 2.8). Of 28 observations where a calibration point was collected both 1 day before and 1 day after a field experiment of one week, 23 showed an increase and 5 a decrease in sensitivity.(Table 2.6). 
Table 2.5 Differences between output of accelerometers $x$ and $y$ of sets A - F (see Table 2.1) when worn under similar circumstances.

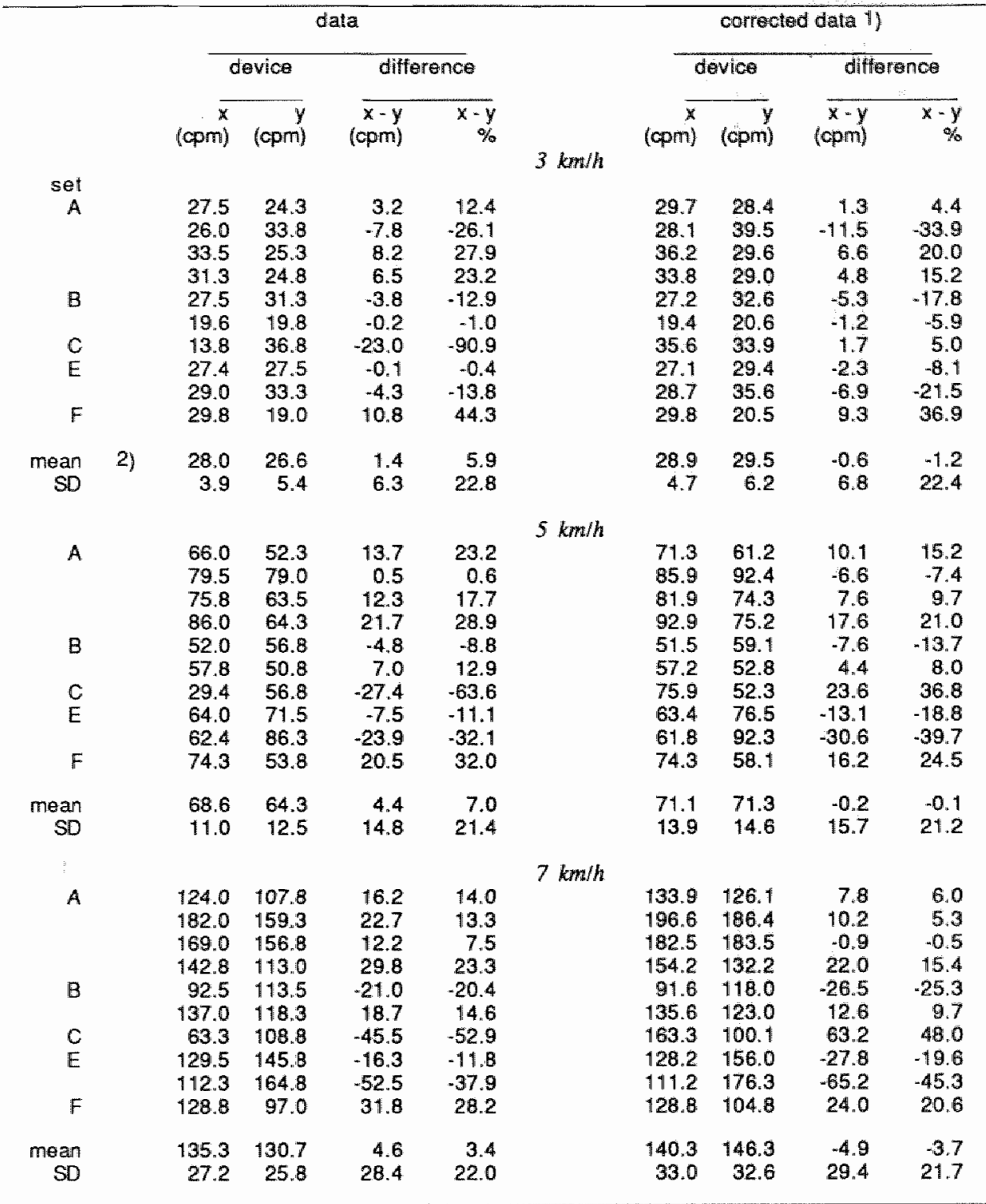

1) Corrected for differences in the bench test calibration (see text).

2) Data of set $C$ were excluded from calculation of mean and SD at all speeds since they lie outside the range: mean \pm 2 times SD at 3 and $5 \mathrm{~km} / \mathrm{h}$. 


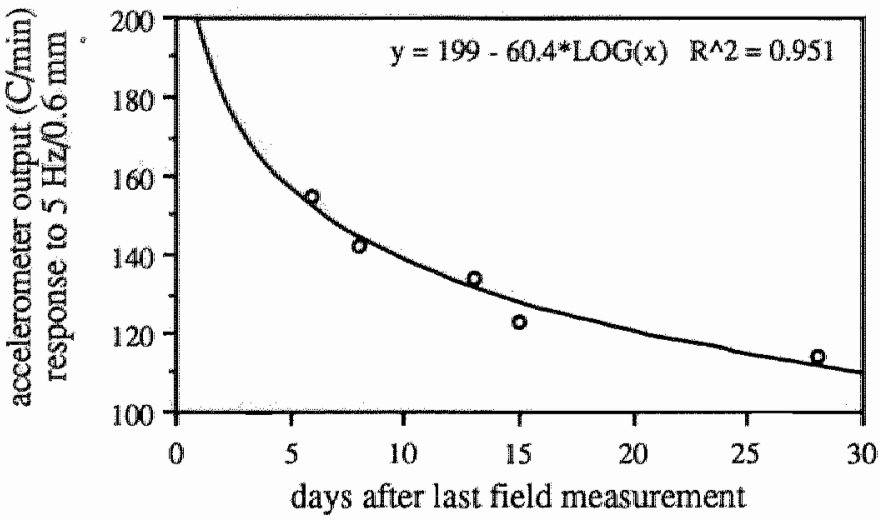

Fig. 2.7 Logarithmic decline of sensitivity of the piezo-electric sensor not used for a longer time.

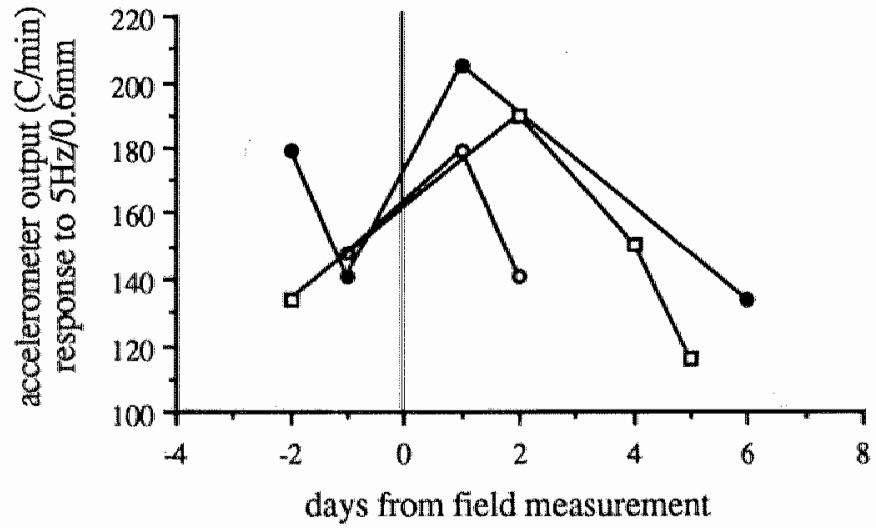

Fig. 2.8 Three observations of the sensitivity of an accelerometer plotted against the day before or after a 7-day field measurement period (vertical line). Note the increase of response after outdoor measurement and subsequent decrease when the accelerometer is not used. 
Table 2.6 Difference in response of accelerometers to the bench test one day before $(d-1)$ and one day after $(d+1)$ a 7 -day field experiment $(n=28)$.

\begin{tabular}{|c|c|c|c|c|c|}
\hline & \multirow{2}{*}{$\begin{array}{c}\text { device } \\
\text { no. }\end{array}$} & \multirow{2}{*}{$\begin{array}{r}d-1 \\
(c p m)\end{array}$} & \multirow{2}{*}{$\begin{array}{c}\mathrm{d}+1 \\
(\mathrm{cpm})\end{array}$} & \multicolumn{2}{|c|}{ difference } \\
\hline & & & & (cpm) & $\%$ \\
\hline \multirow{3}{*}{\multicolumn{2}{|c|}{1}} & 142 & 202 & 60 & 42.3 \\
\hline & & 120 & 88 & -32 & -26.6 \\
\hline & & 63 & 100 & 27 & 42.9 \\
\hline \multirow{3}{*}{\multicolumn{2}{|c|}{3}} & 120 & 173 & 53 & 44.2 \\
\hline & & 142 & 190 & 48 & 33.8 \\
\hline & & 134 & 154 & 20 & 14.9 \\
\hline \multirow{4}{*}{\multicolumn{2}{|c|}{$\begin{array}{l}4 \\
5\end{array}$}} & 146 & 138 & -8 & -5.4 \\
\hline & & 167 & 208 & 31 & 18.6 \\
\hline & & 171 & $21 \|$ & 40 & 23.4 \\
\hline & & 142 & 159 & 17 & 12.0 \\
\hline & & 166 & 159 & -7 & -4.2 \\
\hline \multirow{3}{*}{\multicolumn{2}{|c|}{7}} & 134 & 211 & 77 & 57.5 \\
\hline & & 162 & 212 & 50 & 30.9 \\
\hline & & 132 & 117 & -15 & -11.4 \\
\hline \multirow{4}{*}{\multicolumn{2}{|c|}{8}} & 191 & 212 & 21 & 11.0 \\
\hline & & 150 & 213 & 63 & 42.0 \\
\hline & & 108 & 125 & 17 & 15.7 \\
\hline & & 112 & 205 & 93 & 83.0 \\
\hline \multirow{3}{*}{\multicolumn{2}{|c|}{10}} & 97 & 125 & 28 & 28.9 \\
\hline & & 125 & 137 & 12 & 9.6 \\
\hline & & 95 & 121 & 26 & 27.4 \\
\hline \multirow{5}{*}{\multicolumn{2}{|c|}{$\begin{array}{l}12 \\
13\end{array}$}} & 140 & 192 & 52 & 37.1 \\
\hline & & 107 & 70 & -37 & -34.7 \\
\hline & & 142 & 171 & 29 & 20.4 \\
\hline & & 109 & 186 & 77 & 70.6 \\
\hline & & 123 & 143 & 20 & 16.3 \\
\hline \multirow{2}{*}{\multicolumn{2}{|c|}{14}} & $14 B$ & 179 & 31 & 20.9 \\
\hline & & 141 & 205 & 64 & 45.4 \\
\hline mean & & 133.2 & 164.5 & 30.6 & 23.8 \\
\hline $\mathrm{SD}$ & & 26.9 & 42.3 & 31.9 & 26.3 \\
\hline
\end{tabular}




\section{Discussion}

With respect to the evaluation of different motion sensors for the measurement of human physical activity all authors agree that the recently described accelerometers based on a piezo-electric sensor look most promising $(23,26,45,46)$. However until now very little validation studies have been published. Even less material is available on the reliability of these devices. Only Montoye (23) claims a very good reliability based on a correlation of 0.94 between first and second trial in a test-retest situation. In our test-retest experiment we found a correlation of 0.98 between both trials. However, a more detailed study on the percentage differences shows that there is quite a large error of up to $20 \%$. It is evident that just plotting all activities of trial one versus trial two is not per se concerned with the reproducibility. Activities that were discriminated as being high in the first trial also appear to be high in the second trial. However the absolute outcome in the second trial may differ strongly. Montoye does not present the actual values of his measurements but the scattergram, with different scaling on the $\mathrm{X}$ - and $\mathrm{Y}$-axis, suggests that the mean percentage difference is also about $20 \%$, whereas individual measurements may differ over $100 \%$.

Tryon (12) and Saris (45) argue that the accuracy of motion sensors should be based on data from standardized mechanical movements, because of the irreproducibility of human movement itself. The reproducibility of the accelerometer is indeed better when looking at the response to a standardized mechanical movement; the $\mathrm{CV}$ over 4 trials in one week is less than $10 \%$. Intra-instrument reproducibility in the test-retest experiment is within $20 \%$, whereas inter-instrument variation is about the same. Despite this quite large error, differences between subjects performing the same activities could be discriminated significantly using an Anova ( $p<0.05$ ).

It appears that the sensitivity of a piezo electric sensor may vary largely over time. The logarithmic decrease in sensitivity when the sensor is not used for a longer period is generally known and described as aging of the ceramic (47). The rate of loss of sensitivity of $15 \%$ in the first week we found in this study indicates that our sensors had a good time stability. In general this means that a few weeks after manufacturing the sensitivity will only fall with a very small percentage. Aging occurs as a result of partial depolarisation of the ceramic and inactivation of some of the dipoles in the material. However, both processes are reversible. Sensitivity may be increased again as a result of a mechanical, electro-magnetic or temperature shock. Apart from these effects the sensitivity of the element may vary with temperature and humidity. Although we do not know which of these different factors are responsible for the increase in sensitivity of our sensors after a field measurement of one week, it is clear that they all may occur under these circumstances.

Despite this finding of changing sensitivity to a standardized mechanical test, the corrections we made for these changes did not improve intra- and inter-instrument 
reproducibility in the test-retest experiments. Since this standardized movement lies reasonably close to normal human movements that may be expected at the lower part of the back, it can only be concluded that still other factors influence the output of the accelerometer at same activities. For the intra-instrument reproducibility it may be questioned whether the actual movement of a subject during a standardized activity is reproducible within $20 \%$ over a week. Furthermore the precise attachment site and the tightness of the sensor to the body may be of influence, although this was reasonably under control using a standardized waist belt which ensured the sensor to be firmly bound to the body.

Evaluation of the results of this study with earlier validation studies on motion sensors is quite complex because of the different methods used. For instance Tryon reports very high reproducibility of the actometer on a standard mechanical movement. However, actometer response was tested in ten trials within two hours and without even removing the actometer from the pendulum (12). More recently Morell reported very poor reproducibility of the actometer in a test-retest experiment on 3 consecutive days, the percentage difference being $45 \%$ in subjects walking three laps of respectively 32,128 and 224 yards (48). Since motion sensors are intended to be used over longer periods of several days or even a week, in our opinion reproducibility should at least be studied on a comparable time scale. In this respect an accelerometer based on a piezo-electric sensor seems to be superior to other motion sensors. To improve these devices, the changes in sensitivity we found need further attention, although, the relevance of the bench test in this study may be questioned, as results did not correspond with findings in subjects. An outdoor validation versus the doubly labeled water technique seems the ultimate approach to deal with this problem.

\section{References}

1 Kemper, HCG, R Verschuur, KGA Ras et al. Biological age and habitual activity in relation to physical finess in 12-and 13-year old schoolboys. Z Kinderheilk 119, 169-179, 1975.

2 Stunikard, A. A method of studying physical activity in man. Am J Clin Nutr 8. 595-601, 1960.

3 Sar"s, WHM, and RA Binkhorst. The use of pedometer and actometer in studying daily physical atrivity in man. Part I: reliability of pedometer and actometer. Eur I Appl Physiol 37, 219. 228,1977 .

4 Saris, WHM, and RA Binkhorst. The use of pedometer and actometer in studying daily physical activity in man. Part II: validity measuring the daily physical activity. Eur J Appl Plyysiol 37, $229-235,1977$.

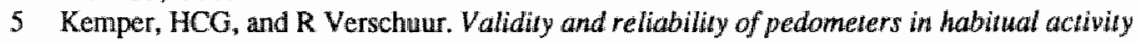
research. Eur J Appl Physiol 37, 71-82, 1977.

6 Verschuur, R, and HCG Kemper. Adjustment of pedometers to make them more valid in assessing running. Int J Sports Med 1, 95-97, 1980.

7 Montoye, HJ, and HL Taylor. Measurement of physical activity in population studies: a review. Hum Bíol 56, 195-216, 1984.

8 Schulman, JL, and JM Reisman. An objective measure of hyperactivity. Am J Ment Defic 64, $455-456,1959$. 
9 Avons, : A method to assess daily energy expendivure accoumed for physical activity. In: AJH van Es (Ed) Human energy metobolism: Physical activity and energy expenditure measurement in epidemiological research based spon direct and indirect calorimetry. Euro-nut rep. 5, pp. 108-110, 1984.

10 Awons, P, P Garthwaite, HL Davies, PR Murgatroyd, and WPT James. Approaches to estimating physical activity in the communty : Calorimetric validation of actometers and heart rate monitoring. Eur J Clin Nutr 42, 185-196. 1988.

11 Johnson, CF. Hyperactivity and the machine: the actometer. Child Dev 42, 2105-2110, 1971.

12 Tryon, WW, and GM Klemuck. The reliability and validity of actometers. In: WW Tryon (ed) Behavioral assessment in behavioral medicine. New York, Springer, 1985, pp. 218-233.

13 Masssey, PS, A Lieberman, and $\mathrm{G}$ Batarseh. Measure of activity level in mentally retarded children and adolescents. Am J Mental Defic 76, 259-261, 1971.

14 Dale, D van, PFM Schoffelen, F ten Hoor, and WHM Saris. Effects of adding exercise to energy restriction on 24 -hour energy expendiure, resting metabolic rate and daily physical activity. Eur J Clin Nutr 43, 441-451, 1989.

15 Kupfer, DJ etal The applicaution of Delgado's telemeric mobility recorder for human siudies. Behavioral Biol 7, 585, 1972.

16 Smit, HvZ, and VA Langeman. A Capacitive method of measuring circadian activity in laboratory animals. Med Biol Eng 12, 831, 1974.

17 Morris, JRW. Accelerometry a technique for the measurement of human body movements. J Biomech 6,729-736, 1973.

18 Colburn, TR, BM Smith, JJ Guarini, and NN Simmons. An ambulatory activity monitor with solid state memtory. ISA Transactions $15,149-154,1976$.

19 Mc Partland, R, F Foster, DJ Kupfer, and B Weis. Activity sensors for use in psychiatric evaluation. IEEE Trans Biomed Eng 23, $175,1976$.

20 Marshall, L. Pedometers link activity with estrus. Computermanagement 18b, USA. 1980.

21 Schulman, JL, TM Stevens, and MJ Kupst. The Biomotometer: a mew device for the measurement and remediation of hyperactivity. Child Dev 48, 1152-1154, 1977.

22 Laporte, RE, LH Kuller, DJ Kupfer, RJ Mc Partland, G Mathews, and C Caspersen. An objective measure of physical activity for epidemiological research. Am J Epidemiol 109, 158-167, 1979.

23 Montoye, HJ, R Washbum, S Servais, A Ertl, JG Webster, and F Nagle. Estimation of energy expenditure by a portable accelerometer. Med Sci Sports. Exerc 15, 403-407, 1983.

24 Wong, TC, JG Webster, HJ Montoye, and R Washburn. Porlable accelerometer for measuring human energy expenditure. IEEE Trans Biomed Eng 28, 467-471, 1981.

25 Servais, S, JG Webster, and HJ Montoye. Estimating human energy expenditure using an accelerometer device. J Clin Eng 9, 159-170, 1984.

26 Meijer, GA, KR Westerterp, $\mathrm{H}$ Koper, and $\mathrm{F}$ ten Hoor. Assessment of energy expenditure by recording heart rate and body acceleration. Med Sci Sports Exerc 21, 343-347, 1989 (dhis Thesis: Chapter 3).

27 Schutz, Y, F Froidevaux, and E Jequier. Estimation of 24 h energy expenditure by a portable accelerometer. Proc Nutr Soc 47, 23A, 1988.

28 Brouha, L. Physiology in Industry. Now York, Pergamon, 1960, pp. 99-108.

29 Ismail, AH, JW Barany, and CB Smith. Relationships between mechanical force and physiological cost during gait in adult man. In: Cooper, MJ (Ed). Biomechanics. Chicago, The athlete instinte, 1971.

30 Reswick, J, J Perry, and D. Antonelli. Preliminary evaluation of the vertical acceleration gait analyzer (VAGA). Proc. 6th Annu. Symp. External control human extremities, Dubrovnik, Yugoslavia, Aug. 28-Sept.1. 1978, pp.305-314.

31 Bhaitachary:a, A, EP Mc Cutcheon, E Shvartz and JE Greenleaf, Body acceleration distribution and O2 uptake during running and jumping. I Appl Physiol: Respirat Environ Exercise Physiol 49. $881-887,1980$.

32 Buss, A, and R Plomin. A temperament theory of personality. New York, Willey, 1975.

33 Werry, J. Measures in pediatric psychopharmacology. In J. Wenry (Ed), Pediauric psychopharmacology: The use of behavior modifying drugs in children. New York, Brumner/Mazel., 1978. 
34 Meijer, GA. Energy requiremens of the obese: The effect of body mass on energy expenditure. Int. J Obes 13 (Suppl. 1), 7, 1989.

35 Balogun, JA, NT Farina, E Fay, K Rossmann, and L Pozyc. Energy cost determination using a portable accelerometer. Phys Ther 66, 1102-1109, 1986.

36 Cawagna, GA, FP Saibene, and R Margaria. External work in walking. J Appl Physiol 18, 1-9, 1963.

37 Cavagna, GA, FP Saibene, and R Margaria. Mechanical work in running. J Appl Physiol 19,249. 254,1964 .

38 Smidt, GL, JS Arora, and RC Johnston. Accelerographic andysis of several types of walking. An J Phys Med 50, 285-300, 1971.

39 Liberson, WT. Biomechanics of gait: A method of study. Arc Phys Med 46, 37-48, 1965.

40 Plaja, J, F Naldonado, and JR Goig. Accelerometric and goniometric patterns of normal and pathological gaiss. In PV Komi (ed) Biomechanics Vol A, Baltimore, U.P.P., 1976, pp. $347-351$.

41 Dupuis, $\mathrm{H}_{4}$ J Draeger, and E Hartung. Vibration transmission to different parts of the body by various locomotions. In PV Komi (ed) Biomechanics Vol A, Baltimore, U.P.P., 1976,. pp. 537 543.

42 Gersten, JW, W Orr, AW Sexton, and D Okin. External work in level walking. J Appl Physiol 26, 286-289, 1969 .

43. Herzog, W, BM Nigg, LJ Read, and E Olsson. Asymmetries in ground reaction force patterns in mormal human gait. Med Sci Sports Exerc 21, 110-114, 1989.

44 Cotes, JE, and $\mathrm{F}$ Meade. The energy expenditure and mechanical energy dentand in walking. Ergonomics 36, 97-119, 1960.

45. Saris, WHM, The assessment and evaluation of daily physical activity in children. A review. Acta Paediatr Scand 318, 37-48, 1985.

46. Groves, D. Beyond the pedometer: New tools for monitoring activity. The Physician and Sportsmed. 16, 160-166, 1988.

47 Randeraat, J van, and RE Setterington (Eds) Piezoelectric ceramics. Eindhoven, Philips NV, 1974, pp. 4-22.

48 Morrell, $\mathrm{EM}_{\psi}$ and $\mathrm{FJ}$ Keefe. The actometer: an evaluation of instrum ent applicability for chronic pain patients. Pain 32, 265-270, 1988. 



\title{
Chapter 3
}

\section{Assessment of energy expenditure by recording heart rate and body acceleration}

\author{
G.A.L. Meijer, K.R. Westerterp, H. Koper, and F. ten Hoor
}

Med. Sci. Sports \& Exerc, 21 (3): 343-347, 1989.

\section{Abstract}

The feasibility of a portable accelerometer equipped with a three-directional sensor for the assessment of physical activity and the consequences for energy expenditure was examined under laboratory conditions and during normal daily life. Heart rate monitoring was also conducted to allow comparison of both techniques.

In the laboratory study 16 healthy subjects performed a number of specified exercises within a range of activity levels that may be expected in normal life. Accelerometer output was compared with energy expenditure measured by continuous respirometry. A linear relationship was found between accelerometer output and energy expenditure for the pooled data. The standard error of estimate is $79.1 \mathrm{~J}_{\mathrm{min}}^{-1} \mathrm{~kg}^{-1}$.

In the field study four subjects were observed during a week under free living conditions. Energy expenditure was calculated from food intake registered over the whole period. Energy expenditure calculated from accelerometer output and heart rate exceeded the energy intake figures by $30 \%$ and $33 \%$ respectively. Possible explanations for this discrepancy are discussed. Despite this discrepancy accelerometer output appeared to correlate highly with energy intake $(r=0.99, p<0.025)$ which suggests accurate performance of the accelerometer under free living conditions. The heart rate method gave much poorer results in estimating individual energy expenditure. 


\section{Introduction}

Studies examining energy expenditure or energy balance still require a method capable of directly measuring physical activity and the energy expenditure resulting from this activity in the individual $(16,19)$. Methods used for this purpose, such as observation, questionnaires and even heart rate monitoring have failed to produce reliable data. The limitations and possible errors of these methods have been discussed elsewhere $(1,6,7,11,20)$.

The recent development of accelerometers for the assessment of physical activity is more promising (12). These devices allow measurement of accelerations and decelerations caused by movements of the body (23). Montoye et al. report a correlation of 0.74 between the integral of the absolute value of body acceleration and oxygen consumption measured with a Beckman Metabolic Chart in subjects performing different exercises during four minute periods. They suggest this relation might even be improved by using a three-directional sensor (18). Schutz et al. (22) report a high correlation $(r=0.92)$ between accelerometer readings and 24 hour energy expenditure measured in a respiration chamber.

It is not known, however, whether an accelerometer allows measurement of energy expenditure resulting from physical activity, during normal daily life. Several sources of disturbing factors which do not occur in the laboratory may appear, for example the vibrations caused by external sources as in driving a car, changes in temperature which might affect the sensor, and the enormous extension of the kinds of movements made by the subject, which usually are not simulated under laboratory conditions. A shortcoming due to an intrinsic property of the accelerometer is that static work, for instance lifting a mass, will not be monitored. This characteristic has led to much discussion $(3,18,23)$ and should be taken into account when accelerometers are applied and in interpreting the results. The primary aim of the present study was to examine the relationship between energy expenditure and body acceleration measured with a three-directional acceleration sensor, which was developed in our department. This was done in a laboratory calibration experiment, in which subjects performed specified exercises, and in a validation study in the field where spontaneous activity was registered. In the laboratory, energy expenditure was measured with respirometry, in the field expenditure was calculated from intakebalance. Heart rate was also monitored to allow a comparison with this technique which is more commonly used in the field.

\section{Methods}

\section{Heart rate (HR) and acceleration monitoring}

The serisor used for detecting body accelerations consisted of a piezo electric element, deformed by a small mass on a lever, bent from one corner to the opposite corner (Fig.3.1). By this construction it is sensitive in three directions with an output of about 
$100 \mathrm{mV} / \mathrm{g}$ in each direction. The vertical axis is slightly more sensitive and therefore this axis of the sensor was allways applied parallel to the vertical axis of the body. The sensor was worn on the lower part of the back, where it was kept in place by a belt which also carried a recorder.

The ECG signal was detected using three electrodes, one on the sternum at the level of the second intercostal space, and two respectively left and right over the sixth rib on the anterior axillary line. This application of electrodes resulted in clearly detectable R-waves, and very few artifacts.

Synchronous recording of ECG and body acceleration was made on a two channel portable tape recorder (Medilog MR-10; mass $350 \mathrm{~g}$ ). Continuous recording over 24 hours was possible without the necessity to interfere with the subject. For analysis the tapes were replayed at 24 times recording speed on a commercial cassette deck. The ECG signal was reduced to heart rate by measuring the time between subsequent $R$-waves and converting these times to beat frequency. The mean value was sampled per minute recording time.

The absolute value of the signal of body acceleration was integrated over one minute periods resulting in the accelerometer output $(\mathrm{AO})$ in counts per minute. Fig. 3.2 shows the record of one observation day.
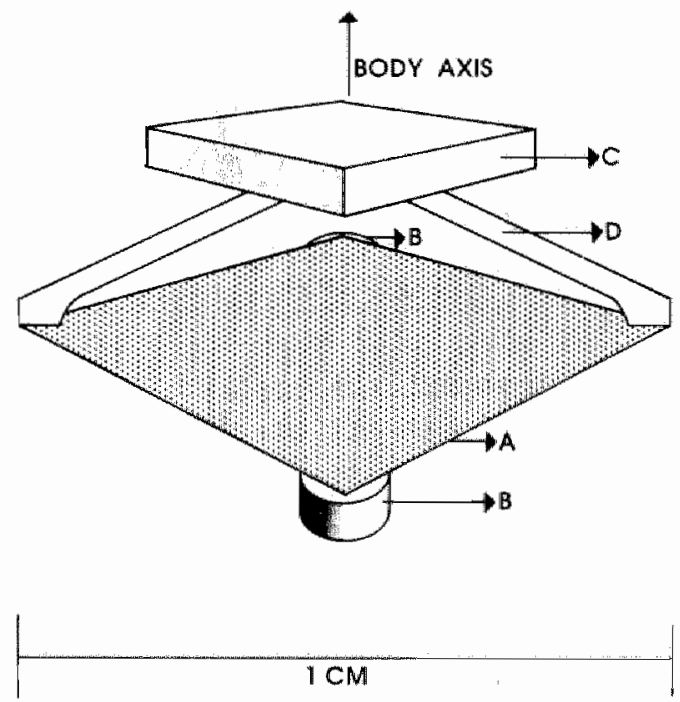

Fig. 3.1 The three-directional sensor for body acceleration used in this study (size approximately $1 \mathrm{~cm}^{3}$, mass $4.5 \mathrm{~g}$ ). The piezo-electric element (A) is mounted on two rubber feet $(B)$ on diagonally opposed corners, and deformed by $a$ small mass $(C)$ on the lever $(D)$ bent over the other corners. The vertical axis of the sensor is applied parallel to the vertical body axis. 


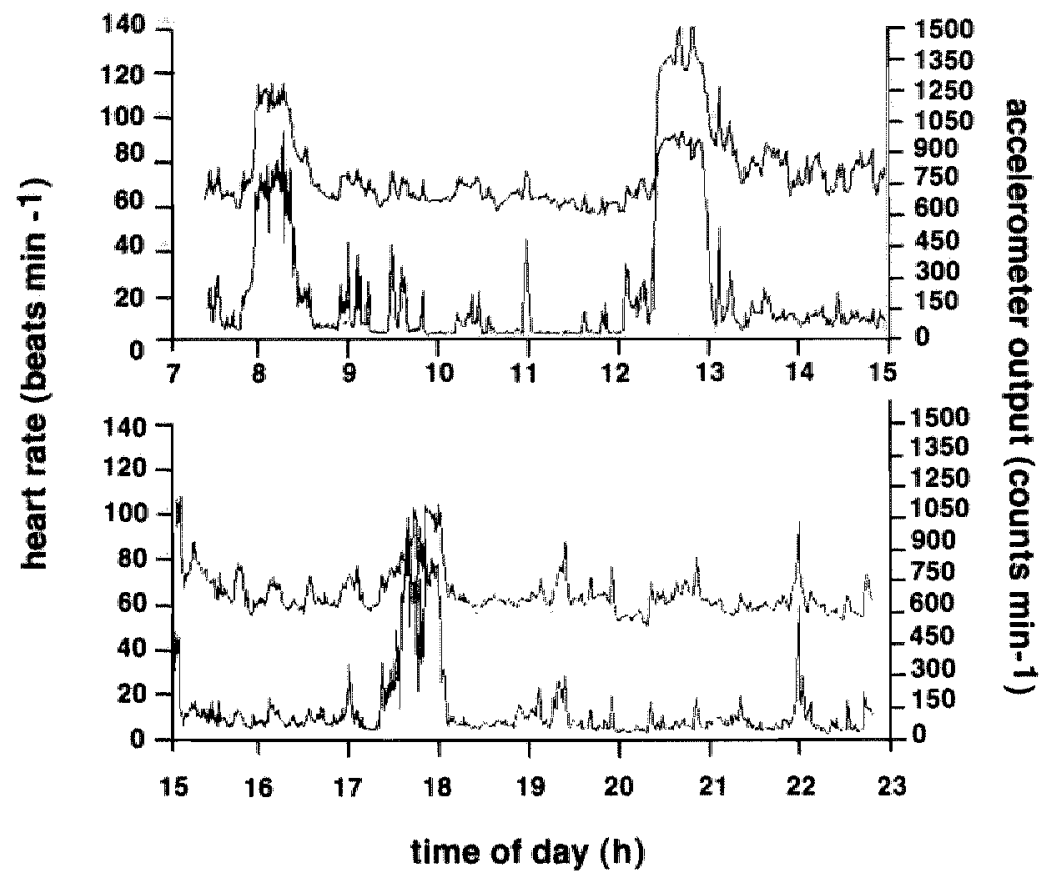

Fig 3.2 Day time recording of heart rate (upper line, beats. min $^{-1}$ ) and accelerometer output (lower line, counts.min-1) of one particular observation day. High activity occurs between 7.50 and $8.30 \mathrm{am}, 12.15$ and $13.00 \mathrm{pm}$ and 17.30 and $18.00 \mathrm{pm}$ (cycling, running and cycling respectively). 


\section{Laboratory study}

In order to determine the relationship between accelerometer output, heart rate and energy expenditure (EE), calibration experiments were done in the laboratory. Sixteen healthy subjects who gave informed consent participated (13 males, 3 females; mean age $29 \mathrm{yr}$, range 20-40, SD 8; mean height $1.77 \mathrm{~m}$, range 1.64-1.91, SD 0.08 ; mean body mass $68 \mathrm{~kg}$, range 58-82, SD 8). They were mostly students and colleagues.

After sitting relaxed for approximately $10 \mathrm{~min}$ to allow heart rate and oxygen consumption to stabilize, the subjects performed the following exercises for 5 min each :

1 sitting relaxed

2 actively sitting (standing up and sitting down each $1 / 2$ min)

3 standing relaxed

4 actively standing (slowly walking a few paces every $1 / 2 \mathrm{~min}$ )

5-7 walking and running on a treadmill at three speeds in a range of $3-13 \mathrm{~km} . \mathrm{h}^{-1}$

The exercises were al ways assigned from the lowest (sitting) to the highest level. Energy expenditure was measured by indirect calorimetry using a Jaeger EOS-sprint analyzer. Calculation of energy expenditure was made after stabilization of $\dot{\mathrm{V}}_{2}$ and $\dot{\mathrm{V}} \mathrm{CO}_{2}$. usually during the last 2-3 min of the exercise. To eliminate the effect of body mass, energy expenditure is expressed as $\mathrm{J}_{\mathrm{min}} \mathrm{m}^{-1} \cdot \mathrm{kg}^{-1}$.

Mean accelerometer output and heart rate were calculated for each exercise period and used for the regression analysis. Individual as well as pooled data regression lines were calculated using the method of least squares.

\section{Field study}

To validate the accelerometer under free living conditions, an experiment was designed in which four subjects ( 3 males, 1 female; mean age $22 \mathrm{yr}$, range 20-24, SD 2; mean height $1.78 \mathrm{~m}$, range $1.74-1.83$, SD 0.04 ; mean body mass $70 \mathrm{~kg}$, range 64-76, SD 5) who gave their informed consent were observed for the period of one week. The subjects were students who all spent a large part of the day in our laboratory. However, they differed fairly in their leisure time activities. One subject travelled more than an hour a day by train. One played tennis at least one hour a day. The other two were intermediate in their leisure time activities. Recordings of body acceleration and heart rate were made during the time they were awake, generally 16 to 19 hours a day. Complete daily recordings could be made on one tape. The subjects were all trained in handling the recorder and changed tapes every morning. The values found for accelerometer output were converted to energy expenditure using the pooled data regression equation as determined in the calibration experiment. Heart rate measurements were converted to energy expenditure using the individual regression lines from the calibration experiment. The cost of sleeping was assumed to be $1 *$ BMR (27). BMR was estimated according to Harris and Benedict (14). Energy expenditure was calculated as the sum of measured expenditure during daytime and estimated expenditure during sleep. 
Energy intake was assessed by a food intake diary used during the whole period. The diary inquired for food consumption during seven periods of the day (meals and between meals) as well as for cooking recipes of the larger meals. Amounts of food were either estimated or in cases of doubt weighed on a balance by the subject. Energy intake was calculated using the Dutch nutrition table (15). Body mass was measured at the beginning and at the end of the recording period.

The period of one week was chosen because it is the shortest period in which balance between energy intake and energy expenditure is expected to be realized $(10,25)$. Lengthening the period might discomfort the subjects.

\section{Results}

\section{Laboratory study}

In each subject a strong linear relationship between accelerometer output and energy expenditure was found. A typical example is shown in Fig. 3.3 Fig.3.4 shows a plot of the pooled data of the 16 subjects $(n=117)$. Here also a linear relation was found, for which the following equation was calculated:

$$
\mathrm{EE}=1.294 * \mathrm{AO}+78
$$

where $\mathrm{EE}$ is energy expenditure (J.min-1. $\left.\mathrm{kg}^{-1}\right)$, and $\mathrm{AO}$ is accelerometer output (counts.min-1). The standard error of estimate is $79.1 \mathrm{~J}_{\mathrm{min}}^{-1} \cdot \mathrm{kg}^{-1}$.

As can be seen in the log-log transformed scatter-diagram (Fig.3.5), linearity also holds at low levels of energy expenditure. At high levels of energy expenditure (specifically in running) accelerometer output systematically seems to underestimate energy expenditure.

Linearity between heart rate and energy expenditure was also high in the individual calibration experiments. However, heart rate values in the lower range of activity levels showed large deviation from linearity in 6 of the 11 subjects (Fig.3.6). The heart rate data of 5 subjects had to be excluded from further analysis because of unmistakable erroneous results that could not be attributed to any technical failure or any deviation from the protocol. 


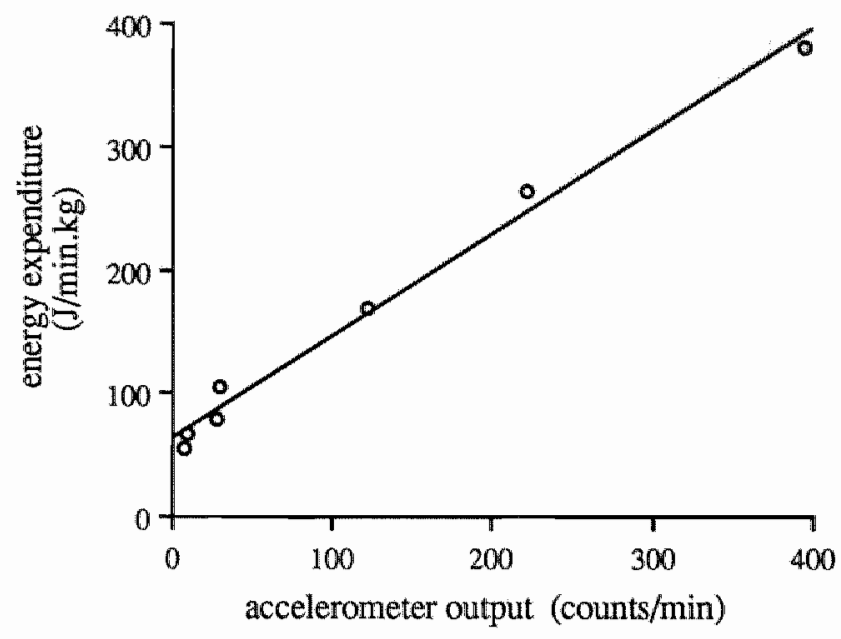

Fig. 3.3 Energy expenditure $\left(J . \mathrm{min}^{-1} \cdot \mathrm{kg}^{-1}\right)$ versus accelerometer output (counts.min-1) in one subject (M16), $S_{y, x}=14.4 \mathrm{~J} . \mathrm{min}^{-1} \mathrm{.} \mathrm{kg}^{-1}$.

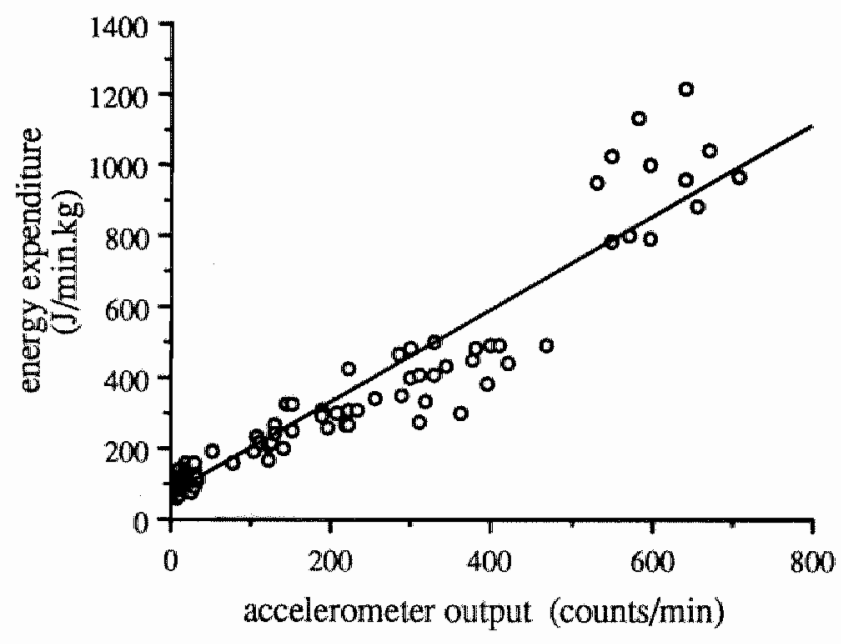

Fig. 3.4 Scatter diagram and regression line for energy expenditure $\left(J . \mathrm{min}^{-1} . \mathrm{kg}^{-1}\right)$ versus accelerometer output (counts. min $^{-1}$ ) of the pooled data of 16 subjects, $S_{y, x}=79.1 \mathrm{~J} \cdot \mathrm{min}^{-1} \cdot \mathrm{kg}^{-1}$. 
Chapter 3

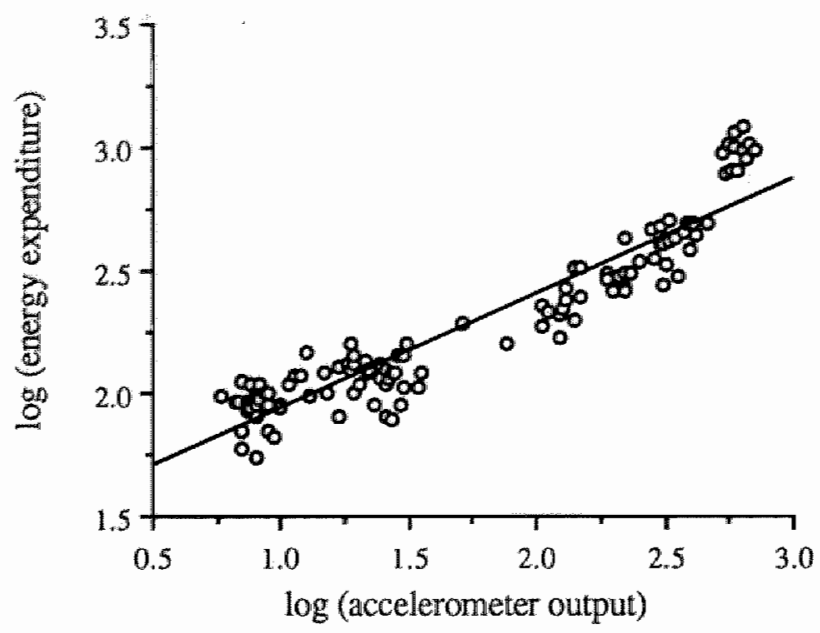

Fig. 3.5 Pooled data scatter diagram for log (energy expenditure) versus log (accelerometer output) showing the variance in the lower range of activity levels.

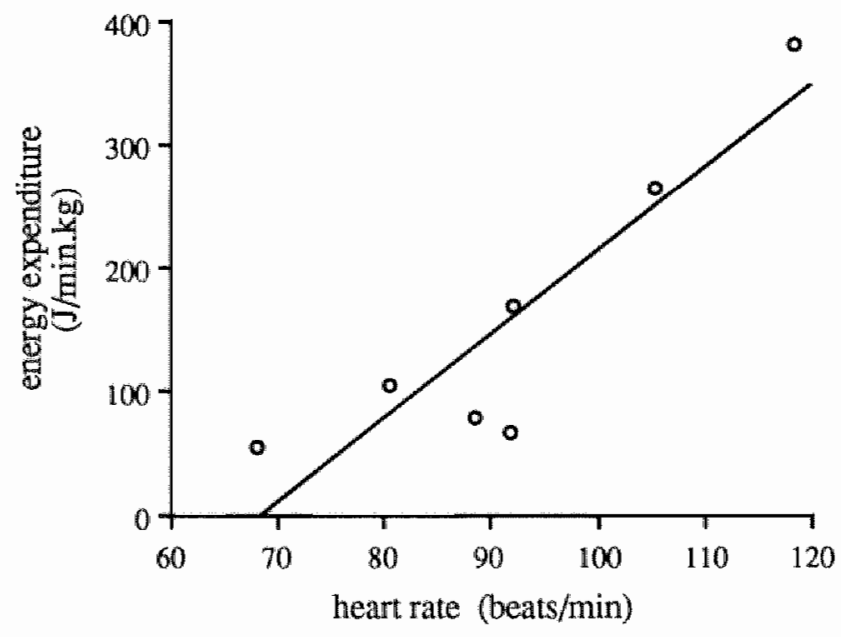

Fig. 3.6 Energy expenditure versus heart rate in one subject (M16). Notice the large deviation from linearity at low levels of energy expenditure, $S_{y, x}=59.5$ J.min- $\operatorname{mg}^{-1} \cdot \mathrm{kg}^{-1}$ 


\section{Field sulty}

Energy intake ranged from 56.6 to $96.6 \mathrm{MJ} /$ week in the four subjects (Table 3.1 ). No significant changes in body mass were measured. There was a high correlation between total accelerometer output (counts.week-1) and energy intake $(r=0.99, p<0.025)$. Energy expenditure calculated from accelerometer output appears to be $30 \%$ higher than calculated from intake-balance. A similar discrepancy was found using the heart rate measurement although individual differences are much higher here.

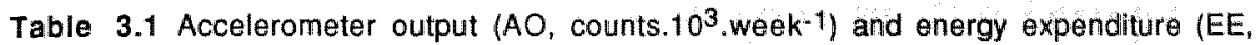
MJ. week-1) calculated from energy intake (EI), accelerometer output and heart rate (HR). Percentage differences are calculated with respect to energy intake.

\begin{tabular}{|c|c|c|c|c|c|c|}
\hline Subject & $\mathrm{AO}$ & $E E(E I)$ & $E E(A O)^{1)}$ & $\begin{array}{c}\% \\
\text { difference }\end{array}$ & $\mathrm{EE}(\mathrm{HR})$ & $\begin{array}{c}\% \\
\text { difference }\end{array}$ \\
\hline $\begin{array}{l}M 1 \\
M 12 \\
M 13 \\
F 4\end{array}$ & $\begin{array}{l}373.1 \\
879.9 \\
539.8 \\
278.7\end{array}$ & $\begin{array}{l}65.2 \\
96.6 \\
78.3 \\
56.6\end{array}$ & $\begin{array}{r}90.3 \\
133.7 \\
90.7 \\
73.0\end{array}$ & $\begin{array}{r}+38.5 \\
+38.4 \\
+15.8 \\
+29.0\end{array}$ & $\begin{array}{r}73.4 \\
102.8 \\
114.7 \\
94.5\end{array}$ & $\begin{array}{r}+12.6 \\
+\quad 6.4 \\
+46.5 \\
+66.9\end{array}$ \\
\hline $\begin{array}{l}\text { mean } \\
\text { SD. }\end{array}$ & & & & $\begin{array}{r}+30.4 \\
10.7\end{array}$ & & $\begin{array}{r}33.1 \\
28.6\end{array}$ \\
\hline
\end{tabular}

1) calculated using equation (i) : $\mathrm{EE}=1.294 * \mathrm{AO}+78$

\section{Discussion}

The calibration experiment has shown that there is overall linearity between accelerometer output and energy expenditure in the complete range of activity levels that may be expected in normal life. From the data reported by Montoye et al. it can be calculated that the standard error of estimate amounts to approximately $9.1 \mathrm{~kJ} . \mathrm{min}^{-1}$ for a subject weighing $70 \mathrm{~kg}(18)$. The standard error found in this study, $5.5 \mathrm{~kJ} \mathrm{~min}^{-1}$ for a similar subject, is much less. In the Montoye study subjects walked and ran at various grades which increases energy expenditure compared to on the level but likely does not increase accelerations. This might explain the larger standard error of estimate. However, it seems to us that the use of a three-directional sensor and the use of continuous respirometry, taking $\mathrm{VCO} 2$ also into account both contribute to the smaller standard error of estimate found here.

The systematic underestimation of energy expenditure by accelerometer output in running on the treadmill might be caused by restrained movement. In ract several subjects showed anxiety when running at high speeds on the treadmill. The damping properties of 
the treadmill may also contribute to the reduction of accelerometer output. Omitting the 12 points measured during running has no significant effect on the calculated regression line. Although it is not clear how these findings should be interpreted, it is obvious that their impact on the accuracy of the accelerometer in normal life is relatively small.

Overestimation of energy expenditure measured with the accelerometer might occur through vibrations when riding in vehicles. For example the high peaks in Fig.3.2 when the subject is riding a bicycle are not easily understood since very few accelerations due to work are to be expected at the lower part of the back. The rest is undoubtedly due to trembling caused by the rough surface of the road. Fortunately the accelerometer does not seem to overestimate the concurring energy expenditure. Vibrations caused by trains or cars could not be determined in the recordings.

The heart rate data found in the calibration experiments did not support the use of any of the more complex regression techniques which have been proposed by many authors $(1,2,5,20)$. Simple linear regression turned out to be the most appropriate technique to deal with these data. This finding may be explained by the fact that lying was not included in our protocol. Data from Booyens and Hervey (5) also show linearity between heart rate and energy expenditure in the range of sitting relaxed to higher levels of activity. In fact all other regression methods proposed try to include heart rate values measured in lower ranges of actiwity, of which the relewance in normal daily life is questionable.

Our data seem to correspond with earlier findings in that the relationship between heart rate and energy expenditure is particularly weak at low activity levels $(1,20)$. This characteristic of the relationship, in combination with the influence of anxiety, heat and posture on heart rate, has a large negative effect on the accuracy of the heart rate method as a measure of energy expenditure of the individual in normal life. This probably explains the erroneous results in our field experiment. Similar poor results have been reported by other researchers $(1,8)$.

A correlation of 0.99 was found between total number of counts registered by the accelerometer and energy intake during a week $(p<0.025)$. In this respect the accelerometer seems to have a greater accuracy than the heart rate method. The consideration that the contribution of static work to daily energy expenditure was trivial in these four subjects is confirmed by the results. Energy expenditure calculated from accelerometer output exceeds energy intake, with $30 \%$ as the mean. Use of the heart rate measurements results in the same mean discrepancy. Comparable differences between energy intake and expenditure have been reported by others $(4,13,24,26)$. Average dailly metabolic rate as a multiple of BMR (ADMR/BMR) calculated from energy intake is 1.47 , which is rather low compared to the advised requirements for these subjects $(1.74$ for moderate work, $(25,27)$ ). ADMR/BMR based on accelerometer output (mean 1.92) comes closer to the expected value, and is almost identical to the results of Schulz et al. who report a value of 1.94 in a comparable population (21). These findings suggest that energy intake is underestimated in our study.

On the other hand energy expenditure might be slightly overestimated by the 
accelerometer since metabolic rate as indicated by the $\mathrm{Y}$-intercept of regression equation (i) is about $10 \%$ higher than BMR calculated according to Harris and Benedict (14). However, this can explain at most $25 \%$ of the total difference between energy intake and energy expenditure. Similar discrepancies between predicted BMR and resting metabolic rate according to accelerometer readings have been reported by other researchers $(9,17,22)$.

Because of the small number of subjects in the present field study, care should be taken in the interpretation of the results. Nevertheless the results of the accelerometer in measuring individual energy expenditure in normal daily life look very promising.

Further research should be undertaken to validate the accelerometer under free living conditions. Because of the difficulties arising in the interpretation of the food intake data, a more objective method such as the doubly labeled water technique should be included in future validation studies.

\section{References}

1 Acheson, K.J., I.T. Campbell, O.G. Edholm, D.S. Miller and M.J. Stock. The measurement of daily energy expenditure - an evaluation of some techniques. Am. J. Clin. Nutr. 33: 1155-1164, 1980.

2 Avons, P. A method to assess daily energy expenditure accounted for physical activity. In: Human Energy Metabolism: Physical activity and energy expenditure measurement in epidemiological research based upon direct and indirect calorimetry, edited by A.J.H. van Es, 1984, 108-110 (EuroNut Rep. 5).

3 Balogun, I.A., N.T. Farina, E. Fay, K. Rossmarn and L. Poxyc. Energy cost determination using a portable accelerometer. Physical Therapy 66:1102-1109, 1986

4 Bandini, L.G., D.A. Schoeller, H. Cyr, V.R. Young, and W.H. Dietz. A validation of energy intake and energy expenditure in obese and non obese adolescents. Int. J. Obes.14:437 A, 1987.

5 Bcoyens, J., and G.R. Hervey. The pulse rate as a means of measuring metabolic rate in man. Can. J. Biochem. Physiol. $38: 1301-1309,1960$.

6 Borel, M.J., R.E. Riley and J.T. Snook. Estimation of energy expenditure and maintenance energy requirements of college-age men and women. Am. J. Clin. Nutr. 40:1264-1272, 1984.

7 Cauley, J.A., R.E. LaPonte, R.B. Sandler, M.M. Schramm and A.M. Kriska, Comparison of methods to measure physical acrivity in postmenopausal women. Am. J. Clin. Nutr. $45: 14+22$, 1987.

8 Christensen, C.C., H.M.M. Firey, E. Foenstelien, E. Aadland, and H.E. Ref sum. A critical evaluation of energy expenditure estimates based on individual Oxonsumption/heart rate curves and awerage daily heart rate. Am. J. Clin. Nutr. $37: 468-472,1983$.

9 Cotes, J.E. and F. Meade. The energy expenditure and mechanical energy demand wa walkig. Ergonomics. 36: 97-119, 1960.

10 Garrow, J.S. Energy balance and obesity in man. Amsterdam: North Holland Publishing Company, 1974 : $5-29$.

11 Geissler, C.A., T.M. Drumbira and M.I. Noor. Validation of a field technique for the measurement of energy expenditure: factorial method versus continuous respirometry. Am. I. Clin. Nutr. 44 : 596-602, 1986.

12 Groves, D. Beyond the pedometer: New tools for monitoring activity. The Physician and Sportsmedicine. 16:160-166, 1988 .

13 Haggarly, P., B.A. McGaw, R.J. Maughan and C. Fenn. Energy expenditure of elite female ahletes measured by the doubly-labelled water method. Proc. Nutr. Soc. 47:35A, 1988.

14 Harris, J.A. and F.G. Benedict A biometric study of basal metabolism in man. Camegie. Institution of Washington, $1919: 190$. 
15 Hatvast, JG. A.J. Onfwikheling wan een systeem om gegevens van woedings-enqueter met behulp van een computer le yerwerken. Voeding The Hague. 36:356-361, 1975.

16 Laporte R.E., H.J. Montoye and C.J. Caspersen. Assesgment of physical activity in epidemiologlcal research: Problems and prospects. Pub. Health Rep. 100:131-146, 1985.

17 Meriden, T. Does the Harris Benediet equation apply to all obese patients using microcomputer, and is the later instrumem a good stimulan for exercise. Int.J. Obes.11:432A, 1987.

18 Montoge, H.I. R. Washburn, S. Servais, A. Ertl, J.G. Webster and F.J. Nagle. Estimation of energy expenditure by a portable accelerometer. Medicine and Science in Sports and Exercise 15 : $403407,1983$.

19 Montoye, H.J. and H.L. Taylor. Measurement of physical activity in population studies: A review. Hum. Bioll, 56:195-216, 1984 .

20 Saris, W.H.M. Habilual physical activity in children: meshodology and findings in health and disease. Medicine and Science in Sponts and Exercise 18: $: 253-263,1986$.

21 Schull $z, \mathrm{KR}$ Westenterp and K Britck. Comparison of energy expenditure by the doubly labeled water lechnique with energy intake, heart rase, and activity recording in man. Am J Clin Nutr 49, $1146-1154,1989$.

22 Schutz, Y., F. Froidevaux and $\mathbb{E}$. Jequier. Estimation of 24 henergy expendiure by a portable accelerometer. Proc. of the Nutr. Soc. $47: 23 \mathrm{~A}, 1988$.

23 Servais, S.B., J.G. Webster, and H.J. Montoye. Essimaling human energy expenditure using an accelerometer device. I. Clin. Eng. $9: 159-170,1984$.

24 Singh, J., W.A. Coward, A. M. Prentice et al. Doubly-labelled water measurements of energy expenditure in Gambian women during the agricultural season. Proc. of the Nutr. Soc. $47: 41 \mathrm{~A}$, 1988.

25 Waterlow. J.C. Notes on the new international estimates of energy requirements. PToc. of the Nutr. Soc. $45: 351-360,1986$.

26 Westerterp, K.R., W.H.M. Saris, M. van Es and F. ten Hoor. Use of the dowbly labeled water technique in humans during heavy sustained exercise. J. Appl.Physiol. 61(6) ; 2162-2167, 1986.

27 World Health Organization. Energy and protein requirements, report of a joint FAO/WHOVUNO expert consultation. Technical Report Series 724, Geneva, 1985:71-79. 


\section{Chapter 4}

\section{Validity of the accelerometer in the field; a comparison with the doubly labeled water technique}

G.A.L.Meijer, K.R. Westerterp, L. Wouters, and F. ten Hoor

submitted for publication

\section{Abstract}

We compared physical activity as measured with an accelerometer for a 7 -day period in normal daily life with energy expenditure due to physical activity and the physical activity index. Physical activity was calculated from average daily metabolic rate (ADMR) measured with the doubly labeled water technique, and sleeping metabolic rate (SMR) measured overnight in a respiration chamber. The physical activity index was calculated as ADMR/SMR and ADMR as a multiple of basal metabolic rate (BMR) according to the formulas of Harris and Benedict. Working with 11 prototype accelerometers developed at our department, we had technical problems which were not all obvious. This made us to exclude data of seven bad performing instruments ( $\sim 50 \%$ of the observations). Nevertheless, the pooled data of the other four instruments show a very strong relationship both with the energy compartment ADMR-SMR $(n=21, r=0.88, p<0.001)$ as well as with $\mathrm{ADMR} / \mathrm{BMR}(\mathrm{n}=21, \mathrm{r}=0.71, \mathrm{p}<0.001)$, providing corrections are made for individual differences in energy expenditure at the same activity. If not corrected for these differences the accelerometer may still be of use in epidemiologic research as correlation with ADMR/BMR is significant $(n=24, r=0.64, p<0.001)$. These results show that the accelerometer is valid and accurate for measuring physical activity in the field. 


\section{Introduction}

Physical activity is a complex of different forms of behawiour that can be analyzed from different points of view. Here we focus on physical activity in terms of energy expenditure (1). Methods for measuring physical activity in normal daily life therefore should in a way reflect the energy expenditure resulting from that activity. The development of motion sensors, of which the accelerometers are the most recent devices, has so far shown to be the most promising attempt to meet this measure in an objective way.

Several researchers, using different types of accelerometers have shown that these instruments are valid in measuring the energy expenditure resulting from physical actiwity $(2,3,4)$. However most of these studies were conducted in the laboratory, or, when conducted in the field, the standard against which validity was examined was rather poor. In a study described previously we found a high correlation between accelerometer output $(A O)$ and energy intake $(r=0.99, p<0.05)$ in 4 adult subjects measured for seven days (3). However, for the calculation of ADMR from intake, energy balance over the period of study had to be assumed. Klesges et al. (5) showed a strong correlation $(r=0.69)$ between observed physical activity and accelerometer readings in 50 adults during one hour of recreational activities, while the correlation was only modest $(r=0.54)$ in children in a playing situation (6). Yet, observation techniques are not clearly linked to an energy measure, and the objectiveness of the method may be questioned.

The doubly labeled water technique is a unique and elegant method to measure energy expenditure of free living subjects $(7,8,9,10)$. As with the food intake method, however, only information on total energy expenditure is obtained. The advantage of the doubly labeled water technique is that no assumptions are necessary on energy balance, and that it is trully objective and yields a straight forward measure of energy expenditure in terms of $\mathrm{CO}_{2}$-production. Therefore this method seems the most preferable standard against which the accelerometer might be validated $(3,11)$. So far no such validation study has been published, however.

In two different studies we collected data on 52 subjects, including the combination of a 7 -day measurement of physical activity with the accelerometer, the measurement of ADMR using doubly labeled water, and the measurement of SMR during one night in a respiration chamber. Here we present the comparison of the results of the accelerometer with the expenditure measurements under free living conditions. 4 expenditure measures which are frequently used in literature for expressing physical activity were evaluated: a) ADMR-SMR; b) ADMR-SMR per $\mathrm{kg}$ body mass (BM); and the physical activity indices: c) ADMR/SMR; and d) ADMR/BMR. 


\section{Subjects and materials}

All subjects from two different studies, which have been described elsewhere $(12,13)$, who had their ADMR measured with the doubly labeled water technique combined with a one week measurement of physical activity with an accelerometer were included. Subject characteristics are presented elsewhere (12,13). The total group of observations consists of 9 obese subjects and 13 control subjects measured once, and of 16 subjects who were measured at the onset of an intervention program; eight of these were measured again after 8 and 20 weeks. One of the 13 control subjects refused doubly labeled water and from one subject of the intervention program accelerometer data were lost due to destruction of a diskette-unit, thus leaving a total of 52 combined observations of the accelerometer versus ADMR. SMR was measured in all subjects during a night in a respiration chamber at the onset of the 7-day measurement period.

Although it was not a standard procedure the accelerometers were often calibrated using the 'speaker-system' described previously (14) at a frequency of $5 \mathrm{~Hz}$ and an amplitude of $0.6 \mathrm{~mm}$. Corrections for differences found in this bench test calibration seemed only valuable when the instruments were calibrated both before and after the recording period (14). This correction (cb) was calculated as:

$$
\mathbf{c b}=\frac{\text { AObefore }+ \text { AOafler }}{2} * \frac{1}{150},
$$

where: AObefore $=$ accelerometer output before outdoor measurement (counts $/ \mathrm{min})$

and AOafier = accelerometer output after outdoor measurement (counts/min)

mathematically adjusting the mean response of the accelerometer to the arbitrary chosen output of 150 counts/min. These data were available for 30 of the 52 cases.

All subjects participated in an exercise test including $15 \mathrm{~min}$ sitting and $5 \mathrm{~min}$ level walking at $5 \mathrm{~km} / \mathrm{h}$. Energy expenditure (EE) was measured with an automated indirect calorimeter using a face mask (3). The individual net $\mathrm{EE}$ per count $\mathrm{AO}(\mathrm{cc})$ was calculated as:

$$
\operatorname{cc}(\mathrm{kJ} / \mathrm{count})=\frac{\mathrm{EE}(5 \mathrm{~km} / \mathrm{h})-\mathrm{EE} \text { (siling) }}{\mathrm{AO}(5 \mathrm{~km} / \mathrm{h})} \text {. }
$$

as $\mathrm{AO}$ was always zero when sitting. Due to the diskette loss mentioned before, data of 3 subjects got lost; two other subjects showed too much fear to complete the treadmill-test.

ADMR was calculated over the first week after administration of the doubly labeled water, which covered the 7-day period of accelerometry. SMR was measured in a respiration chamber, from $3.00 \mathrm{am}$ to $6.00 \mathrm{am}$ while the subjects were asleep. BMR was calculated using the formulas of Harris and Benedict (15). AO was calculated as the average of the 7-day period and is expressed in counts/day. 
The energy expenditure due to physical activity usually is about $25 \%$ of ADMR (Fig. 4.1). The energy compartment ADMR-SMR consists of diet induced thermogenesis and energy expenditure due to physical activity. Assuming diet induced thermogenesis to show little variance in the population (16) ADMR-SMR was used as the energetic measure of physical activity. To allow comparison between subjects this energy compartment is often expressed per $\mathrm{kg}$ BM. In this analysis both measures of expenditure were included. The physical activity index, which is now favoured by the WHO/FAO (17), expresses ADMR as a multiple of BMR. Usually ADMR/BMR ranges from 1.4 2.0 between individuals. We calculated both $A D M R / B M R$ and ADMR/SMR for comparison with $\mathrm{AO}$, as the latter represents a true measure of metabolic rate.

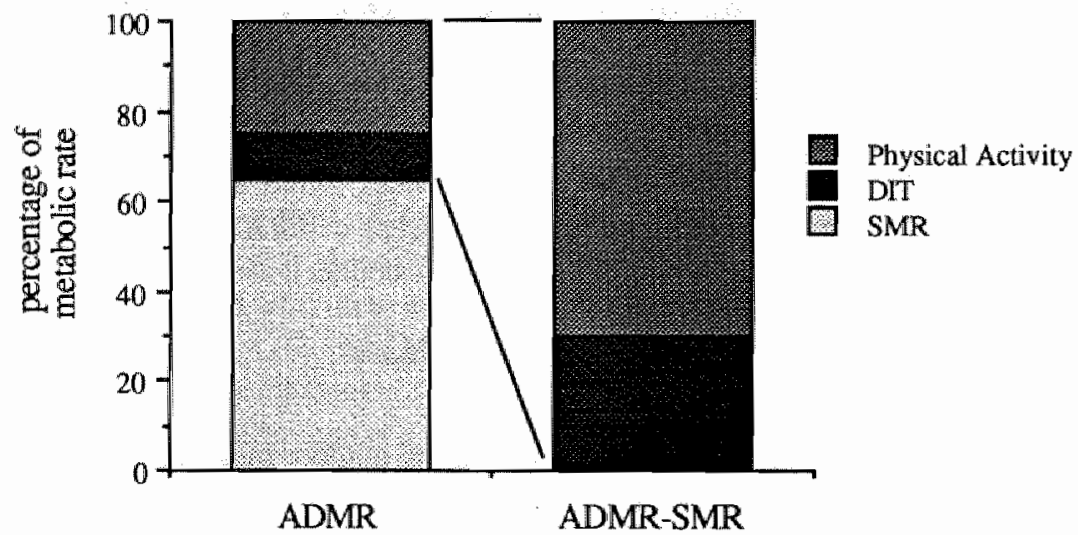

Fig $4.1 \quad$ Relative contribution of the energy compartments sleeping metabolic rate (SMR), diet-induced thermogenesis (DIT), and physical activity in a normal healthy subject.

\section{Results}

Values of accelerometer output usually range from 2500 to 19000 counts/day. However, in 6 cases we found values of over 20000 counts up to 65000 counts in one case (Fig. 4.2). These values did not match the other data on physical activity of the subjects. The reason for the appearance of these high values is not known, they may be due to an over-sensitivity of the accelerometer either for physical activity itself or perhaps for a disturbing factor in the specific environment of these subjects. Therefore, for further analysis, values of $A O>20000$ counts/day were excluded. This resulted in the elimination of instruments no. 1 and 4 due to the lack of sufficient data. (Table 4.1). 
Table 4.1 Frequency of observations per instrument in which accelerometer output (AO) was > 20000 counts/day.

\begin{tabular}{ccc}
\hline $\begin{array}{c}\text { instrument } \\
\text { no. }\end{array}$ & $\begin{array}{c}\text { number of } \\
\text { observations }\end{array}$ & AO 20000 \\
1 & 2 & 2 \\
3 & 3 & 0 \\
4 & 2 & 1 \\
5 & 7 & 0 \\
7 & 4 & 1 \\
8 & 6 & 0 \\
9 & 6 & 1 \\
10 & 5 & 0 \\
12 & 5 & 0 \\
13 & 5 & 0 \\
14 & 7 & 1 \\
total & & 6 \\
& 52 & $11.5 \%$
\end{tabular}

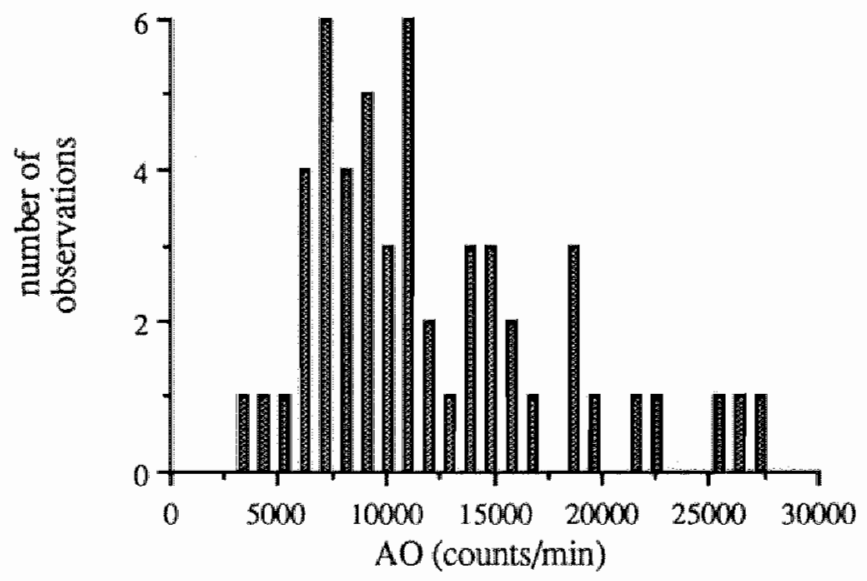

Fig. 4.2 Frequency distribution of accelerometer output (AO) of 51 subjects. One case $(A O=65000)$ is not shown. 
Table 4.2 Correlation coefficients ( $)$ between accelerometer output (AO) and ADMR-SMR, (ADMR-SMR)/kg body mass, ADMRISMR and ADMR/BMR.

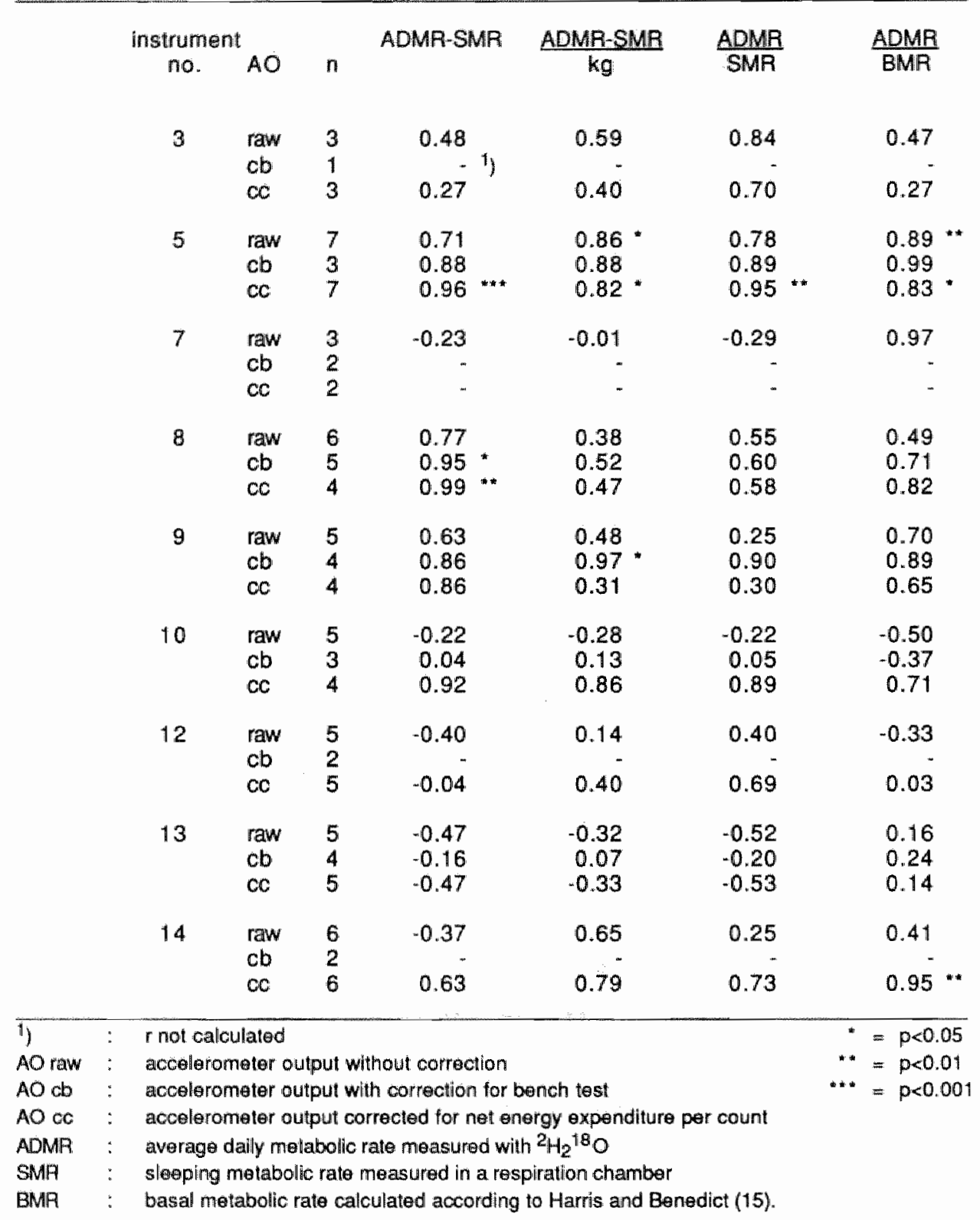


When comparing $A O$ with the four expenditure measures, results differed strongly depending on the device used (Table 4.2). Significant correlations between $\mathrm{AO}$ and energy expenditure could be found for devices no. 5, 8,9 and 14 whereas the other devices performed less well. For the devices no. 3 and 7 it can be argued that the number of observations was perhaps too low to detect a significant relationship, however, nos. 10,12 and 13 show only negative or very weak associations while the number of observations are comparable with the better performing instruments.

Correcting for differences found in the bench test (cb) shows a significant improvement for the relationships with the expenditure measures in devices no. 8 and 9 . The correction factor $c c$ has a significant and larger effect in devices no. 5, 8, and 14.

The effect of combining both corrections was analyzed by pooling the data of the instruments that showed a significant relationship with energy expenditure (Table 4.2 ; nos. 5,89 , and 14). This reveals that $c b$ is only of minor significance as compared to the effect of $c c$ (Table 4.3). The combination of both corrections $(n=12)$ seems to result in a further improvement of the data but this is only due to a selective effect since these cases are even better related to energy expenditure when only cc is applied.

Table 4.3 Correlation coefficients ( $n$ ) between accelerometer output (AO) and ADMR-SMR, (ADMR-SMR)/kg body mass, ADMR/SMR and ADMR/BMR. Pooled data of instruments $5,8,9$, and 14 .

\begin{tabular}{|c|c|c|c|c|c|c|}
\hline $\mathrm{AO}$ & n & ADMR-SMR & $\frac{\text { ADMR-SMR }}{\mathrm{kg}}$ & $\frac{\text { ADMR }}{\text { SMR }}$ & & $\frac{\mathrm{ADMR}}{\mathrm{BMR}}$ \\
\hline raw & 24 & 0.49 & $0.64 * *$ & 0.54 & $* *$ & 0.64 \\
\hline $\mathrm{cb}$ & 14 & 0.62 & $0.60^{\circ}$ & 0.54 & $*$ & 0.64 \\
\hline $\mathrm{Cc}$ & 21 & $0.88 \cdots$ & 0.64 & 0.75 & $* *$ & 0.77 \\
\hline $\mathrm{cb}+\infty \mathrm{c}$ & 12 & $0.91 \ldots$ & 0.61 & 0.73 & $*$ & 0.79 \\
\hline $\mathrm{CC}$ & 12 & 0.94 & 0.70 & 0.80 & $* *$ & 0.84 \\
\hline
\end{tabular}

For explanation of abbreviations and significance levels see Table 4.2

Thus the correction factor $\mathrm{ce}$ reflecting the net $\mathrm{EE}$ per count $\mathrm{AO}$ seems to be most appropriate. Apparently physical activity as reflected by the accelerometer is mostly associated with the absolute value of energy expenditure ADMR-SMR, and with the physical activity index expressed as ADMR/BMR (Fig. 4.3 and 4.4). The standard error of estimate $\left(S_{y, x}\right)$ is 706 and $942 \mathrm{~kJ} /$ day respectively. 


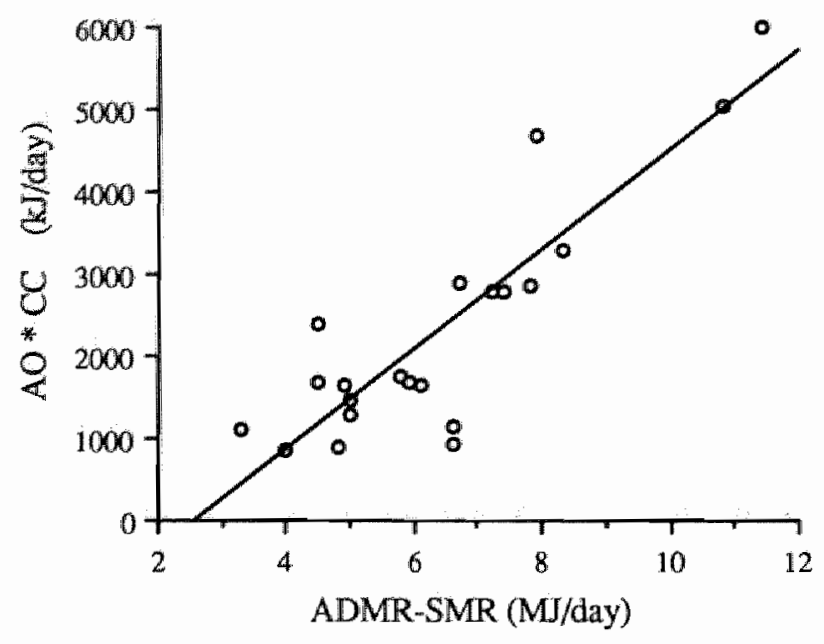

Fig. 4.3 Accelerometer output ( $A O$, with appliance of the individual correction factor cc) compared with average daily metabolic rate (ADMR) minus sleeping metabolic rate (SMR), as measured using doubly labeled water and respiration chamber, respectively $n=21, r=0.88, p<0.001, S_{y, x}=706 \mathrm{~kJ} / \mathrm{day}$ )

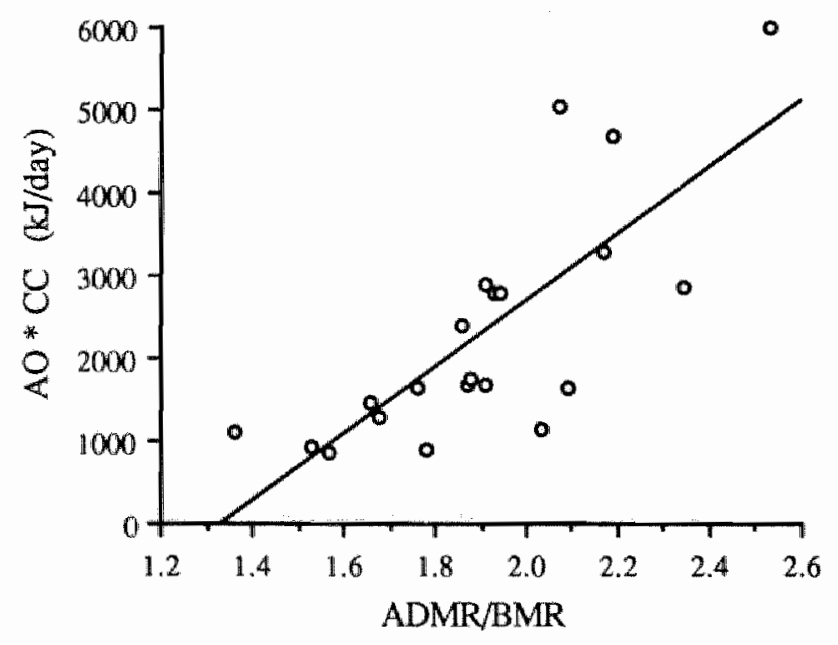

Fig. 4.4 Accelerometer output ( $A O$, with appliance of the individual correction factor cc) compared with the average daily metabolic rate as a multiple of basal metabolic rate (ADMR/BMR). $n=21, r=0.77, p<0.001, S_{y, x}=942 \mathrm{~kJ} / \mathrm{d}$ lay). 


\section{Discussion}

This validation study was conducted using 11 prototype accelerometers developed at our department. After evaluating the results we had to conclude that some devices performed bad, whereas others measured activity very accurate in terms of energy expenditure. Apart from this, in 6 cases we found values of $A O>20000$ counts/day that did not match other data on physical activity of the subjects. So far it is not clear which phenomena are responsible for these observations. It can be easily thought of that these high values are caused by an increasing sensitivity of the accelerometer during the seven day outdoor measurement, as this was found in many cases during bench test calibration (14). However, we could not find such a direct relation. Also speaking against this hypothesis is the small influence that is found when $\mathrm{AO}$ is corrected for this changing sensitivity. This confirmed our earlier findings in the test-retest experiment (14), and again the relevance of bench test calibration of motion sensors, as favoured by some researchers may be questioned $(18,19)$. From a larger set of data we collected on 7-day accelerometry that was not combined with the measurement of average daily metabolic rate and therefore not presented here, it appeared that values of $A O>20000$ counts/day occurred in 100 and $80 \%$ of the observations when using instrument nos. 1 and 4 respectively, whilst in the other instruments this percentage was less than $15 \%$. This suggests some technical problem in instrument nos. 1 and 4 . However this does not explain the occurrence of these observations in the other instruments. Therefore, it may also be that some disturbing factor in the environment or behaviour of the subject causes these high outputs.

For the comparison of $\mathrm{AO}$ with energy expenditure due to physical activity, we excluded all observations of $\mathrm{AO}>20000$ counts/day, and all observations that were collected with instruments of which the results did not correlate significantly with these expenditure measures. This reduced our sample size to 24 subjects of which data were collected using four accelerometers.

The pooled data on $\mathrm{AO}$ of these 24 cases, either raw or corrected, showed significant correlations with all four expenditure measures we calculated from ADMR, SMR and $B M R$. From the four expenditure measures $A O$ correlates best with the energy compartment ADMR-SMR, and with the physical activity index ADMR/BMR. It seems reasonable that ADMR-SMR would reflect physical activity in a better way when expressed per $\mathrm{kg}$ body mass, and indeed it does when the raw accelerometer data are looked upon $(r=0.64, p<0.001$ versus $r=0.49, p<0.05$ for ADMR-SMR). This suggests that $\mathrm{AO}$ - without corrections made - indicates the amount of body movement per se. However, when applying $\mathrm{cc}$ which is not expressed per $\mathrm{kg}$ body mass $\mathrm{AO}$ shows a closer relationship with ADMR-SMR ( $\mathrm{r}=0.88$ versus $\mathrm{r}=0.64$ for $(\mathrm{ADMR}-\mathrm{SMR}) / \mathrm{kg}$ ). When comparing ADMR/BMR with ADMR/SMR one might expect the latter to be a more 
accurate index of physical activity since it represents a direct measure of resting metabolic rate over a predicted one. Yet the explained variation in accelerometer output is always about 10\% higher when using ADMR/BMR. This may be explained assuming that physical activity itself influences resting metabolic rate, a topic largely debated nowadays $(20,21)$. If an increase in physical activity induces an increase in sleeping metabolic rate without a change in body mass, this would reduce the effect on the activity index ADMR/SMR whereas ADMR/BMR would increase.

The correction factor based upon the bench test calibration (cb) did not significantly improve any of the relationships, which indicates that differences between the four instruments are probably not reflected in outdoor measurement circumstances. Correction for differences between subjects in net EE spent per count movement registered (cc), however, had a large positive effect. This correction factor varied largely within the population studied and ranged from 0.08 to $0.45 \mathrm{~kJ} /$ count. Two major factors may be responsible for these large inter-individual differences, that will be subject of future analysis. The first is body mass, a heavier subject spending more energy than a light one performing the same activity (22). The second one is what may be called activity economy, some subjects being better skilled to perform particular activities than others $(23,24)$.

EE as calculated from $\mathrm{AO}$ is about $50 \%$ of ADMR-SMR (Fig. 4.3). However, one should not forget that the energy compartment ADMR-SMR also includes diet induced thermogenesis which - being $10 \%$ of ADMR - is about $30 \%$ of that compartment (Fig. 4.1) and, secondly, there is an extra cost of sitting over SMR which is not detected by the accelerometer. The combination of these two factors will largely explain the apparent discrepancy. Assuming a variation in diet induced thermogenesis between $7 \%$ and $14 \%$ of ADMR within this population $(16,25)$, it can be calculated that physical activity will explain at most about $80 \%$ of the variation in ADMR-SMR. Both compared with this estimation, as well as with earlier validation studies, the explanation of $77 \%$ of the variation of ADMR-SMR from AO, as found in this study, is outstanding, and shows the prospects of this instrument for future research on physical activity. The need of an individual correction factor in net calories per count, al though quite easily assessed in a 30 min laboratory test using standardized equipment, however, will reduce the power of this technique, since it blocks the way of studying larger populations. Therefore future research should concern the physiological factors responsible for these individual differences, providing the possibility of a good estimate of this individual value. 


\section{References}

1 Caspersen, CC, KE Powell, and GM Christenson. Physictal activity, exertise and physical finess. Definitions and distinctions for health-related research. Publ Health Rep 100, 126-131. 1985.

2 Montoye, HJ, R Washburn, S Servais, A Ertl, JG Webster, and F Nagle. Estimation of energy expenditure by a porlable accelerometer. Med Sci Sports Exerc 15, 403-407, 1983.

3 Meijer, GA, KR Westerterp. H Koper, and F ten Hoor. Assessment of energy expenditure by recording heart rate and body acceleration. Med Sci Sports Exerc 21, 343-347, 1989.

4 Avons, P, P Garthwaite, HL Davies, PR Murgatroyd and WPT James. Approaches to estimating physical activity in the community, Calorimetric validation of actometers and heart rate monitoring. Eur J Clin Nutr 42,185-196, 1988.

5 Klesges, RC, LM Klesges, AM Swenson, and AM Pheley. A validation of two motion sensars im the prediction of child and adult physical activity levels. Am J Epidemiol 122, 400-410, 1985.

6 Klesges, LM, and RC Klesges. The assessment of children 's physical activity: a comparison of methods. Med Sci Sports Exerc 19,511-517, 1987.

7 Lifson, N, R McClintock. Theory of the wse of the turnover rates of body water for measuring energy and material balance. J Theor Biol $12,46-74,1966$.

8 Schoeller, DA. Energy expenditure from doubly labeled water: some fundamental considerationss in humans. Am J Clin Nutr 38, 999-1005,1983.

9 Westerterp, KR, WHM Saris, M van Es, and F ten Hoor. Use of the dowbly labeled water technique in humans during heavy sustained exercise. J Appl Physiol 61, 2162-2167, 1986.

10 Prentice AM, WA Coward. HL Davies et al. Unexpectedly low levels of energy expendiure in healthy women. Lancet $i_{1}$ 1419-1422, 1985.

11 LaPorte, RE, HJ Montoye, and CJ Caspersen. Assessment of physical activity in epidemiological research: problems and prospects. Publ Health Rep 100, 131-146, 1985.

12 Meijer, GAL, KR Westerterp. AMP van Hulsel, and Fen Hoor. Physical activity and energy expenditure in lean and obese adult human subjects. this Thesis, Chapter 5.

13 Meijer, GAL, GME Janssen, KR Westerterp, F Verhoeven, WHM Saris, and F ten Hoor. The effect of a 5-monh endurance-training program on physical activity: evidence for a sex-difference in the metabolic response to exercise. this thesis, Chapter 6.

14 Meijer, GAL, KR Westerterp, F Verhoeven, H Koper, and F ten Hoor. Methods to assess physical activity with special reference to motion sensors and accelerometers. this Thesis, Chapter 2.

15 Harris, JA, and FG Benedict. A biometric sindy of basal metabolism in man. Carnegie Institution of Washington, 1919, pp. 190.

16 Sims, EAH, and E Danforth. Expenditure and storage of energy in men. I Clin Invest 79, 1019$1025,1987$.

17 World Health Organization. Energy and protein requirements, report of a joint FAO/WHOIUNO expert consultation. Technical Report Series 724, Geneva, 1985, pp. 71.79.

18 Tryon,WW, and GM Klemuck, The reliability and validity of actometers. In: WW Tryon (ed), Behavioral assessmemt in behawioral medicine. New York, Springer, 1985, pp. 218-233

19 Saris, WHM. The assessment and evaluaton of daily physicat activity in children. A review. Acia Poediatr Scand $318,37-48,1985$.

20 Tremblay, A, A Nadeau, G Foumier, and C Bouchard. Effect of a three doy internuption of exercise training on resting metabolic rate and ghcose-induced thermogenesis in trained individuals. Int I Obes $12,163-168,1988$.

21 Westerterp, KR. GAL Meijer, WHM Saris, PB Soeters, Y Winants, and F Ien Hoor. Physical activity and sleeping metabolic rate (submitted for publication).

22 Meijer, GA. Energy requirements of the abese: The effect of body mass on energy expenditure. Int J Obes 13 (Suppl. 1), 7, 1989.

23 Maloye, GMO, NC Heglund, LM Prager, CA Cavagna, and CR Taylor. Energetic cost of carrying loads: have African women discovered an economic way? Nature 319, 668-669, 1986.

24 Cavanagh, PR, and R Kram. The efficiency of human movement - a statement of the problem. Med Sci Sports Exerc 17, 304-308, 1985.

25 Weststrate, JA, P Deurenberg, and JGA J Hautvast. Naure and magnitude of inter-individuel differences in resting metabolic rate and diet-induced thermogenes is in lean and obese individuals. PhD. thesis, Wageningen. The Notherlands, 989 , pp. 140-159. 


\title{
Chapter 5
}

\section{Physical activity and energy expenditure in lean and obese adult human subjects}

\author{
G.A. L. Meijer, K.R. Westerterp, A.M.P van Hulsel, and F, ten Hoor
}

submitted for publication

\begin{abstract}
Low levels of physical activity might play a role in the development of adult obesity. We compared physical activity of 13 lean and 9 obese men and women and found no significant differences in either the amount of movement registered with an accelerometer over a 7-day period ( $9712 \pm 3557 \vee 9687 \pm 2753$ counts/day), nor in the energy expenditure due to physical activity reflected by average daily metabolic rate (ADMR) as measured by the doubly labeled water technique minus sleeping metabolic rate (SMR) measured in a respiration chamber. Yet, the obese tended to have a higher energy expenditure due to physical activity (ADMR-SMR: $6.9 \pm 2.1 v 5.9 \pm 2.1 \mathrm{MJ} /$ day in the lean). This extra energy expenditure probably resulted from the extra cost of weight bearing activities as it was shown that the net cost of walking at $5 \mathrm{~km} / \mathrm{h}$ on the level was significantly higher in the obese $(0.26 \pm 0.11 v 0.18 \pm 0.08 \mathrm{~kJ} / \mathrm{count}, \mathrm{p}<0.05)$. When expressed per $\mathrm{kg}$ fat free mass (FFM) ADMR-SMR did not differ between lean and obese

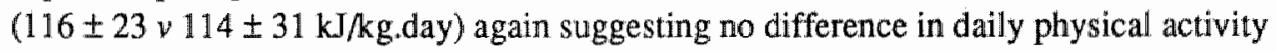
between the groups. Energy intake was measured by a 7-day food diary. On average it was slightly less than ADMR in the lean subjects (-1.5 MJ/day), in the obese group the discrepancy with ADMR was much higher ( $-4.5 \mathrm{MJ} / \mathrm{day})$. No metabolic disorder could be found in the obese while changes in body mass suggest that both dieting and undertecording of energy intake occurred.
\end{abstract}




\section{Introduction}

Despite an enormous amount of research in the last three decades the question of the etiology of obesity is still not solved. All hypotheses being proposed concern either reduced energy expenditure in one or more of the major energy compartments, resting metabolic rate $(1,2)$, diet induced thermogenesis (3) and the energy expenditure due to physical activity (4), or an increased energy intake when compared to energy requirements $(5,6)$. Both effects would result in a positive energy balance inducing energy storage in fat. When comparing food intake of obese subjects with that of lean ones the results of different studies are quite uniform and show that intake in both groups is equal or even less in the obese $(5-10,52)$. This finding has led to the hypothesis of large and small eaters, the latter being somehow more efficient and therefore predisposed for obesity $(11,12)$, and has drawn attention to the expenditure site of energy balance.

Most studies reported up till now on resting metabolic rate show that this energy compartment is strongly related to active cell mass, mostly measured as fat free mass (FFM) using underwater weighing or dilution techniques (13-15,19). When expressed in absolute values, resting metabolic rate is increased in obese subjects. However, when expressed per $\mathrm{kg}$ FFM resting metabolic rate does not differ from that in lean subjects or may be slightly higher (13-19). However, in a more recent prospective study on Pima Indians, Ravussin et al. show that 1.5 subjects who gained more than $10 \mathrm{~kg}$ in 4 years had initial lower $(-4 \%)$ metabolic rate -adjusted for body composition, sex, and age- than a control group of 111 subjects (20). Another recent study of Weststrate et al. shows that adjusted resting metabolic rate is lower $(-10 \%)$ in obese women with a non-abdominal fat distribution compared to obese women with abdominal fat distribution and to control women (21).

Some studies on diet induced thermogenesis showed reduced values for the obese $(22,23)$, however, in most studies no difference between obese and non-obese subjects could be found $(17,18,24,25,28)$.

The existence of a deficit in resting metabolic rate or in diet induced thermogenesis in obese individuals may be controversial, this is even more so for the energy expenditure due to physical activity. In an extensive review on this matter Thompson et al. (26) report on 9 studies that found obese to be less active than non-obese, while 7 studies found no differences. The major problem in drawing conclusions from this finding is the variety of methods which have been used to measure physical activity. However, when these methods are categorized, it appears that from 8 studies using teacher ratings, activity diaries and observational-and recall techniques, 6 report the obese to be less active, while from 8 studies using pedometers, actometers, heart rate monitoring or other movement recordings, only three do so. Assuming the latter techniques to be more accurate in measuring physical activity it may be concluded that no difference in physical activity exists between obese and lean subjects. This conclusion is confirmed in more recent 
research on free living energy expenditure in lean and obese adults (10). Above this it should be reminded that the observation of less physical activity does not directly imply lower energy expenditure as most activities result in extra expenditure in the obese due to their higher body mass. However, two studies on energy expenditure in children of lean and obese parents show convincing evidence of lower energy expenditure in the latter group that must be attributed to lower physical activity $(27,28)$. Roberts et al. (28) showed a decreased energy expenditure measured with the doubly labeled water technique in children three months of age, born to overweight mothers, who became overweight in their first year of live. This decrease was most probably due to decreased physical activity, the mean difference in energy expenditure with children of lean mothers being sufficient to explain the rate of energy deposition in their first 12 months. Therefore reduced physical activity during childhood might play an important role in the onset of obesity. This finding leads to the question why this decrease in activity cannot be found when studying adults since it seems unlikely that activity would increase again due to the higher efforts necessary after weight gain. Methodological problems in the earlier studies on physical activity may have masked such a decrease.

The purpose of this study was to compare physical activity and energy expenditure under free living conditions - of adult obese men and women with that of lean control subjects, with the aid of two new techniques. A previously described accelerometer was used to measure body acceleration during seven days $(29,30)$, and the doubly labeled water technique was used for the measurement of $\operatorname{ADMR}(31,32)$. Additional measurements of body composition, sleeping metabolic rate (SMR) and energy expenditure during level walking at $5 \mathrm{~km} / \mathrm{h}$ were conducted at the laboratory.

\section{Methods}

\section{Subjects}

Subjects were recruited by advertisement in two local newspapers and via a local radio station. After information on the aim and protocol of the study 13 lean (6 male, 7 female) and 9 obese ( 4 male, 5 female) subjects gave their consent and adhered to the study. All subjects reported stable body mass (changes $<\sim 2 \mathrm{~kg}$ ) during the last year and none of the subjects had followed a diet during the last year or planned to do so during the course of the study. A medical examination before the start of study, showed them to be in normal healthy condition. The cut off point for classification of the subjects as being obese was set at Quetelet index (QI) $>27$ (33). Subject characteristics are shown in Table 5.1. When using the cut off point QI $>25$ (34) 2 males and 2 females of the lean group were moderate obese. However, the body composition of the male subjects showed that they were muscular and had a normal body fat content. Therefore they were assigned to the lean group. The two females with QI $>25$ hadl a higher \% body fat than the others in the lean group, which is probably due to their older age. Age and height of the subjects were 
well matched between the obese and control group, although the females were on average 6 years younger than the males.

\section{Protocol}

All subjects entered the laboratory on day zero at 18.30 for an overnight sleep in the respiration chamber (Fig. 5.1) (35). Sleeping metabolic rate was measured from 3.00 to $6.00 \mathrm{~h}$ when subjects were asleep. Basal metabolic rate was calculated according to the equations of Harris and Benedict (36). After entrance of the respiration chamber no meals were eaten, drinking was allowed only before 22.00 . At 22.30 the isotope drink was administered after emptying the bladder (control sample). One subject (F10) refused drinking the doubly labeled water. The dosage calculation was based on body mass in order to create a $2 \mathrm{H}$ excess of $150 \mathrm{ppm}$ and an $18 \mathrm{O}$ excess of $300 \mathrm{ppm}$. Further urine samples were collected on day one in the moming after the first voiding and by the subjects at home on day one, $7,8,14$ and 15 at $20.00 \mathrm{~h}$. ADMR was calculated using the equations of Schoeller (37).

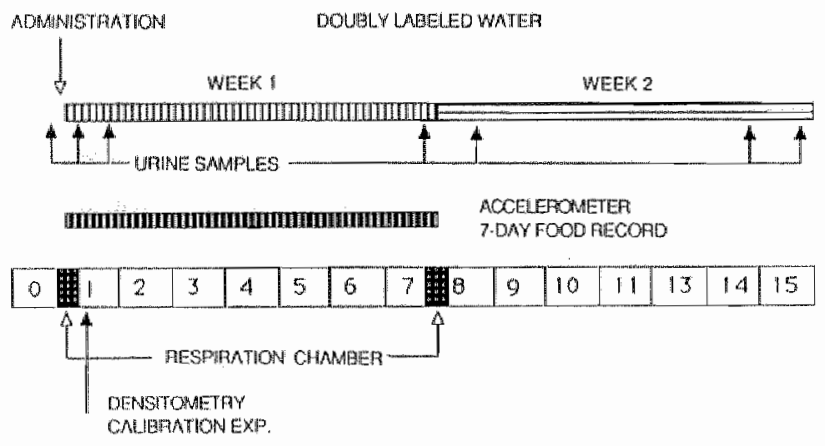

Fig. 5.I Schematic presentation of the protocol used in this study.

Body mass was measured directly after waking up at 7.30 in the morning, after emptying the bladder and without clothing. After a light breakfast body composition was measured by densitometry and an experiment was conducted to achieve the individual relationship between accelerometer output ( $\mathrm{AO}$ ) and energy expenditure. This test consisted of $15 \mathrm{~min}$ sitting and 5 min level walking on a treadmill. Energy expenditure was measured by an automated indirect calorimeter using a face mask (Ergoscreen, Fenyvus and Gut, Basel, Switzerland). The calorimeter was calibrated before each session using calibration gases. Two subjects showed too much fear for the treadmill. Subjects who were not able to 
participate in these measurements during the morning of day 1 were measured within a week before or after the field measurement week.

Subjects wore the accelerometer from day 1 up to day 7 during the time of the day they were awake. They came back to the laboratory on day 7 at 18.30 for a second overnight sleep in the respiration chamber, after which body mass was measured again. Because of malfunctioning of some of the accelerometers only data gathered with instrument nos. 5, 8, 9, and 14 were included (38).

Table 5.1 Subject characteristics

\begin{tabular}{|c|c|c|c|c|c|c|c|}
\hline $\begin{array}{c}\text { subject } \\
\text { no. }\end{array}$ & & $\begin{array}{c}\text { age } \\
\text { (years) }\end{array}$ & $\begin{array}{l}\text { height } \\
(\mathrm{cm})\end{array}$ & $\begin{array}{c}\text { body mass } \\
(\mathrm{kg})\end{array}$ & $\begin{array}{c}\text { Ql } \\
\mathrm{kg} / \mathrm{m}^{2}\end{array}$ & $\begin{array}{l}\text { tat free } \\
\text { mass }(\mathrm{kg})\end{array}$ & $\begin{array}{c}\% \\
\text { body fat }\end{array}$ \\
\hline \multicolumn{8}{|c|}{ lean group } \\
\hline $\begin{array}{ll}M & 1 \\
M & 2 \\
M & 3 \\
M & 4 \\
M & 5 \\
M & 6\end{array}$ & & $\begin{array}{l}39 \\
38 \\
39 \\
39 \\
32 \\
34\end{array}$ & $\begin{array}{l}170 \\
173 \\
178 \\
182 \\
179 \\
169\end{array}$ & $\begin{array}{l}62.3 \\
72.1 \\
80.2 \\
85.0 \\
77.1 \\
67.2\end{array}$ & $\begin{array}{l}21.6 \\
24.1 \\
25.3 \\
25.7 \\
24.1 \\
23.5\end{array}$ & $\begin{array}{l}50.7 \\
56.5 \\
67.5 \\
71.9 \\
61.2 \\
56.4\end{array}$ & $\begin{array}{l}18.6 \\
21.6 \\
15.8 \\
15.4 \\
20.6 \\
16.1\end{array}$ \\
\hline $\begin{array}{l}F 7 \\
F 8 \\
F 9 \\
F 10 \\
F 11 \\
F 12 \\
F 13\end{array}$ & & $\begin{array}{l}38 \\
23 \\
42 \\
37 \\
30 \\
21 \\
27\end{array}$ & $\begin{array}{l}161 \\
163 \\
163 \\
167 \\
171 \\
167 \\
166\end{array}$ & $\begin{array}{l}54.2 \\
52.0 \\
70.1 \\
72.6 \\
51.2 \\
55.6 \\
56.0\end{array}$ & $\begin{array}{l}20.9 \\
19.6 \\
26.4 \\
26.0 \\
17.5 \\
19.9 \\
20.3\end{array}$ & $\begin{array}{l}40.7 \\
38.8 \\
43.5 \\
47.7 \\
41.9 \\
44.7 \\
43.8\end{array}$ & $\begin{array}{l}24.9 \\
25.4 \\
37.9 \\
34.3 \\
18.2 \\
19.6 \\
21.8\end{array}$ \\
\hline mean $\pm S D$ & $\stackrel{M}{\mathrm{M}}$ & $\begin{array}{l}37 \pm 3 \\
31 \pm 8\end{array}$ & $\begin{array}{l}175 \pm 5 \\
165 \pm 3\end{array}$ & $\begin{array}{l}74.0 \pm 8.4 \\
58.8 \pm 8.8\end{array}$ & $\begin{array}{l}24.1 \pm 1.5 \\
21.5 \pm 3.4\end{array}$ & $\begin{array}{l}60.7 \pm 7.8 \\
43.0 \pm 2.9\end{array}$ & $\begin{array}{l}18.0 \pm 2.7 \\
26.0 \pm 7.4\end{array}$ \\
\hline \multicolumn{8}{|c|}{ abese group } \\
\hline $\begin{array}{l}\text { M14 } \\
\text { M15 } \\
\text { M16 } \\
\text { M17 }\end{array}$ & & $\begin{array}{l}38 \\
32 \\
41 \\
37\end{array}$ & $\begin{array}{l}187 \\
188 \\
176 \\
181\end{array}$ & $\begin{array}{r}127.8 \\
125.1 \\
89.0 \\
94.7\end{array}$ & $\begin{array}{l}36.5 \\
35.4 \\
28.7 \\
28.9\end{array}$ & $\begin{array}{l}90.7 \\
72.4 \\
60.8 \\
68.3\end{array}$ & $\begin{array}{l}29.0 \\
42.1 \\
31.7 \\
27.9\end{array}$ \\
\hline $\begin{array}{l}F 18 \\
F 19 \\
F 20 \\
F 21 \\
F 22\end{array}$ & & $\begin{array}{l}24 \\
311 \\
41 \\
29 \\
25\end{array}$ & $\begin{array}{l}155 \\
168 \\
180 \\
162 \\
169\end{array}$ & $\begin{array}{c}68.6 \\
94.5 \\
103.5 \\
86.6 \\
85.2\end{array}$ & $\begin{array}{l}28.6 \\
33.5 \\
31.9 \\
33.0 \\
29.8\end{array}$ & $\begin{array}{l}42.3 \\
50.4 \\
54.5 \\
50.3 \\
45.9\end{array}$ & $\begin{array}{l}38.3 \\
46.7 \\
47.3 \\
41.9 \\
46.1\end{array}$ \\
\hline $\operatorname{moan} \pm S D$ & $\stackrel{M}{F}$ & $\begin{array}{l}37 \pm 4 \\
30 \pm 7\end{array}$ & $\begin{array}{l}183 \pm 6 \\
167 \pm 9\end{array}$ & $\begin{array}{r}109.2 \pm 20.1 \\
87.7 \pm 12.9\end{array}$ & $\begin{array}{l}32.4 \pm 4.2 \\
31.4 \pm 2.1\end{array}$ & $\begin{array}{l}73.1 \pm 12.7 \\
48.7 \pm 4.7\end{array}$ & $\begin{array}{l}32.7 \pm 6.5 \\
44.1 \pm 3.9\end{array}$ \\
\hline
\end{tabular}




\section{Food intake}

Subjects recorded their food intake from day 1 to 7 in a diary that was divided in 7 periods a day ( 3 meals, 4 inter meal periods). Subjects estimated portions or in case of doubt weighed them on a balance. Brand names were asked for as well as cooking recipes that were used. Repeatedly used amounts were measured with a $400 \mathrm{ml}$ cup with $10 \mathrm{ml}$ scaling. During a short session with the subject directly after the measurement week, two dietitians examined the diary to eliminate inconsistencies and other problems. Nutrient content of the foods was calculated using the Dutch nutrient table (39).

\section{Results}

\section{Physical activity}

The energy compartment ADMR-SMR which is largely accounted for by physical activity tended to be higher in the obese (men: $7.8 \vee 6.7 \mathrm{MJ} / \mathrm{day}, \mathrm{NS}$; women: $6.1 \vee 5.0 \mathrm{MJ} / \mathrm{day}$ NS; Table 5.2). However, ADMR-SMR was related to FFM ( $\mathrm{r}=0.65, \mathrm{p}<0.005)$ and when adjusted for FFM it was equal both in groups and sexes (men: $106 v 111$ $\mathrm{kJ} / \mathrm{kg}$.day, NS); women: $124 v 117 \mathrm{~kJ} / \mathrm{kg}$.day, NS). This suggests the difference in ADMR-SMR to be due to differences in body mass, resulting in higher energy expenditure in the obese at an activity level comparable to that in the lean. Although the number of observations with accelerometry is low in all groups, due to the exclusion of three instruments (40), the results do not show any difference in $A O$ between lean and obese. However, there is a large variation in individual $A O$, the coefficient of variance being $56 \%$ in the lean males. Similarly ADMR/BMR was equal in all groups, the lean males again showing the largest variance.

Net energy expenditure when level walking at $5 \mathrm{~km} / \mathrm{h}$ was higher in the obese (men $20.5 \vee 13.7 \mathrm{~kJ} / \mathrm{min}, \mathrm{p}<0.01$; women: $20.0 \vee 15.1 \mathrm{~kJ} / \mathrm{min}, \mathrm{p}<0.05$ ). It was linearly related to body mass $(n=20, r=0.72, p<0.001$; Fig 5.2). Expressing net $E E$ in $k J /$ count, values also were higher in the obese al though only significant in obese men $(p<0.05)$. For all subjects only a weak linear relationship with body mass was found $(n=20, r=0.39$, $\mathrm{p}=0.09)$. 
Table 5.2 Accelerometer output (AO) 1), average daily metabolic rate minus sleeping metabolic rate (ADMR-SMR), (ADMR-SMR)/kg lat free masis (FFM). ADMR as a multiple of basal metabolic rate (BMA), and net energy expenditure (EE) when level walking at $5 \mathrm{~km} / \mathrm{h}$.

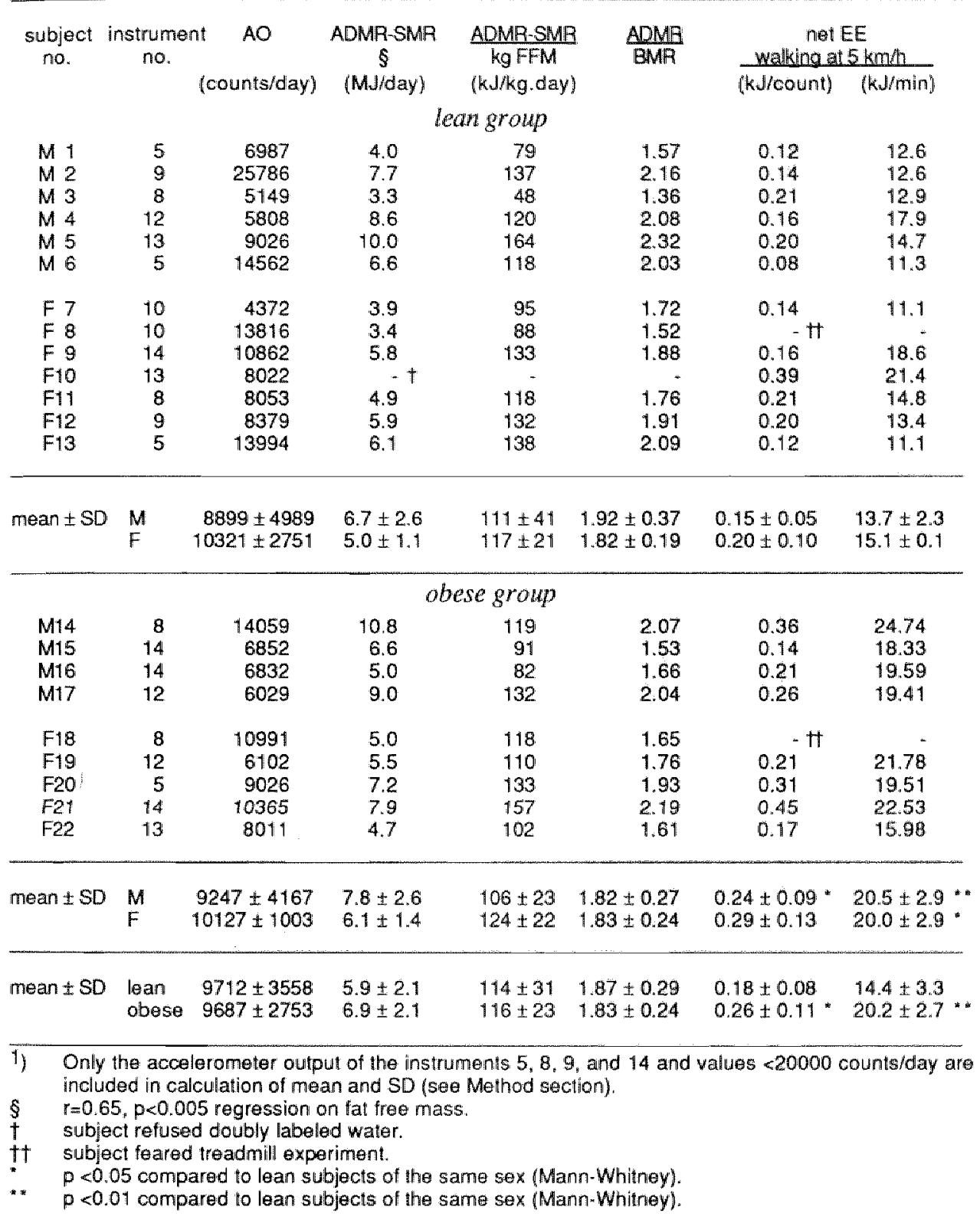




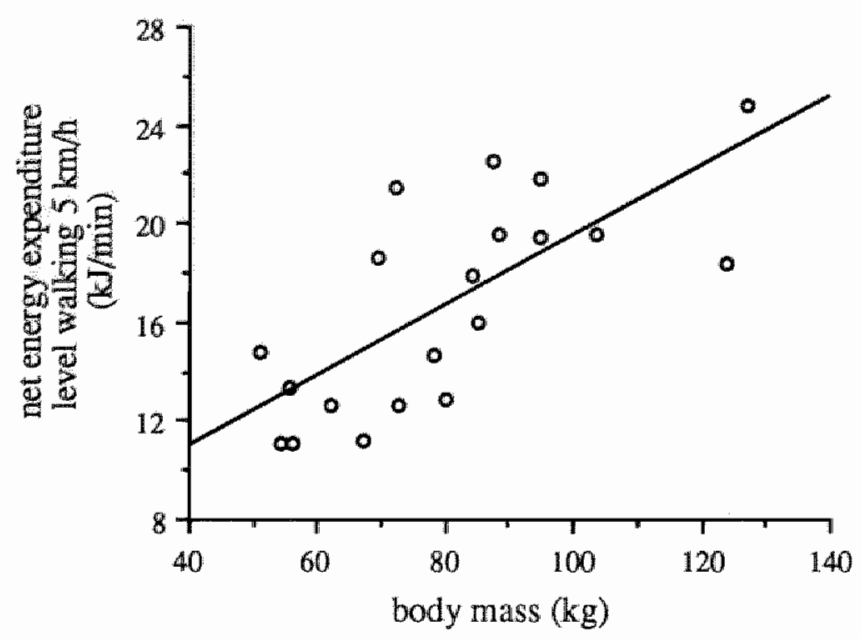

Fig. 5.2 Net energy expenditure when level walking at a speed of $5 \mathrm{~km} / \mathrm{h}$ compared with body mass $(n=20, r=0.72, p<0.001)$.

\section{Sleeping metabolic rate}

SMR was significantly higher in the obese compared to the lean (men: $9.2 v 7.1 \mathrm{~kJ} / \mathrm{day}$, $p<0.01$; women: $6.6 \times 5.5 \mathrm{~kJ} / \mathrm{day}, \mathrm{p}<0.05$, Table 5.3). These differences are largely due to differences in fat free mass (FFM). SMR/kg FFM was not significantly different between the groups. In both groups males had lower SMR/kg FFM than females $(p<0.05)$. SMR did not significantly differ from BMR in any of the groups. Here the females show lower values (SMR is 95 and $96 \%$ of BMR in lean and obese respectively; in males: SMR is $99 \%$ of BMR in both groups). The individual values ranged from 84 to $106 \%$ of BMR.

\section{Energy expenditure and energy intake}

ADMR was $3.2 \mathrm{MJ} /$ day higher for obese men and $2.4 \mathrm{MJ} /$ day higher for obese women compared to lean men and women respectively (Table 5.3). These differences were not statistically signilicant. Energy intake was lower than ADMR in all four groups. Seven subjects reported an energy intake within $1 \mathrm{MJ} /$ day $(\sim 10 \%)$ from ADMR as measured with doubly labeled water. Six of them were lean. The discrepancy with ADMR increases with body mass ( $n=21, r=0.69, p<0.001$, Fig 5.3). The changes in body mass found, suggest that dieting may have occurred in the obese men and in one obese woman. Assuming body mass loss to consist of fat mass only with an energy density of 37.7 $\mathrm{MJ} / \mathrm{kg}$ (34) this explains $97 \%$ of the average discrepancy found in the obese men. However, in the other three groups such adjusted energy intakes match worse with ADMR than reported intakes only. 
Table 5.3 Sleeping metabolic rate (SMR), SMR/kg fat free mass (FFM), SMR/basal metabolic rate (BMR), average daily metabolic rate (ADMR), energy intake and change in body mass over the measurement period.

\begin{tabular}{|c|c|c|c|c|c|c|c|}
\hline $\begin{array}{l}\text { subject } \\
\text { no. }\end{array}$ & & $\begin{array}{c}\text { SMR } \\
\text { (MJ/day) }\end{array}$ & $\frac{\text { SMR }}{\text { FFM }}$ & $\frac{\mathrm{SMB}}{\mathrm{BMR}}$ & $\begin{array}{c}\text { ADMR } \\
s \\
\text { (MJiday) }\end{array}$ & $\begin{array}{l}\text { eniergy } \\
\text { intake } \\
\text { (MJ/diay) }\end{array}$ & $\begin{array}{c}\text { body mass } \\
\text { change } \\
(\mathrm{kg})\end{array}$ \\
\hline \multicolumn{8}{|c|}{ lean group } \\
\hline $\begin{array}{l}M 1 \\
M 2 \\
M 3 \\
M 4 \\
M 5 \\
M 6\end{array}$ & & $\begin{array}{l}5.9 \\
7.4 \\
6.9 \\
7.8 \\
7.6 \\
7.0\end{array}$ & $\begin{array}{l}116 \\
131 \\
103 \\
109 \\
124 \\
124\end{array}$ & $\begin{array}{l}0.93 \\
1.06 \\
0.93 \\
0.99 \\
1.00 \\
1.04\end{array}$ & $\begin{array}{r}9.9 \\
15.1 \\
10.2 \\
16.4 \\
17.6 \\
13.6\end{array}$ & $\begin{array}{l}10.5 \\
15.2 \\
10.8 \\
11.9 \\
13.1 \\
10.0\end{array}$ & $\begin{array}{l}0.0 \\
-0.8 \\
-0.1 \\
-1.1 \\
2.5 \\
-0.3\end{array}$ \\
\hline $\begin{array}{l}F 7 \\
F 8 \\
F 9 \\
F 10 \\
F 11 \\
F 12 \\
F 13\end{array}$ & & $\begin{array}{l}5.4 \\
5.1 \\
5.5 \\
6.5 \\
4.8 \\
5.2 \\
5.8\end{array}$ & $\begin{array}{l}134 \\
131 \\
126 \\
137 \\
113 \\
117 \\
133\end{array}$ & $\begin{array}{l}1.01 \\
0.91 \\
0.92 \\
1.05 \\
0.86 \\
0.90 \\
1.03\end{array}$ & $\begin{array}{r}9.3 \\
8.5 \\
11.3 \\
*+7 \\
9.7 \\
11.1 \\
11.9\end{array}$ & $\begin{array}{r}6.5 \\
8.9 \\
8.8 \\
10.1 \\
8.7 \\
8.9 \\
12.4\end{array}$ & $\begin{array}{r}0.2 \\
0.0 \\
0.9 \\
-0.5 \\
0.0 \\
0.1 \\
0.1\end{array}$ \\
\hline mean $\pm S D$ & $\begin{array}{l}M \\
F\end{array}$ & $\begin{array}{l}7.1 \pm 0.7 \\
5.5 \pm 0.6 \infty\end{array}$ & $\begin{array}{l}118 \pm 10 \\
127 \pm 9^{\circ}\end{array}$ & $\begin{array}{l}0.99 \pm 0.05 \\
0.95 \pm 0.07\end{array}$ & $\begin{array}{l}13.8 \pm 3.2 \\
10.3 \pm 1.3 \circ\end{array}$ & $\begin{array}{l}11.9 \pm 2.0 \\
9.2 \pm 1.8^{\circ}\end{array}$ & $\begin{array}{r}0.0 \pm 1.3 \\
-0.1 \pm 0.4\end{array}$ \\
\hline \multicolumn{8}{|c|}{ obese group } \\
\hline $\begin{array}{l}\text { M14 } \\
\text { M15 } \\
\text { M16 } \\
\text { M17 }\end{array}$ & & $\begin{array}{r}10.7 \\
9.5 \\
8.1 \\
8.3\end{array}$ & $\begin{array}{l}118 \\
132 \\
133 \\
122\end{array}$ & $\begin{array}{l}1.03 \\
0.91 \\
1.02 \\
0.98\end{array}$ & $\begin{array}{l}21.5 \\
16.1 \\
13.1 \\
17.3\end{array}$ & $\begin{array}{r}8.1 \\
90.8 \\
11.1 \\
91.1\end{array}$ & $\begin{array}{r}-1.1 \\
-2.1 \\
-1.0 \\
0.0\end{array}$ \\
\hline $\begin{array}{l}F 18 \\
F 19 \\
F 20 \\
F 21 \\
F 22\end{array}$ & & $\begin{array}{l}5.2 \\
7.2 \\
7.3 \\
7.2 \\
6.4\end{array}$ & $\begin{array}{l}124 \\
142 \\
133 \\
143 \\
140\end{array}$ & $\begin{array}{l}0.84 \\
0.99 \\
0.97 \\
1.04 \\
0.93\end{array}$ & $\begin{array}{l}10.2 \\
12.7 \\
14.5 \\
15.1 \\
11.1\end{array}$ & $\begin{array}{r}5.7 \\
9.2 \\
9.5 \\
95.6 \\
8.5\end{array}$ & $\begin{array}{l}-2.3 \\
0.5 \\
0.1 \\
1.4 \\
0.2\end{array}$ \\
\hline $\operatorname{mean} \# \mathrm{SD}$ & $\begin{array}{l}M \\
F\end{array}$ & $\begin{array}{l}9.2 \pm 1.2 \\
6.6 \pm 0.9\end{array}$ & $\begin{array}{l}126 \pm 7 \\
136 \pm 8^{\circ}\end{array}$ & $\begin{array}{l}0.99 \pm 0.06 \\
0.96 \pm 0.07\end{array}$ & $\begin{array}{l}17.0 \pm 3.5 \\
12.7 \pm 2.1^{\circ}\end{array}$ & $\begin{array}{l}10.3 \pm 1.5 \\
9.7 \pm 3.6\end{array}$ & $\begin{array}{r}1.1 \pm 0.9 \\
0.0 \pm 1.4\end{array}$ \\
\hline \multicolumn{8}{|c|}{$\begin{array}{l}\text { BMA calculated according to the equations of } \mathrm{H} \\
\text { t } \quad \text { subject refused doubly labeled water. } \\
\$ \quad r=0.83, p<0.0001 \text {, regression on fat free } \\
p<0.05 \text { compared to lean subjects of the sa } \\
\text {.* } p<0.01 \text { compared to lean subjects of the sa } \\
\text { p } p<0.05 \text { compared to } M \text { (Mann Whitney). } \\
p<0.01 \text { compared to } M \text { (Mann Whitney). }\end{array}$} \\
\hline
\end{tabular}




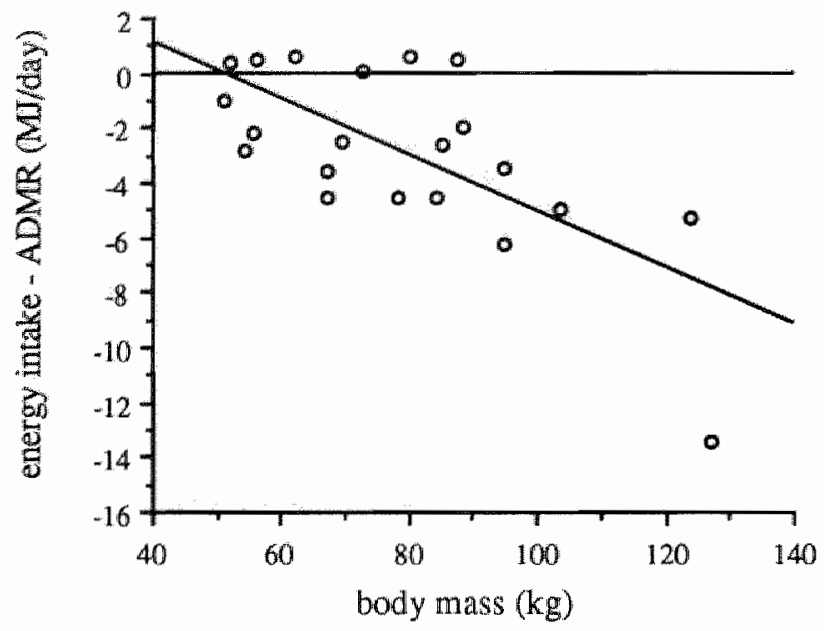

Fig 5.3 Energy intake minus average daily metabolic rate (ADMR) as measured with the doubly labeled water technique compared with body mass $(n=20$, $r=0.69, p<0.001$ ).

\section{Discussion}

The major impact of this study was that no metabolic disorder was found in adult obese subjects. Physical activity as assessed by the accelerometer did not show any difference between the lean and obese groups. Elsewhere $(29,38)$ we showed the accelerometer to be one of the better available techniques for measuring physical activity under free living conditions, AO explaining 77\% of the inter-individual variation in ADMR-SMR. This finding corresponds with numerous studies that used motion sensors in comparing physical activity of lean and obese (40-44). However, others did find decreased activity in obese subjects using equal techniques $(45,46)$. In an attempt to explain these different findings Tryon (44) suggests activity may only decrease above a certain percentage overweight. "To our knowledge no studies have been reported up till now to verify this hypothesis. The range of percentage overweight Tryon proposes as cut off range for decline of activity (between 20 and $54 \%$ for men and between 18 and $62 \%$ for women), is largely covered by our subjects, yet the data do not show any sharp decline in activity above a certain body mass. If this hypothesis was verified however, it would seem more likely that the decline in activity appears as a result of overweight rather than causing the overweight.

The results of indirect calorimetry confirm those of the accelerometer. ADMR-SMR was slightly -though not significantly- higher in the obese $(6.9 \pm 2.1 \vee 5.9 \pm 2.1 \mathrm{MJ} / \mathrm{day}$ 
in the lean), and related to FFM. This may be expected when most of daytime is spent on sedentary activities (19). When expressed per $\mathrm{kg}$ FFM, ADMR-SMR was not different between groups or sexes (116 $\pm 23 \vee 114 \pm 31 \mathrm{~kJ} / \mathrm{kg}$.day). The physical activity index (ADMR/BMR) was also equal in both groups and sexes $(1.83 \pm 0.24 v 1.87 \pm 0.29$, NS). Thus no differences are found in the energy expenditure due to physical activity when comparing lean and obese subjects.

Net energy expenditure for activity (kJ/min) during level walking at $5 \mathrm{~km} / \mathrm{h}$ was strongly related to body mass ( $r=0.72, p<0.001)$. This is due to the extra cost of weight bearing resulting from a larger body mass, and has been reported several times $(47,48)$. It is of interest that when expressed in $\mathrm{kJ} /$ count, net expenditure shows no relation with body mass $(r=0.39, N S)$, implying that different subjects may actually show quite a different type of body movement when walking at a natural speed. This needs further study.

As in earlier studies on resting metabolic rate, SMR was strongly related to FFM (13-15,19). Adjusted for FFM, SMR did not differ between lean and obese subjects. However, SMR/kgFFM was about $8 \%$ higher in females compared to males in both groups $(p<0.05)$. This was also found in a recent study of Weststrate et al. (25). They suggest that the contribution of active organs versus muscles to FFM may be higher in females compared to the more muscular males. As the contribution to metabolism in resting muscle may be expected to be low, this might explain the higher values found in females. On average SMR appeared to be $92 \%$ of BMR as calculated according to Harris and Benedict (36). Individual values ranged from 0.84 to $1.06 * \mathrm{BMR}$. This finding is very similar to that of Goldberg et all. (49) who used a larger data set on 80 subjects (mean $\mathrm{SMR}=0.95 * \mathrm{BMR}$, range 0.85-1.02*BMR).

Energy intake was on average lower than ADMR in all groups (intake-expenditure: lean men $-1.9 \mathrm{MJ} /$ day, women $-0.9 \mathrm{MJ} /$ day: obese men $-6.7 \mathrm{MJ} /$ day, women -3.0 $\mathrm{MJ} /$ day. Only seven subjects reported an energy intake differing less than $\mathbb{M J} /$ day from ADMR (Fig. 5.3). Six of them were lean. Other studies show that intake may be accurately assessed by a 7 day food diary in normal healthy subjects $(50,51)$. The difference between energy intake and expenditure correlated with body mass $(r=0.69$, $\mathrm{p}<0.001)$. These results correspond with epidemiologic findings $(7,9)$, as well as with a recent study of Lissner et al. (52) who found a negative correlation between intake minus expenditure and energy requirements as measured from intake in a metabolic ward. Prentice et al. present similar results, although absolute values of expenditure were lower in their subjects (10). One reason might be that obese subjects are dieting during the course of the study, despite the fact they promised and reported not to do so. Although interpretation of body mass change over a short period of one week in terms of energy storage may be imprecise (34) body mass change in 3 obese men (M14-M17) and one obese woman (F18) suggest that dieting may have occurred. Nevertheless when intake was adjusted for this change in body mass the discrepancy with ADMR was only reduced in the obese men (97\%), while in obese women this had no effect, suggesting that both 
dieting and underrecording have occurred in this study.

This study examined physical activity and energy expenditure resulting from this activity in free living subjects using two independent and accurate techniques. Both measurements indicate that there are no differences in physical activity between obese and control subjects. These results correspond with a large amount of recent studies on energy metabolism in lean and obese people. The occurrence of dieting and under-recording of food intake in several studies -including this one-suggests eating behaviour should be paid more attention to in future research.

\section{References}

1 Bogardus, C, $\mathrm{S}$ Lillioja, E Ravussin et al. Familial dependence of the resting metabolic rate. $\mathrm{N}$ Engl J Med 315, 96-100, 1986.

2 Jarres, WPT, and P Trayhurn. An integrated view of the metabolic and genetic basis for obesity. Lancet 2, 770-773, 1976.

3 Sims, EA. Energy balance in human beings: the problems of plenitude. Vitam Horm 43, 1-101, 1986.

4 Brownell, KD, AJ Stunkard, Physical activity in the development and control of abesity. In Stunkard, AJ (Ed.) Obesity. Philadelphia, WB Saunders, 1980, pp. 300-324

5 Ohlson, MA, and LI Harper. Longitudinal studies of food intake and weight of women from ages. 18 to 56 years. J Am Diet Assoc 69, 626 631, 1976.

6 Kulesza, W. Dietary intakes in obese women. Appetite 3, 61-68, 1982.

7 Baecke, JA, WA van Staveren, and J Burema. Food consumpuion, habitual physical activity, and body falness in young Dutch adwhs. Am J Clin Nutr 37, 278 286, 1983.

8 Griffiths, M, JPW Rivers, and PR Payne. Energy intake in children at high and low risk of obesity. Hum Nutr: Clin Nutr 41C, 425-430, 1987.

9 Kromhout, D. Energy and macronutrient intake in lean and obese middle aged men (the Zutphen siudy). Am J Clin Nutr 37, 295-299, 1983.

10 Prentice, AM. AE Black, WA Coward, et al, High levels of energy expendinure in abese women. Brit Med J 292, 983-987, 1986.

11 Rose, GA, and RT Williams. Metabolic studies on large eaters and small eaters. Br J Nutr 15, 1-9, 1961.

12 George, V, A Tremblay, JP Despres, C LeBlanc, L Perusse, and C Bouchard. Evidence for the existence of small eaters and large eaters of similar far-free mass and activily level. Int J Obes 13 . $43-53,1989$.

13 Rawussin, E, B Burnand, Y Schutz, and E Jéquier. Twenty-four-hour energy expenditure and resting metabolic rate in obese, moderalely obese, and comtrol subjects. Am I Clin Nutr 35, 566-573, 1982.

14 Cunningham, JJ. A reanalysis of the factors influencing basal metabolic rate in normal adults. Am $J$ Clin Nutr 33, 2372-2374, 1980.

15 Hoffmans, M. WA Pfeffer, BL Gundlacl et al. Resting metabolic rate in obese and normal weight women. Int J Obes 3, 111-118, 1979.

16 Epstein, LH, RR Wing. P Cluss et al. Resting metabolic rate in lean and obese children: relationship to child and parent weight and percentage overweight change. An J Clin Nutr 49 . $331-336,1989$.

17 Felig, P. J Cunningham, M Levitt, R Hendler, and E Nadel. Energy expenditure in obesily in fasting and postprandial state. Am J Physiol 244 (Endocrinol. Metab. 7), E45-E51, 1983.

18 Owen, EO, JL Holup, DA D'Alessio, et al. A reappraisal of the caloric requirements of men. Am J Clin Nutr 46, 875-885, 1987. 
19 Webb, P. Energy expenditure and fa-free nass in men and women. Am J Clin Nutr 34, 18:161826,1981 .

20 Ravussin, E, SL Lillioja ${ }_{0}$ WC Knowler et al. Reduced rate of energy expendinure as a risk factor for body-weight gain. New Eng I Med 318, 467-472, 1988 .

21. Weststrate, JA, J Dekker, M Stoel, L Begheijn, P Deurenberg, and JGAI Hautwast Resting energy expenditure in women: impact of obesity and body far distributton. Metabolism 1989 (in press).

22 Schutz, $\mathrm{Y}, \mathrm{T}$ Bessard, and $\mathrm{E}$ Jéquier. Diet-induced thermogenesis measured over a whole day in obese and non-obese women. Am I Clin Nutr 40, 542-552, 1984.

23. Swaminathan, R, RFGJ King, J Holmfiell, RA Siwak, M Baker, and JK Wales, Thermic effect of feeding carbohydrate, fat, protein and mixed meal in lean and obese subjects. Am. J Clin Nutr 43, $177-181,1985$

24 D'Alessio, DA, EC Kavle, MA Mozzoli et al. Thermic effect of food in lean and obese men. J Clin Invest 81, 1781-1789, 1988.

25. Weststrate, JA, P Deurenberg, and JGAJ Hautvast. Nature and magnitude of inter-individuel differences in resting metabolic rate and diet-induced thermogenesis in lecan and obese individwats. PhD. Thesis, Wageningen, The Netherlands, 1989, pp. 140-159.

26 Thompson, JK, GJ Jarvie, BB Lahey, and KJ Cureton. Exercise and obesity: Etiology, physiology, and intervention. Psychol Bull 91, 55-79, 1982.

27 Griffiths, M, and PR Payne. Energy expenditure in small children of obese and non-obese parents. Nature 260, 698-700, 1976.

28 Roberts, SB, I Savage, WA Coward, B Chew, and A Lucas. Energy expenditure and intake in infants born to lean and overweight mothers. New Eng J Med 318, 461-466, 1988.

29 Meijer, GA, KR Westerterp. H Koper, and F ten Hoor. Assessment of energy expenditure by recording heart rate and body acceleration. Med Sci Sports Exerc 21, 343-347, 1989 (this Thesis: Chapter 3).

30 Meijer, GAL, KR Westerterp, F Verhoeven, H Koper, and F ten Hoor . Methods to assess physical activity with special reference to motion sensors and accelerometers. this Thesis. Chapter 2.

31 Westerterp, KR, WHM Saris, M van Es, and $\mathrm{F}$ ten Hoor. Use of the doubly labeled water technique in humans during heavy sust ained exercise. J ApplPhysiol 61.(6), 2162-2167, 1986.

32 Schoeller, DA. Energy expenditure from do bly labeled water: some fundamental considerations in humans. Am J Clin Nutr 38, 999-1005, \983.

33 Quetelet, LAJ. Avuropométrie ou mesure des diffêrentes facultés de l'homme. Brussels, Muquard, 1871.

34 Garrow, JS, Energy balance and obesity in man. Amsterdam, North Holland Publ Company 1974.

35. Schoffelen, PFM, WHM Saris, KR Westerterp, and F ten Hoor. Evaluation of an automated indirect calorimeter for measurement of energy balance in man. In: Es, AJH van (Ed.) Human energy metabolism: Physical activity and energy expenditure measurements in epidemiological resecarch based upon direct and indirect calorimetry. Wageningen, The Netherlands, Euro-Nut rep. no. 5, 1984, pp. 51-54.

36 Harris, JA, and FG Benedict. A biometric stady of basal metabolism in man. Camegie Institution of Washington, 1919, pp. 190.

37 Schoeller, DA, E Ravussin, Y Schutz, KJ Acheson, P Baertschi, and E Jéquier. Energy expenditure by dowbly labeled water: validation in hwmans and proposed calculation. Am J Physiol 250, R823. R830, 1986.

38. Meijer, GAL, KR Westerterp, L Wouters, and F ten Howr. Validity of the accelerometer in the field; a comparison with the doubly labeled water tecknique. this Thesis, Chapter 4 .

39 Hautvast, JGAJ. Ontwikkeling van een systeem om gegevens van voedings-enquetes met behulp van een computer te verwerken. Voeding, The Hague, 36, 356-361, 1975.

40 Stunkard, AJ, and J Pestka. The physical activity of obese girls. Am J Diseases Childh 103, 812817,1962 .

41 Wilkinsin, PW, JM Parkin, G Pearlson, H Strong, and P Sykes. Energy invake and physical activity in obese children. Brit Med JI, 756, 1977.

42 Greenfield, NS, and CH Fellner, Resting level of physical activity in obese females. Am I Clin Nutr 22, 1418-1419, 1969.

43 Maxfield, E, and F Konishi. Patterns offood intake and physical acrivily in obesity. I Am Dict Assoc 49, 406-408, 1966. 
44. Tryon, WW. Achuity as a function of body weight. Am J Clin Natr 46, 451-455, 1987.

45 Dorris, RJ, AJ Slunkard. Physical activity: performance and attitudes of a group of obese women. Am J Med Sci 223,622-628, 1957 .

46 Chirica, AM, A.J Stunkard. Physical activity and human obesity. N Engl J Med 263, 935-940, 1960.

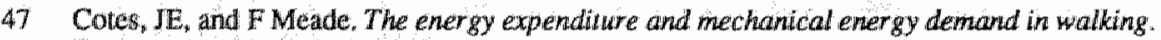
Ergonomics 36, 97-119, 1960.

48 Durnin, JVGA, and R Passmore. Energy, work and leisure. London, Heineman, 1967.

49 Goldberg, GR, AM Prentice, HL Davies, and PR Murgatroyd. Overnight and basal metabolic rates in men and women. Eur $\mathrm{J}$ Clìn Nutt $42,137-144,1988$.

50 Acheson, KJ, IT Champbell, OG Edholm, DS Miller, and MJ Stock. The measuremen of food and energy iniake in man-an evaluation of some techniques. Am J Clin Nutr 33, 1147-1154, 1980.

5.1 Schulz, S, KR Westerterp, and K Brtick. Comparison of energy expenditure by the doubly labeled water techinique with energy intake, hear" rate, and activity recording in man. Am J Clin Nutr 49, 1146-1154, 1989.

52 Lissner, L, J.P Habicht, BJ Strupp, DA Levitsky, JD Haas, and DA Roe. Body composition and energy intake: do overweight women overeat and underreport? Am J Clin Nutr 49, 320-325, 1989. 


\section{Chapter 6}

\section{The effect of a 5-month endurance-training program on physical activity: evidence for a sex-difference in the metabolic response to exercise}

G.A.L. Meijer, G.M.E. Janssen, K.R. Westerterp, F. Verhoeven, W.H.M Saris, and F.ten Hoor

to be submitted

\section{Abstract}

The effect of a 5-month endurance training program on physical activity and average daily metabolic rate (ADMR) was studied. Subjects were 16 males and 16 females preparing for a $1 / 2$ marathon. Total physical activity, measured using an accelerometer, increased with 62 and $63 \%$ after 20 weeks in males and females, respectively. Physical activity during the non-exercise part of the day increased with $15 \%$ on average in males and showed no response in females. In males ADMR increased significantly after 8 and 20 weeks $(+2.3$ and $+3.3 \mathrm{MJ} /$ day, respectively, $\mathrm{p}<0.05)$ and outlived the net energy expenditure for endurance-training 3 to 4 times. In females no significant increase in ADMR was found $(+1.5$ and $+1.3 \mathrm{MJ} / \mathrm{day}$, after 8 and 20 weeks, respectively). In females the change in ADMR could be largely attributed to the net cost of running itself and a small increase (10\%) in resting metabolic rate (RMR) during the time of day they were awake. In males a discrepancy is observed between the increase of ADMR and the expenditure due to exercise and non-exercise activities. We suggest exercise stimulates physical activity and diet-induced thermogenesis (DIT) in males but not in females. 


\section{Introduction}

In Western society a secular trend of decreasing physical activity occurs as a result of more automation and mechanization (1). This effect can be found both in industrial work and in transport, two major sources of physical activity. Since work itself becomes less strenuous in terms of energy expenditure, an increase in physical activity can only be reached by stimulating leisure time activities. During the last decade sports like running and jogging have become very popular, stimulating health and a feeling of well being. Moreover, physical activity may reduce the risk for coronary heart disease (2) and exercise may be a successful strategy in the prevention of overweight (5). Exercise in combination with a slimming diet is reported to result in a larger weight loss compared with diet alone (3), reducing the concurring loss of fat free mass (FFM) (4). As the energy expenditure resulting from exercise itself is only a small fraction of ADMR, it has been suggested that this effect is due to inhibition of a reduction in resting metabolic rate (RMR) that usually occurs in dieting (5-9), whereas diet-induced thermogenesis (DIT) might even be increased (10).

The modulation of RMR and DIT as a result of increasing activity is probably mediated by activation of the sympathetic nervous system (11-14), although the regulatory mechanism is still largely unknown. Thompson (12) suggests a model in which physical activity initially stimulates the sympathetic nervous system after which adaptive reductions in sympathetic arousal may occur as a result of intensive training. Subsequently higher training levels should be achieved to produce pre-training physiological arousal. This might explain exercise dependence as usually reported by highly trained athletes and suggests training stimulates physical activity. However, it might also imply reduced physical activity in moderately training subjects and thereby compensate for the added exercise.

In studies investigating the long term effect of exercise on energy metabolism physical activity is usually assumed to increase, although mostly no measurements are conducted to verify this. It might be questioned whether the added exercise is compensated for by lower activity levels during the rest of the day. The sometimes disappointing results of adding exercise to a diet in weight-loss programs (15) might be partially due to such a compensatory mechanism. However, so far only one study reported on the effect of exercise on physical activity during the rest of the day (16). This is probably due to the lack of a valid method for measuring physical activity under free living conditions. The accelerometer we described earlier (17) in combination with the doubly labeled water technique allows examination of changes in this part of energy metabolism. In this study we examined the effect of a 5-month training program for endurance-running in 32 untrained non-obese subjects on physical activity level and ADMR. 


\section{Methods}

\section{Subjects}

Thirly two subjects (16 males, 16 females) were selected out of 370 respondents to advertisements in two local newspapers and to a local radio station. Respondents who participated in any sport like running or jogging or who were active for more than one hour per week in other recreational sports were excluded. Further criteria applied were chosen in a way to select homogeneous and comparable groups of males and females for age, body mass, and Quetelet index (QI). Subject characteristics are presented in Table 6.1. Age ranged from $28-41 \mathrm{yr}$, and QI from $19.4-26.4 \mathrm{~kg} / \mathrm{m}^{2}$. All subjects gave their written informed consent after two subsequent information sessions. A medical examination was part of the pre-study procedure.

\section{Training program}

After initial control measurements ( 0 weeks) a training program was started which aimed at running a $1 / 2$ marathon competition after 10 months. The schedule was essentially the same as previously described by Janssen et al. (18). On a weekly basis training consisted of $1 \mathrm{~h}$ of training under supervision of one of the authors (GMEJ) while the subjects had to work on three training sessions by themselves. The training included three elements: long distance running, running at high speed, and interval training. Aside this attention was paid to style and technique of running, stretching, warming-up, and cooling down. Running time increased from 4 times a week during 10-30 min after 8 weeks to 4 times a week during 20-60 min after 20 weeks. In order to motivate the subjects, competitions were aimed at at regular intervals and, in addition, they were individually advised on running shoes for the initial expense of which an allowance was given. Subjects ran a 10 $\mathrm{km}$ and $15 \mathrm{~km}$ race, after 10 and 24 weeks, respectively.

\section{Protocol}

The measurement protocol was essentially similar to the one we described previously (19). In short, body composition, sleeping metabolic rate (SMR), physical activity and exercise performance were measured in all subjects before the start of the training program, after 8 to 12 weeks just before the $10 \mathrm{~km}$ competition, and after 20-24 weeks anticipating the $15 \mathrm{~km}$ race. The three measurement periods will be referred to as 0,8 , and 20 weeks, respectively. Running at $10 \mathrm{~km} / \mathrm{h}$ was added to the exercise test on the treadmill during the second and third measurement period as this was the average speed subjects ran outdoor. The results of the measurements of body composition and SMR are reported elsewhere (20). Here we will focus on changes in physical activity and ADMR. 
Table 6.4 Subject characteristics

\begin{tabular}{|c|c|c|c|c|c|}
\hline $\begin{array}{c}\text { Subject } \\
\text { no. }\end{array}$ & $\begin{array}{l}\text { age } \\
(y r)\end{array}$ & $\begin{array}{l}\text { length } \\
(\mathrm{m})\end{array}$ & $\begin{array}{c}\text { body mass } \\
(\mathrm{kg})\end{array}$ & $\begin{array}{l}\text { Quetelet } \\
\text { index } \\
\left(\mathrm{kg} / \mathrm{m}^{2}\right)\end{array}$ & $\begin{array}{c}\% \text { body } \\
\text { fat }\end{array}$ \\
\hline $\begin{array}{l}M 1 \\
M 2 \\
M 3 \\
M 4 \\
M 5 \\
M 6 \\
M 7 \\
M 8 \\
M 9 \\
M 10 \\
M 11 \\
M 12 \\
M 13 \\
M 14 \\
M 15 \\
M 16\end{array}$ & $\begin{array}{l}33 \\
35 \\
36 \\
35 \\
37 \\
40 \\
40 \\
39 \\
32 \\
39 \\
34 \\
41 \\
40 \\
39 \\
33 \\
40\end{array}$ & $\begin{array}{l}1.79 \\
1.80 \\
1.78 \\
1.80 \\
1.69 \\
1.79 \\
1.80 \\
1.85 \\
1.86 \\
1.80 \\
1.88 \\
1.73 \\
1.73 \\
1.75 \\
1.73 \\
1.76\end{array}$ & $\begin{array}{l}69.4 \\
72.0 \\
77.3 \\
79.3 \\
70.3 \\
66.3 \\
75.7 \\
74.2 \\
79.6 \\
79.5 \\
75.6 \\
68.0 \\
77.0 \\
59.4 \\
63.2 \\
69.7\end{array}$ & $\begin{array}{l}21.7 \\
22.2 \\
24.4 \\
24.5 \\
24.6 \\
20.7 \\
23.4 \\
21.7 \\
23.0 \\
24.5 \\
21.4 \\
22.7 \\
25.7 \\
19.4 \\
21.1 \\
22.5\end{array}$ & $\begin{array}{l}22.0 \\
19.2 \\
24.4 \\
28.1 \\
24.3 \\
17.7 \\
21.2 \\
23.1 \\
17.3 \\
23.5 \\
12.3 \\
29.1 \\
23.7 \\
16.8 \\
12.7 \\
15.6\end{array}$ \\
\hline $\begin{array}{c}\text { mean } \\
\mathrm{SD}\end{array}$ & $\begin{array}{r}37.1 \\
3.0\end{array}$ & $\begin{array}{l}1.78 \\
0.05\end{array}$ & $\begin{array}{r}72.3 \\
6.1\end{array}$ & $\begin{array}{r}22.7 \\
1.7\end{array}$ & $\begin{array}{r}20.7 \\
5.0\end{array}$ \\
\hline $\begin{array}{l}\text { F17 } \\
\text { F18 } \\
F 19 \\
F 20 \\
F 21 \\
F 22 \\
\text { F23 } \\
\text { F24 } \\
\text { F25 } \\
\text { F26 } \\
\text { F27 } \\
\text { F28 } \\
\text { F29 } \\
\text { F30 } \\
\text { F31 } \\
\text { F32 }\end{array}$ & $\begin{array}{l}32 \\
35 \\
41 \\
39 \\
40 \\
28 \\
38 \\
36 \\
32 \\
38 \\
32 \\
35 \\
41 \\
31 \\
32 \\
35\end{array}$ & $\begin{array}{l}1.63 \\
1.67 \\
1.68 \\
1.68 \\
1.79 \\
1.68 \\
1.65 \\
1.76 \\
1.81 \\
1.73 \\
1.58 \\
1.72 \\
1.65 \\
1.64 \\
1.57 \\
1.67\end{array}$ & $\begin{array}{l}54.0 \\
60.1 \\
65.8 \\
74.6 \\
83.3 \\
68.8 \\
61.0 \\
66.8 \\
70.4 \\
68.5 \\
61.1 \\
63.3 \\
64.4 \\
65.6 \\
52.6 \\
73.7\end{array}$ & $\begin{array}{l}20.3 \\
21.5 \\
23.3 \\
26.4 \\
26.0 \\
24.4 \\
22.4 \\
21.6 \\
21.5 \\
22.9 \\
24.5 \\
21.4 \\
23.7 \\
24.4 \\
21.3 \\
26.4\end{array}$ & $\begin{array}{l}23.2 \\
27.1 \\
32.4 \\
42.8 \\
32.9 \\
34.3 \\
30.5 \\
25.7 \\
28.2 \\
29.9 \\
33.2 \\
22.8 \\
24.3 \\
40.7 \\
25.0 \\
35.7\end{array}$ \\
\hline $\begin{array}{l}\text { mean } \\
\text { SD }\end{array}$ & $\begin{array}{r}35.3 \\
3.9\end{array}$ & $\begin{array}{l}1.68 \\
0.07\end{array}$ & $\begin{array}{r}65.9 \\
7.7\end{array}$ & $\begin{array}{r}23.3 \\
2.0\end{array}$ & $\begin{array}{r}30.5 \\
6.0\end{array}$ \\
\hline
\end{tabular}

$M=m a l e, F=f e m a l \theta$.

$\%$ body fat was determined using hydrostatic weighing. 


\section{Physical activity}

Physical activity was measured for one week using an accelerometer. Accelerometer output (AO) was calculated as the average of the seven days. For measurement of habitual physical activity only recordings of instrument nos. $5,8,9,11$, and 14 were used (21). Training times were reported by the subjects and could be easily recognized and checked in the recordings (Fig. 6.1). AO attributed to running $\left(\mathrm{AO}_{\mathrm{run}}\right)$ was calculated for all recordings. Exercise was also expressed as running time (min/day) based on the accelerometer readings, representing actual running time which was usually less than total training time reported. As subjects trained on 3 or 4 days of week, the min/day value presented here is lower than the running time per training. From 8 males and 8 females who were randomly chosen, initial ADMR was measured using the doubly labeled water technique. ADMR was measured again after 8 and 20 weeks in 4 males and 4 females. One of the females withdraw from the study after 10 weeks. Therefore in the third period (20 weeks) ADMR was measured in another female from the 8 measured originally.

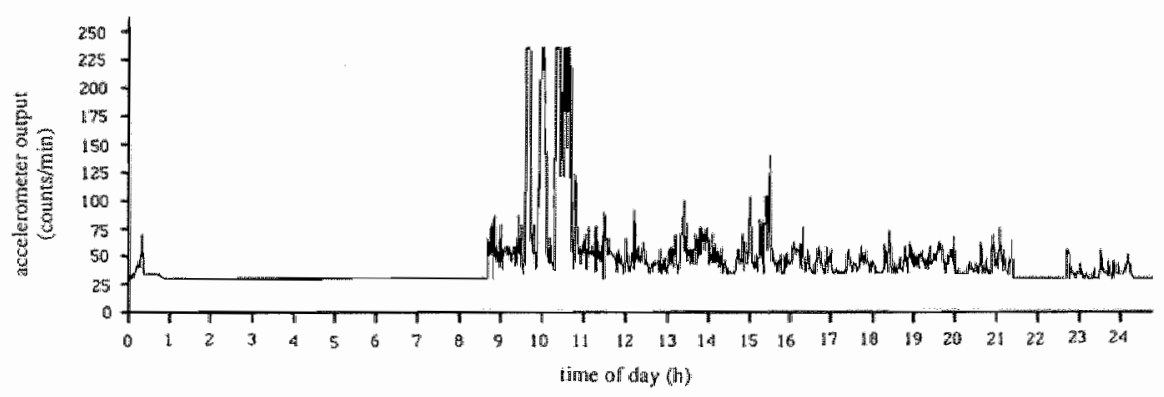

Fig. 6.1 Accelerometer recording of one day showing an exercise-bout from 9.30 $10.45 \mathrm{~h}$ (Subject M8, 8 weeks). 


\section{Results}

Physical activity

AO was significantly higher after 8 weeks (men) and after 20 weeks (men and women) when compated with the control measurement (Table 6.2). This increase was almost completely due to the extra running activity $\left(\mathrm{AO}_{\mathrm{run}}\right)$ resulting from the training schedule (Fig 6.2). Rest activities ( $\mathrm{AO}_{\mathrm{n}-\mathrm{ex}}$ ) increased about $15 \%$ in men, although this change was not significant. After 8 weeks the subjects ran on average 15 min per day, which increased to $20 \mathrm{~min}$ per day after 20 weeks (Table 6.3). These figures are in correspondence with the training schedule at that time and indicate good compliance. The resulting $\mathrm{AO}$ from running $(-200$ counts $/ \mathrm{min})$ indicates that subjects ran with a speed of $10 \mathrm{~km} / \mathrm{h}$ on average. After 20 weeks 4 subjects ( 1 male, 3 females) had withdrawn from the program. One female (F20) had severe problems with breathing during running and complained of a back-injury. The other two had no major problems, yet, they could not keep up with the training schedule nor with the time table of the different measurements.

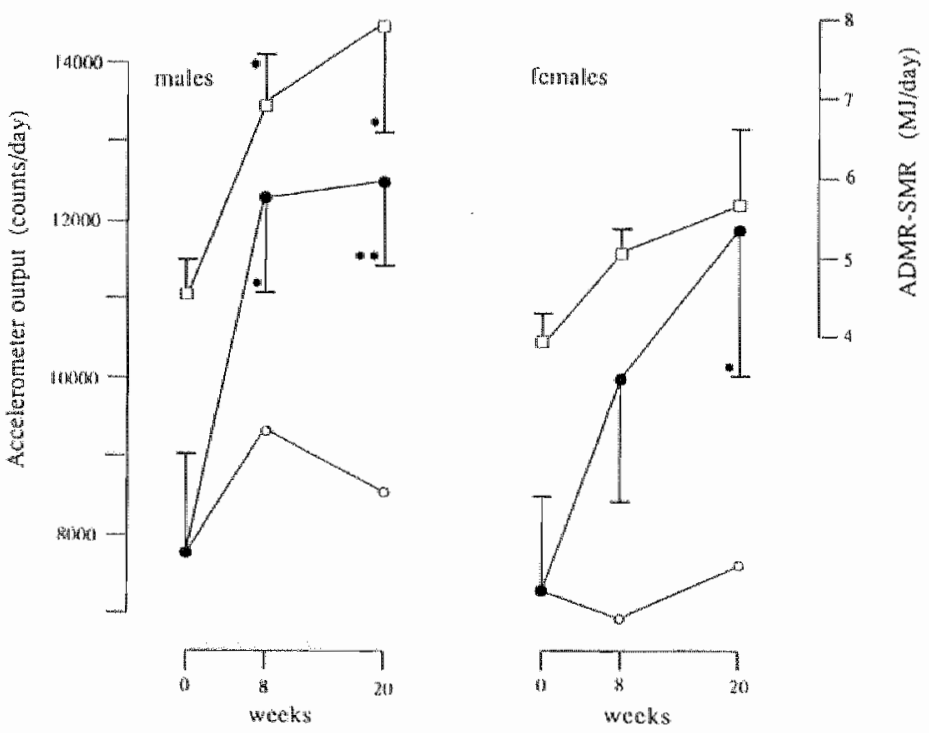

Fig. 6.2 ADMR-SMR (口), accelerometer output $(A O, \bullet)$ as measured during the whole day and $A O-A O_{\text {run }}\left(A O_{n-e x}\right.$, Olin males (left) and females (right) at 0,8 , and 20 weeks. (Y-error bars represent SEM;* $p<0.05 ; * * p<0.01$ compared with values at 0 weeks). 
Table 6.2 Accelerometer output (AO) and instrument used 1 ) before and 8 and 20 weeks after the start of the training program.

\begin{tabular}{|c|c|c|c|c|c|c|c|}
\hline & \multirow{2}{*}{$\begin{array}{c}\text { subject } \\
\text { no. }\end{array}$} & \multicolumn{2}{|c|}{ a weeks } & \multicolumn{2}{|c|}{ B woeks } & \multicolumn{2}{|c|}{20 weeks } \\
\hline & & $\begin{array}{c}\text { unstrument } \\
\text { no. }\end{array}$ & $\frac{\overline{A O}}{(\text { counts/day) }}$ & $\begin{array}{l}\text { instrument } \\
\text { no. }\end{array}$ & $\begin{array}{l}A O \\
\text { (counts/diay) }\end{array}$ & $\begin{array}{c}\text { instrument } \\
\text { no. }\end{array}$ & $\begin{array}{c}\mathrm{AO} \\
\text { (counts/day) }\end{array}$ \\
\hline & M 1 & 7 & 3250 & 10 & 11757 & 9 & 14299 \\
\hline & $M 2$ & 3 & 7786 & 7 & 6936 & 12 & 23056 \\
\hline & $M 3$ & 14 & 3387 & 5 & 7709 & 14 & 9298 \\
\hline & $\mathrm{M} 4$ & 9 & 8729 & 9 & 11757 & 8 & 9377 \\
\hline & M 5 & 3 & 6599 & 11 & 17580 & 11 & 13735 \\
\hline & $M 6$ & 8 & 9274 & 4 & 22319 & 4 & 20248 \\
\hline & $M 7$ & 13 & 21103 & 5 & 15137 & - & -1 \\
\hline & $M B$ & - & $-\pi$ & 9 & 13402 & 5 & 15561 \\
\hline & M 9 & 10 & 8161 & 10 & $1314: 2$ & 13 & 9780 \\
\hline & M1O & 12 & 13068 & 9 & 14420 & 3 & 15534 \\
\hline & M11 & 1 & 51642 & 7 & 13930 & 5 & 16441 \\
\hline & M12 & 13 & 18220 & 3 & 113398 & 3 & 13360 \\
\hline & $M+3$ & 14 & 10369 & 8 & 8295 & 10 & 7437 \\
\hline & $M 14$ & 10 & 9382 & 9 & 9886 & $B$ & 9415 \\
\hline & M15 & 10 & 10553 & 1 & 60012 & 10 & 13801 \\
\hline & $M 16$ & 5 & 7397 & 13 & 18197 & 7 & 22306 \\
\hline & mean & & 7751 & & $12273^{\circ}$ & & 12590 \\
\hline & SD & & 2870 & & 3482 & & 3139 \\
\hline & $\mathrm{F} 17$ & - & $-H$ & 8 & 4877 & 13 & 16030 \\
\hline & F18 & - & $-\pi$ & 3 & 13799 & 1 & 74019 \\
\hline & $F_{19}$ & 8 & 5030 & 4 & 27284 & 4 & 10893 \\
\hline & $F 20$ & 7 & 2968 & - & $-\dagger$ & . & $-\pi$ \\
\hline & $F 21$ & 5 & 4593 & 5 & 5781 & - & $-\pi$ \\
\hline & $F 22$ & 11 & 8779 & 12 & 16562 & 7 & 4776 \\
\hline & $F 23$ & 7 & 2162 & 14 & 13401 & 12 & 15875 \\
\hline & F 24 & 9 & 5982 & 5 & 6714 & 11 & 9393 \\
\hline & $F 25$ & 9 & 7167 & 1 & 31052 & 13 & 14420 \\
\hline & $\mathrm{F} 26$ & $i$ & 26210 & 13 & 16653 & 5 & 15585 \\
\hline & $F 27$ & 14 & 12480 & 4 & 27288 & 14 & 16651 \\
\hline & $F_{28}$ & 10 & 13230 & 8 & 11321 & $\theta$ & 6324 \\
\hline & $F 29$ & 7 & 5190 & 13 & 12531 & 3 & 14988 \\
\hline & $F 30$ & 3 & 10450 & 10 & 14760 & 12 & 18313 \\
\hline & $F 31$ & 12 & 12545 & 14 & 18029 & 9 & 11466 \\
\hline & $\mathrm{F} 32$ & 13 & 19454 & 14 & 21662 & - & -1 \\
\hline & $\begin{array}{l}\text { mean } \\
\mathrm{SD}\end{array}$ & & $\begin{array}{l}7289 \\
2837\end{array}$ & & $\begin{array}{r}10021 \\
5150\end{array}$ & & $\begin{array}{l}11884^{\infty} \\
4293\end{array}$ \\
\hline & \multirow{2}{*}{\multicolumn{7}{|c|}{ Oniy instruments $5,8,9,11$ and 14 and values of $\mathrm{AO}<20000$ are included in mean and $\mathrm{SD}$. }} \\
\hline & \multirow{2}{*}{\multicolumn{7}{|c|}{ Data were lost due to breakage of a diskette. }} \\
\hline$t t$ & & & & & & & \\
\hline & \multicolumn{7}{|c|}{ p<0.05 compared to control measurement at o weeks (Mann-Whitney) } \\
\hline
\end{tabular}


Table 6.3 Compliance to the training schedule after 8 and 20 weeks as measured by the accelerometer.

\begin{tabular}{|c|c|c|c|c|}
\hline \multirow[b]{2}{*}{$\begin{array}{c}\text { subject } \\
\text { no. }\end{array}$} & \multicolumn{2}{|c|}{8 weaks } & \multicolumn{2}{|c|}{20 weeks } \\
\hline & $\begin{array}{l}\text { running } \\
\text { (mintiday) }\end{array}$ & $\begin{array}{r}\text { AOrun } \\
\text { (counts/diay) }\end{array}$ & $\begin{array}{l}\text { running } \\
\text { (min/day) }\end{array}$ & $\begin{array}{r}\text { AOrun } \\
\text { (counts/day) }\end{array}$ \\
\hline M 1 & 17 & 3304 & 28. & 5652 \\
\hline$M 2$ & 13 & 2841 & 31 & 6414 \\
\hline $\mathrm{M} \mathrm{3}^{3}$ & 6 & 1266 & 9 & 1961 \\
\hline M 4 & 16 & 3267 & 29 & 6128 \\
\hline M 51 & 0 & 0 & 0 & 0 \\
\hline$M B$ & 13 & 2694 & 22 & 4495 \\
\hline$M 7$ & 1 & 283 & & $=t$ \\
\hline$M 8$ & 17 & 3590 & 24 & 5142 \\
\hline$M 9$ & 13 & 2533 & 27 & 5227 \\
\hline$M 10$ & 13 & 2707 & 22 & 4153 \\
\hline M11 & 15 & 3227 & 17 & 3591 \\
\hline$M 12$ & 23 & 4397 & 25 & 4777 \\
\hline$M 13$ & 18 & 3755 & 8 & 1588 \\
\hline M14 & 12 & 2443 & 18 & 3944 \\
\hline M15 & 11 & 2291 & 12 & 2199 \\
\hline M16 & 12 & 2436 & 6 & 1284 \\
\hline $\begin{array}{r}\text { mean } \\
\mathrm{SD}\end{array}$ & $\begin{array}{r}14 \\
4\end{array}$ & $\begin{array}{r}2911 \\
761\end{array}$ & $\frac{20^{\circ}}{8}$ & $\begin{array}{l}4040^{\circ} \\
1699\end{array}$ \\
\hline$F_{17}$ & 01 & 01 & 22 & 4362 \\
\hline$F 18$ & 18 & 3371 & 38 & 7763 \\
\hline$F_{19}$ & 11 & 2247 & 6 & 1305 \\
\hline $\mathrm{F} 201$ & 0 & 0 & - &.+ \\
\hline$F 21$ & 0 & 0 & . & $-t$ \\
\hline$F_{22}$ & 11 & 2302 & 7 & 1498 \\
\hline$F_{23}$ & 14 & 2952 & 43 & 8652 \\
\hline$F_{24}$ & 12 & 2502 & 17 & 2950 \\
\hline$F 25$ & 18 & 3589 & 37 & 7224 \\
\hline$F 26$ & 19 & 3752 & 26 & 5447 \\
\hline$F 27$ & 21 & 4317 & 11 & 2347 \\
\hline$F 28$ & 17 & 3591 & 9 & 1997 \\
\hline $1=29$ & 19 & 3761 & 27 & 5211 \\
\hline$F 30$ & 11 & 2061 & 15 & 3015 \\
\hline F 31 & 13 & 2730 & 20 & 4159 \\
\hline F32 & 7 & 1417 & 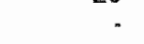 & $-\dagger$ \\
\hline mean & 15 & 3098 & 21 & 4302 \\
\hline SD & 4 & 730 & 12 & 2434 \\
\hline
\end{tabular}

I Excluded from calculations (subjects were not able to attend to the training program).

t Subject withdrew from the study.

- $\quad p<0.05$ compared with B weeks values (Wilcoxon signed-rank). 
Metabolic rate

ADMR increased during the first 8 weeks of the intervention program with 2.3 and 1.5 $\mathrm{MJ} / \mathrm{day}$ in men and women respectively and showed a further increase in men of $1 \mathrm{MJ} /$ day after 20 weeks (Table 6.4). Changes in ADMR-SMR were slightly more pronounced (2.5 and $1.2 \mathrm{MJ} /$ day after 8 weeks, 3.5 and $1.8 \mathrm{MJ} /$ day after 20 weeks in men and women respectively) (Table 6.4, Fig 6.2).

Tablle 6.4 Average daily metabolic rate (ADMR) and ADMR - sleeping metabolic rate (SMR) before and 8 and 20 weeks after start of the training program)

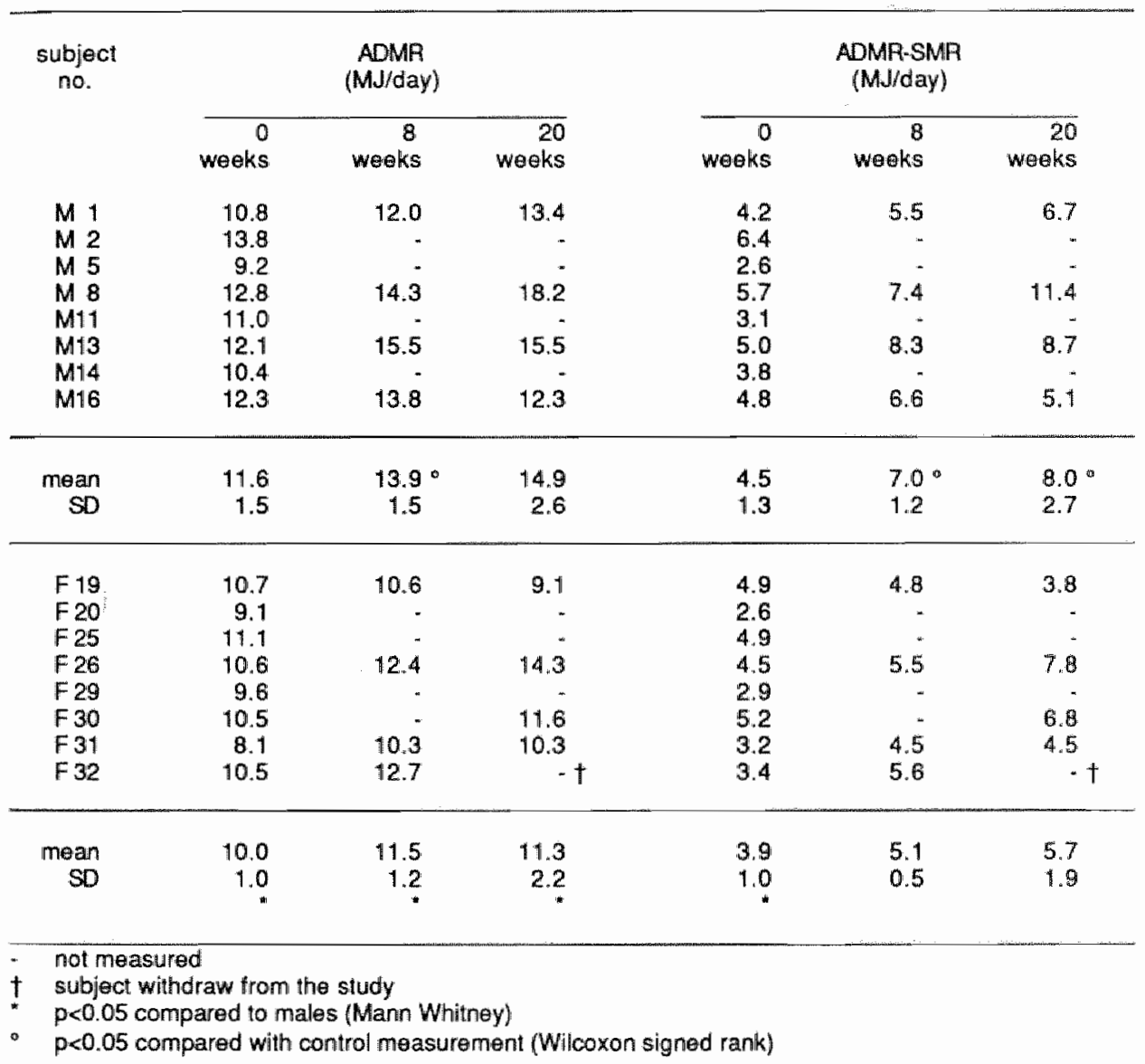


Tablle 6.5 Average daily metabolic rate (ADMA) expressed per $\mathrm{kg}$ body mass and per $\mathrm{kg}$ fat free mass (FFM) before and 8 and 20 weeks after start of the training program.

\begin{tabular}{|c|c|c|c|c|c|c|}
\hline \multirow[t]{2}{*}{$\begin{array}{l}\text { Subjoct } \\
\text { no. }\end{array}$} & \multicolumn{3}{|c|}{$\begin{array}{c}\text { ADMR/kg body mass } \\
(\mathrm{kJ} / \mathrm{kg} \text { day })\end{array}$} & \multicolumn{3}{|c|}{$\begin{array}{l}\text { ADNR/kg FFM } \\
\text { (kJ/kg day) }\end{array}$} \\
\hline & $\begin{array}{r}0 \\
\text { weieks }\end{array}$ & $\begin{array}{r}8 \\
\text { wooks }\end{array}$ & $\begin{array}{c}20 \\
\text { weelks }\end{array}$ & $\begin{array}{r}0 \\
\text { weeks }\end{array}$ & $\begin{array}{r}8 \\
\text { weelks }\end{array}$ & $\begin{array}{r}20 \\
\text { weeks }\end{array}$ \\
\hline$M 1$ & 155 & 173 & 197 & 198 & 231 & 243 \\
\hline$M 2$ & 189 & . & . & 233 & 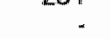 & . \\
\hline$M 5$ & 129 & - & - & 170 & - & - \\
\hline$M 8$ & 172 & 193 & 252 & 223 & 236 & 311 \\
\hline M11 & 147 & . & & 168 & . & . \\
\hline M13 & 156 & 204 & 209 & 204 & 254 & 240 \\
\hline$M 14$ & 176 & . & . & 211 & & \\
\hline$M 16$ & 174 & 193 & 177 & 206 & 230 & 210 \\
\hline $\begin{array}{r}\text { mean } \\
\text { SD }\end{array}$ & $\begin{array}{r}162 \\
19\end{array}$ & $\begin{array}{c}190^{\circ} \\
13\end{array}$ & $\begin{array}{c}208^{\circ} \\
32\end{array}$ & $\begin{array}{r}202 \\
23\end{array}$ & $\begin{array}{c}238^{\circ} \\
11^{\circ}\end{array}$ & $\begin{array}{c}251^{\circ} \\
43\end{array}$ \\
\hline$F 19$ & 162 & 162 & 143 & 239 & 235 & 206 \\
\hline $\mathrm{F} 20$ & 121 & 106 & 140 & 212 & $=$ & 200 \\
\hline F 25 & 153 & - & - & 213 & . & . \\
\hline F 26 & 154 & 179 & 205 & 219 & 248 & 291 \\
\hline$F_{29}$ & 147 & . & . & 195 & . & - \\
\hline F 30 & 157 & - & 174 & 264 & - & 277 \\
\hline$F_{31}$ & 153 & 188 & 187 & 204 & 248 & 243 \\
\hline F 32 & 140 & 165 & $+t$ & 218 & 257 & $-\dagger$ \\
\hline & & & & & 247 & \\
\hline SD & $\begin{array}{r}138 \\
13\end{array}$ & 12 & $\begin{array}{r}17 \\
26\end{array}$ & $\begin{array}{r}221 \\
22\end{array}$ & $\begin{array}{r}241 \\
9\end{array}$ & $\begin{array}{r}254 \\
38\end{array}$ \\
\hline
\end{tabular}

For explanation of symbols see Table 6.4

ADMR was significantly lower in females in all three periods of the study, which is due to their lower body mass. When expressing ADMR per $\mathrm{kg}$ body mass or per $\mathrm{kg}$ FFM, this difference disappears except for ADMR/kg body mass after 8 weeks (Table 6.5).

Energy expenditure measured during different activities showed no significant changes in males during the three measurement periods (Table 6.6). In females energy expenditure increased after 20 weeks during standing and running at $10 \mathrm{~km} / \mathrm{h}(\mathrm{p}<0.05)$. Differences in energy expenditure between males and females during comparable activities are due to differences in body mass, as there were no sex differences when expressing energy expenditure per $\mathrm{kg}$ body mass. 
Table 6.6 Energy expenditure (mean+SD) of males and females at 6 activities, during the three periods of measurement $(0,8$, and 20 weeks).

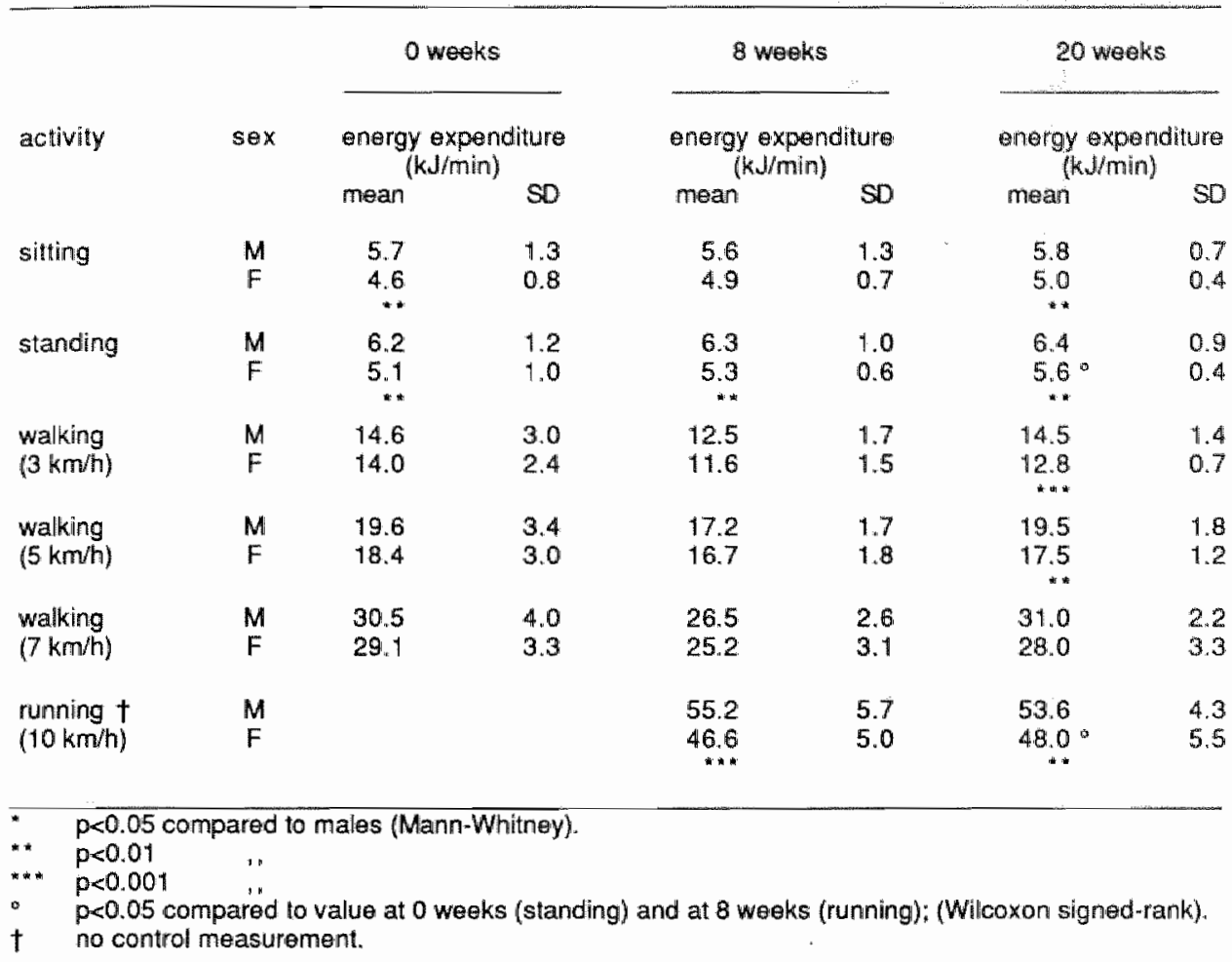

\section{Discussion}

We questioned the influence of an endurance-training program on habitual (non-exercise) activity level. Summarizing the results of this study ADMR-SMR increased both in males $(\mathrm{p}<0.05)$ and in females. When calculating the net energy expenditure due to running [min/day (Table 6.3)* kJ/min (Table 6.6)] it appears to be only part of the total increase in ADMR-SMR (Table 6.7). This suggests that non-exercise activity has increased with 55 and $28 \%$ after 20 weeks in men and women respectively. However, the accelerometer data do not confirm this finding. Here in men an increase of $21 \%$ is found during the second period ( 8 weeks), which reduces to $10 \%$ after 20 weeks, while in females $\mathrm{AO}_{\mathrm{n}-\mathrm{cx}}$ is reduced with $5 \%$ after 8 weeks and shows an increase with $4 \%$ after 20 weeks (Fig.6.2). None of these changes were significant. Yet changes in $\mathrm{AO}_{\text {run }}$ are strongly correlated ( $r=0.78, n=14, p<0.01$ ) to changes in ADMR-SMR (Fig. 6.3), suggesting both measurements to be accurate. 


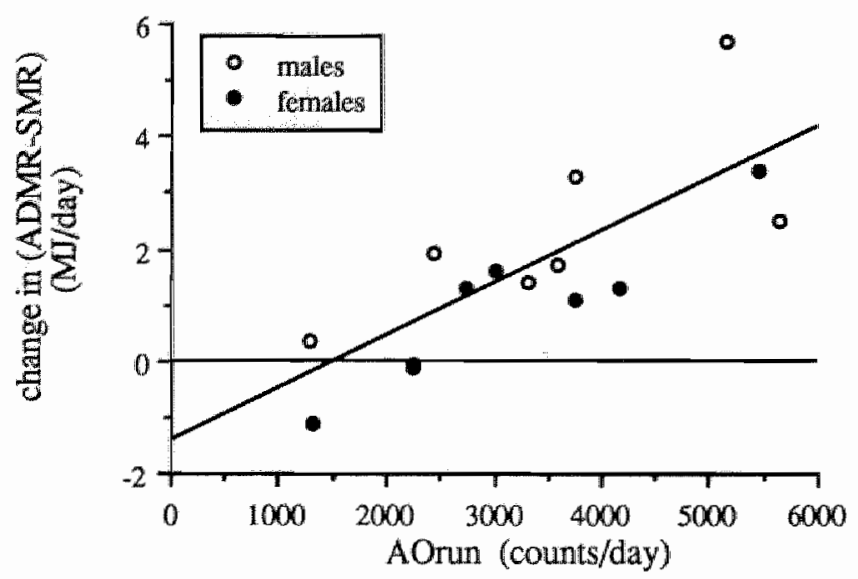

Fig. 6.3 Change in the energy compartment ADMR-SMR versus accelerometer output due to running ( $A O_{\text {run }}$ ) exercise in males and females. Data of abservations from 8 weeks and 20 weeks after start of the training program are combined $(n=14, r=0.61, p<0.05)$.

The following potential factors may explain the discrepancy found:

1) Although $\mathrm{AO}_{\text {run }}$ correlates well with changes in $\mathrm{ADMR}-\mathrm{SMR}$, and running time recorded corresponds with the training schedule, it might be that $\mathrm{AO}_{\mathrm{n}-\mathrm{ex}}$ is underrecorded after 8 and 20 weeks as subjects did complain about wearing the instrument for a whole week. Total time the accelerometer was worn was 908,892 and 875 min/day during the three subsequent periods. The decrease is not significant. This means that of the expected 16 hours per day on average 15 h are covered by accelerometry. Start and end times of the daily recordings suggest that most time is lost just after waking up and in the late evening. Assuming activities at this time to be sitting, washing, dressing etcetera, metabolic rate may be estimated to be $1.4 *$ SMR (22). The resulting net effect is $0.1 \mathrm{MJ} /$ day for men and women (Table 6.7).

2) Assuming diet induced thermogenesis to be $10 \%$ of ADMR (23) this energy compartment increases with 0.2 and $0.3 \mathrm{MJ} /$ day in men and with $0.1 \mathrm{MJ} /$ day in women after 8 and 20 weeks respectively (Table 6.7).

3) We found no change in SMR measured from $3.00-6.00 \mathrm{~h}$ in a respiration chamber (20). However, resting metabolic rate might be increased during the time of the day subjects were awake. The measurements of energy expenditure at different activities (Table 6.6) show a significant increase of energy expenditure during standing of $10 \%$ in females and a comparable tendency during sitting. However, in males no increases of these costs were found. Using the value of a $10 \%$ increased resting meta- 
Table 6.7 Changes in the energy compartments ADMR-SMR, energy expenditure due to running $\left(\mathrm{EE}_{\mathrm{run}}\right)$ and non-exercise activities $\left(\mathrm{EE}_{\mathrm{n}-\mathrm{ex}}\right)$ as measured by indirect calorimetry and the accelerometer. Assumptions on changes in diet-induced thermogenesis (DIT), and resting metabolic rate are added. See discussion ( $\dagger$ ).

\begin{tabular}{|c|c|c|c|c|c|}
\hline \multirow{2}{*}{ measured } & & \multicolumn{2}{|c|}{$\begin{array}{l}\text { difference } \\
\text { (with control measurement) } \\
\text { after } 8 \text { weeks } \\
\text { (MJ/day) }\end{array}$} & \multicolumn{2}{|c|}{$\begin{array}{c}\text { difference } \\
\text { (with control measurement) } \\
\text { atter } 20 \text { woeks } \\
\text { (MJ/day) }\end{array}$} \\
\hline & & males & fernales & males & females \\
\hline \multicolumn{2}{|l|}{ ADMR-SMR } & $+2.5^{\circ}$ & +1.2 & $+3.5^{\circ}$ & +1.8 \\
\hline \multicolumn{2}{|l|}{$\begin{array}{l}\text { EErun } \\
\text { EEn-ex }\end{array}$} & $\begin{array}{l}+0.7 \\
+0.3\end{array}$ & $\begin{array}{r}+0.6 \\
0.0\end{array}$ & $\begin{array}{l}+1.0 \\
+0.2\end{array}$ & $\begin{array}{r}+0.7 \\
0.0\end{array}$ \\
\hline \multicolumn{2}{|c|}{$\begin{array}{l}\text { discrepancy: } \\
\text { (ADMR-SMR)-EE(run + n-ex) }\end{array}$} & +1.5 & +0.6 & +2.3 & +1.1 \\
\hline \multicolumn{6}{|l|}{ assumptions $\dagger$} \\
\hline $\begin{array}{l}\text { EEn-ex missed } \\
1 \mathrm{~h} / 1.4^{*} \mathrm{SMR}\end{array}$ & (1) & +0.1 & +0.1 & +0.1 & 40.1 \\
\hline $\begin{array}{l}\text { DIT } \\
(10 \% \text { of ADMR) }\end{array}$ & (2) & +0.2 & +0.1 & +0.3 & +0.1 \\
\hline $\begin{array}{l}10 \% \text { increase } \\
\text { in RMR }\end{array}$ & (3) & - & +0.4 & - & +0.4 \\
\hline $\begin{array}{l}\text { SMR increase } \\
\text { (short-term effect) }\end{array}$ & (4) & +0.4 & +0.4 & +0.4 & +0.4 \\
\hline $\begin{array}{l}\text { remaining } \\
\text { discrepancy }\end{array}$ & & +0.8 & -0.4 & +1.7 & +0.1 \\
\hline
\end{tabular}

- pe0.05 compared to the control measurement at o weeks (Wilcoxon signed rank).

t numbers in parenthesis refer to the texi (Discussion).

bolic rate during the active part of the day resuits in an increase of $0.4 \mathrm{MJ} /$ day of ADMR-SMR in females.

4) Apart from an increase in RMR, we may have overlooked a short-term effect of exercise on SMR as SMR was measured at least $36 \mathrm{~h}$ after the last training. Although evidence on this short-term effect is contradictory (10) it may be estimated to increase SMR with $10 \%$ at most. Calculations based on this assumption leave an increase of metabolic rate of $0.4 \mathrm{MJ} /$ day both for males and femalles (Table 6.7). 
5) $\mathrm{AO}_{\text {run was about }} 200$ counts/min in all subjects which indicates a running speed of $\sim 10 \mathrm{~km} / \mathrm{h}$. This speed was also reported by the subjects who generally knew the length of their parcours as well as their running times. The energy expenditure we measured on the treadmill at $10 \mathrm{~km} / \mathrm{h}$ (54 and $47 \mathrm{~kJ} / \mathrm{min}$ in men and women respectively) corresponds with values reported by others $(24,25)$. However, these are all values from laboratory (treadmill) studies. Expenditure in the field may be higher, due to inclines and declines of the course, or lower because no face mask has to be carried. Therefore we think these figures represent a reasonable estimate of the cost of outdoor running. Assuming an error of $10 \%$ in either direction has very little effect on total metabolic rate due to the short time these activities are performed.

The result of this calculation is that the difference [(ADMR-SMR) - EE(run + n-ex)] as found in the females after 8 and 20 weeks may be explained using one or more of the assumptions made (Table 6.7). However, in the males a discrepancy remains of 0.8 and $1.7 \mathrm{MJ} /$ day after 8 and 20 weeks, respectively.

In a recent study Bingham et al. (26) report an increase of ADMR of $4.0 \mathrm{MJ} / \mathrm{day}$ in 3 males and $1.0 \mathrm{MJ} / \mathrm{day}$ in 2 females attending to a 9 week training schedule that was slightly more intensive than our schedule. They also found no change in SMR. Estimating net energy expenditure from the exercise added in their study reveals a similarly large discrepancy in males as we found here. Janssen et al. report an increase of $21 \%$ in energy intake in males as a response to an endurance-training program while no increase in intake could be found in females (18). When comparing studies on the effect of exercise added to a slimming diet in order to lose weight, it appears that a positive effect can be found in men (3), but no effect in women (15). Saris (11) concludes the difference between the sexes to be due to differences in patterns of fat distribution, the male abdominal fat being more sensitive for release and storage of triglyceride. The abdominal fat-cell has been shown to have more B-receptors than fat cells in the femoral region (27). Recently weststrate et al. showed that men had higher DIT than women after a standard test meal. The obligatory component of DIT was $77 \%$ in males and $99 \%$ in females, suggesting no facultative component of DIT exists in females (28). In another study Weststrate et al. show psychological stress to significantly increase DIT in men (13), indicating the role of the sympathetic nervous system.

Summarizing we found exercise to stimulate physical activity during the rest of the day with approximately $15 \%$ in men but not in women. The increase in ADMR outlived expenditure due to exercise 3 to 4 times in men and 2 times in women. No sustained effect on SMR was found in both sexes. The discrepancies between increase in ADMRSMR in females could be largely explained by a $10 \%$ increase in RMR during the active part of the day and assuming DIT to raise parallel to increasing metabolic rate. However, these factors were not sufficient to explain the discrepancy found in men. These results fit in with other recent studies on the influence of exercise on energy metabolism and show that the metabolic response to exercise is much larger in males than in females and 
outlives the net cost of exercise itself. We suggest that exercise in males leads to stimulation of both physical activity and DIT, possibly through activation of the sympathetic nervous system, whereas females do not show such a response.

\section{References}

1 Reiff, GG, HJ Montoye, et al. Assessment of physical acrivity by questionnaire and interview. I Sports Med 7, 135-142, 198

2 Paffenbarger, RS, and RT Hyde. Exercise in the primary prevention of ischemic heart disease. In: RP Welsh, and RJ Shephard (Eds). Current therapy in sports medicine. Decker, 1985, pp. 76-80.

3 Tremblay, A. J-P Despres, C Leblanc, and C Bouchard. Sex dumorphism in fat loss in response to exercise training. J Obes Weight Reg 3, 193-203, 1984.

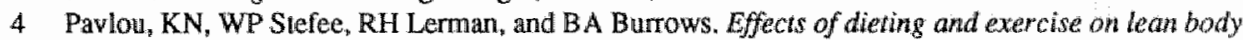
mass, oxygen uptake, and strength. Med Sci Sports Exerc 17, 466-471, 1985.

5 Garrow. IS. Effect of exercise on Obesity. Acta Med Scand, Suppl. 711, 67-73, 1986/7?.

6 Mole, PA, IS Ster, CL Schulz, EM Bernauer, and BJ Holcomb. Exercise reverses depressed metabolic rate produced by severe caloric restriction. Med Sci Sports Exerc 21, 29-33, 1989.

7 Ravussin, E, B Burnand, Y Schutz, and E Jéquier. Energy expenditure before and dwring energy restriction in obese patients. Am J Clin Nutr 41, 753-759, 1985.

8 Weigle, DS, KJ Sande, PH Iverius, ER Monsen, and JD Brunzell. Weight loss leads to a marked decrease in non-resting energy expenditure in ambulatory human subjects. Metabolism 37, 930936, 1988.

9 Elliot, DL, L Goldberg, KS Kuehl, and WM Bennet. Sustained depression of the resting metabolic rate after massive weight loss. Am I Clin Nutr 49, 93-96, 1989.

10 Tremblay, A.J-P Despres, and C Bouchard. The effects of exercise-training on energy balance and adipose tissue morphology and metabolism. Sports Med 2, 223-233, 1985.

11 Saris, WHM. Physiological aspects of exercise in weight cycling. Am IClin Nutr 49, 1099-1104. 1989.

12 Thompson, $\mathrm{KJ}$, and P Blanton. Energy conservation and exercise dependence: a sympathelic arousal hypothesis. Med Sci Sports Exerc 19, 91-99, 1987.

13 Weststrate, JA, K van der Kooy, P Deunenberg, and JGAJ Hautvast. Surprising ly large impact of psychological stress on diet-indaced thermogenesis but not on resting metabolic rate. PHD Thesis, Wageningen. The Netherlands, 1989, pp. 131-139.

$14 \mathrm{Kjor}, \mathrm{M}$. Epinephrine and some other hormonal responses to exercise in man: with special reference to physical training. Int I Sports Med 10, 2-15, 1989.

15 Dale, D van, WHM Saris, PFM Schoftelen, and F ten Hoor. Does exercise give an additional effect in weight reduction regimes? Int J Obes $11,367-375,1987$.

16 Dale, D van, PFM Schoffelen, F ten Hoor, and WHM Saris. Effects of adding exercise to energy restriction on 24-hour energy expenditure, resting metabolic rate and daily physical activity. Eur I Clin Nutr $43,441-451,1989$.

17 Meijer, GA, KR Westerterp, H Koper, and $F$ ten Hoor. Assessment of energy expenditure by recording heart rate and body acceleration. Med Sci Sports Exerc 21, 343-347, 1989 (his Thesis: Chapter 3).

18 Janssen GME, CJI Graef, and WHM Saris. Food intake and body composition in novice athletes during a training period to run a marathon. Int J Sports Med 10, s17-s21, 1989.

19 Meijer, GAL, KR Westerterp. AMP van Hulsel, and F ten Hoor. Physical activity and energy expenditure in lean and obese adul human subjects. this Thesis, Chapier 5.

20 Meijer, GAL, KR Westerterp, GHP Seyts" GME Janssen, WHM Saris, and F ten Hoor, Body composition and sleeping metabolic rate in response to a 5-month endurance training program. this Thesis, Chapter 7. 


\section{Chapter 6}

21 Meijer, GAL, KR Westerterp. L Wouters, and F ten Hoor. Validity of ihe accelerometer in the field; a comparison with the doubly labeled water technique. this Thesis, Chapter 4.

22 World Healit Organization. Energy and protein requirements, report of a jount FAO/WHONNO expert consultation. Genewa, Technical report series 724,1985 , pp. 71-79.

23 Sirns, EAH, E Danforth. Expenditure and storage of energy in man. J Clin Invest 79, 1019-1025, 1987.

24 Durnin; IVGA, and R Passmore. Energy, work and leisure. London, Heineman, 1967.

25 Cotes, JE, and $\mathrm{F}$ Meade. The energy expendiure and mecharical energy demand in walking. Ergonomics 36, 97-119, 1960.

26 Bingham, SA, GR Goldberg, WA Coward, AM Prentice, and IH Cummings. The effect of exercise and improved physical finess on basal metabolic rate. Brit I Nutr $61,155-173,1989$.

27 Leibel, RL, J Hirsch, EM Berry, RK Gruen. Atterations in adipocyte free fatty acid reesterification associated with obesity and weigh reduction in man. Am J Clin Nutr 42, 198-206, 1985.

28 Weststrate, JA, $\mathrm{P}$ Deurenberg, and JGAJ Hautvast. Nature and magnitude of inter-individuel differences in resting metabolic rate and diet-induced thermogenesis in lean and obese individuals. PhD. Thesis, Wageningen, The Netherlands, 1989, pp. 140-159. 


\title{
Chapter 7
}

\section{Body composition and sleeping metabolic rate in response to a 5-month endurance- training program in adults}

G.A.L. Meijer, K.R. Westerterp, G.H.P. Seyts, G.M.E. Janssen, W.H.M. Saris, and F. ten Hoor

to be submitted

\begin{abstract}
Recently we reported on the effect of long-term exercise training on habitual physical activity level and average daily metabolic rate. In this paper data from the same study on body composition and sleeping metabolic rate (SMR) of 15 males and 13 females were analyzed. Body mass (BM) was measured after waking up, fasted and with an empty bladder. Body composition was assessed using densitometry. SMR was measured from $3.00-6.00 \mathrm{~h}$ during an overnight sleep in a respiration chamber. Assessment of SMR was at least $36 \mathrm{~h}$ after last exercise-training. After 20 weeks of endurance training no change in body mass (BM) was observed. However, body composition changed significantly. On average men lost $2.4 \mathrm{~kg}$ body fat $(\mathrm{p}<0.01)$ and gained $1.7 \mathrm{~kg}$ fat free mass (FFM) $(p<0.01)$. In women fat loss averaged $0.9 \mathrm{~kg}$ after 20 weeks $(p<0.01)$, while FFM increased with $1.0 \mathrm{~kg}(\mathrm{p}<0.05)$. Loss of fat mass $(\mathrm{FM})$ was significantly larger in males $(p<0.05)$. No changes in SMR were found, neither in absolute terms, nor when expressed per $\mathrm{kg} \mathrm{BM}$ or per $\mathrm{kg}$ FFM. Therefore we conclude exercise training has no long-term effect on SMR. A possible explanation for this outcome in the view of different findings in similar studies is discussed.
\end{abstract}




\section{Introduction}

Exercise training may be of great importance in the treatment of obesity $(1,2,3)$. Numerous studies show that the repression of resting metabolic rate which usually occurs during caloric restriction may be reduced by adding exercise to the slimming diet $(4,5,6)$, although others could not reproduce these findings (2,7-11). Most studies report a larger decrease of body fat mass (FM) when the combination of diet and exercise is compared to diet alone $(4,5,7-10)$. However, the expected preservation of fat free mass (FFM) is almost never found in this type of studies $(2,4,5,7,8,9,11)$.

In healthy normal weight subjects increased oxygen uptake may be observed up to $24 \mathrm{~h}$ after exercise (12-15). This increase in metabolic rate has been shown to correlate with the intensity of the exercise bout (15). Others could not reproduce these findings (16-18). Most of these studies are cross-sectional, comparing subjects of different habitual activity level, in contrast to obesity-linked studies. On the other hand in the latter type of studies the effects of exercise on body composition and resting metabolic rate are always confounded by a slimming diet.

In order to examine the effect of exercise only, we assessed habitual physical activity, metabolic rate, exercise performance, and body composition in 32 normal weight, untrained subjects with low habitual physical activity level, before, and 8 and 20 weeks after the onset of an endurance-training program aiming at the ultimate goal of running a $1 / 2$ marathon competition after 10 months. The results on physical activity, average daily metabolic rate and exercise performance have been reported elsewhere (19). The present paper reports on the effects of exercise training on body composition and sleeping metabolic rate (SMR).

\section{Methods}

\section{Protocol and subjects}

Measurement and training protocol have been described previously (19). In this study we present results on body composition ( 15 male/13 female) and SMR ( 13 male/ 12 female) of subjects who completed a 5 -month training schedule just before they ran a $15 \mathrm{~km}$ competition. Subjects were selected on a low habitual physical activity level. Of the original 32 subjects (Table 6.1) 1 man and 3 women had withdrawn from the study at the time of the third measurement period (after 20 weeks /Table 6.2). Due to diskette breakage SMR-data of 2 males and one female got lost during the control measurement. Body composition and SMR were assessed before ( 0 weeks), and 8 and 20 weeks after onset of the training schedule. 


\section{Sleeping metabolic rate}

All subjects entered the laboratory at 18.30 for an overnight sleep in a respiration chamber (20). Subjects had their meal at home just before coming to the laboratory. After entrance of the respiration chamber no meals were eaten, drinking was allowed only before 22.00 h. Sleeping metabolic rate was measured from 3.00 to $6.00 \mathrm{~h}$ when subjects were asleep. In order to prevent short term effects of exercise to be assessed, training was not allowed during the day preceding the overnight sleep at the laboratory. Thus assessment of SMR was at least $9 \mathrm{~h}$ after the last meal and $36 \mathrm{~h}$ after the last exercise bout.

\section{Bady composition}

BM was measured just after waking up in the respiration chamber. At that time subjects were fasted and had emptied their bladder. Body composition was assessed using under water weighing. Rest volume in the lungs was measured when subjects were under water using a respirometer (Volugraph 2000, Mijnhardt, The Netherlands). Body fat \% was calculated using the equations of Siri (21).

FM was calculated from body fat $\% *$ BM. FFM was calculated as BM-FM.

\section{Results}

\section{Body composition}

The endurance-training program had no effect on BM neither in men nor in women (Table 7.1). However, body composition changed in that fat was lost and FFM increased. (Fig 7.1). On average men lost $2.4 \mathrm{~kg}$ body fat ( $16 \%, \mathrm{p}<0.01)$ after 20 weeks and gained $1.7 \mathrm{~kg}$ FFM $(3 \%, \mathrm{p}<0.01)$. The females lost $0.9 \mathrm{~kg} \mathrm{FM}(5 \%, \mathrm{p}<0.05)$ and gained $1.0 \mathrm{~kg} \mathrm{FFM} \mathrm{(2 \% ,} \mathrm{p<0.05).} \mathrm{After} 20$ weeks loss of FM was significantly larger in males compared to females $(\mathrm{p}<0.05)$.

\section{Sleeping metabolic rate}

On average there were no significant changes in SMR of men and women, neither in absolute terms, nor when SMR was expressed per $\mathrm{kg} \mathrm{BM}$ or per $\mathrm{kg} \mathrm{FFM} \mathrm{(Table} \mathrm{7.2).}$ The only eye catching change is the tendency of decreasing SMR/kgFFM both in males and females which is completely due to increasing FFM (Table 7.1) whereas the absolute value of SMR shows no response. Another striking result is that SMR is equal in males and females when expressed per $\mathrm{kg} \mathrm{BM}$, and not as one would expect per $\mathrm{kg} F F M$. The difference in SMR/kgFFM between males and females was statistically significant during all three measurement periods $(p<0.01)$. Individual changes in SMR during the training program were sometimes quite large, yet completely at random (Fig. 7.2). 
Table 7.1 Body mass, percentage body fat, fat mass and fat free mass (Mean and SD)of 15 male and 13 female subjects before onset ( $O$ weeks) and after $B$ and 20 weeks during an endurance training program.

\begin{tabular}{|c|c|c|c|c|}
\hline & & o weeks & 8 weeks & 20 weeks \\
\hline \multicolumn{5}{|l|}{ males } \\
\hline $\begin{array}{l}\text { body mass } \\
\text { body fat } \\
\text { fat mass } \\
\text { fat free mass }\end{array}$ & $\begin{array}{l}(\mathrm{kg}) \\
(\%) \\
(\mathrm{kg}) \\
(\mathrm{kg})\end{array}$ & $\begin{array}{l}72.1 \pm 6.2 \\
20.7 \pm 5.2 \\
15.0 \pm 4.3 \\
57.1 \pm 5.0\end{array}$ & $\begin{array}{l}72.4 \pm 6.1 \\
19.7 \pm 5.1 \\
14.3 \pm 4.2 \\
58.1 \pm 5.6\end{array}$ & $\begin{array}{l}71.4 \pm 5.8 \\
17.6 \pm 4.5 \\
12.6 \pm 3.7 \\
58.8 \pm 5.3\end{array}$ \\
\hline \multicolumn{5}{|l|}{ females } \\
\hline $\begin{array}{l}\text { body mass } \\
\text { body falt } \\
\text { fat mass } \\
\text { fat free mass }\end{array}$ & $\begin{array}{l}(\mathrm{kg}) \\
(\%) \\
(\mathrm{kg}) \\
(\mathrm{kg})\end{array}$ & $\begin{array}{l}63.3 \pm 5.4 \\
29.0 \pm 5.2 \\
18.5 \pm 4.1 \\
44.8 \pm 4.0\end{array}$ & $\begin{array}{l}64.1 \pm 5.2 \\
27.8 \pm 5.2 \\
17.9 \pm 4.0 \\
46.2 \pm 4.3\end{array}$ & $\begin{array}{l}63.4 \pm 5.4 \\
27.6 \pm 5.3 \\
17.6 \pm 4.1 \\
45.8 \pm 4.4\end{array}$ \\
\hline
\end{tabular}
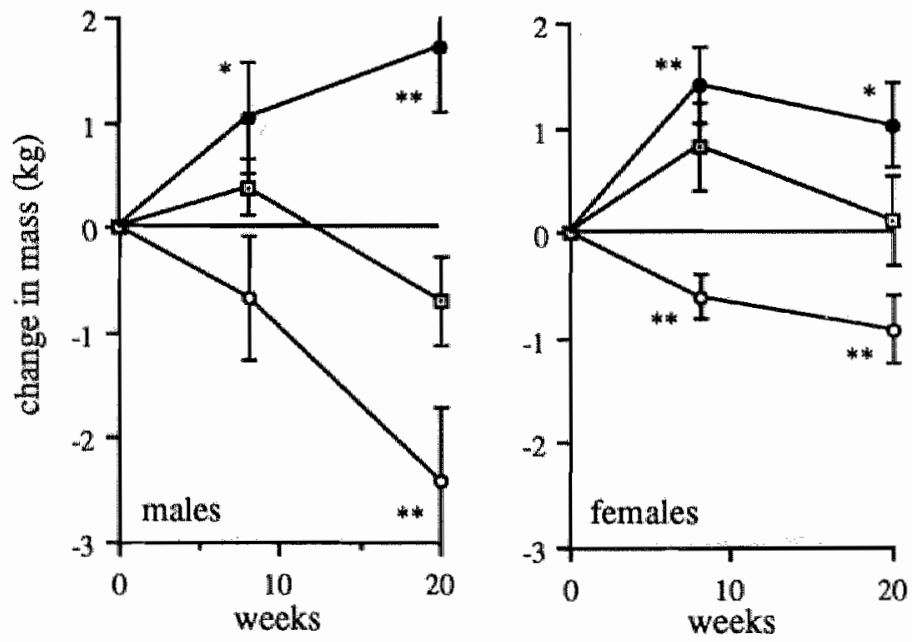

Fig 7.1 Change in body mass (四), fat mass (o), and fat free mass (๑), in 15 males and 13 females after 8 and 20 weeks during an endurance training program. (Y-error bars represent SEM, $* p<0.05, * * p<0.01$ ). 
Table 7.2 Sleeping metabolic rate (SMR), SMR/kg body mass (BM), and SMR/ $\mathrm{kg}$ fat free mass (FFM) of 13 male and 12 female subjects betore onset (0 weeks) and after 8 and 20 weeks during an endurance training program.

\begin{tabular}{|c|c|c|c|c|}
\hline & & 0 weeks & B weeks & 20 weeks \\
\hline \multicolumn{5}{|l|}{ males } \\
\hline $\begin{array}{l}\text { SMR } \\
\text { SMRNg BM } \\
\text { SMRikg FFM }\end{array}$ & $\begin{array}{l}(\mathrm{kJ} / \mathrm{min}) \\
(\mathrm{J} / \mathrm{min} . \mathrm{kg}) \\
(\mathrm{J} / \mathrm{min} . \mathrm{kg})\end{array}$ & $\begin{array}{l}4.75 \pm 0.39 \\
67.3 \pm 6.6 \\
84.0 \pm 6.5\end{array}$ & $\begin{array}{l}4.78 \pm 0.35 \\
67.1 \pm 5.5 \\
82.8 \pm 5.5\end{array}$ & $\begin{array}{l}4.81 \pm 0.45 \\
68.2 \pm 5.2 \\
81.8 \pm 4.4\end{array}$ \\
\hline \multicolumn{5}{|l|}{ females } \\
\hline $\begin{array}{l}\text { SMR } \\
\text { SMR/kg BM } \\
\text { SMR/kg FFM }\end{array}$ & $\begin{array}{l}(\mathrm{kJ} / \mathrm{min}) \\
(\mathrm{J} / \mathrm{min} . \mathrm{kg}) \\
(\mathrm{J} / \mathrm{min} . \mathrm{kg})\end{array}$ & $\begin{array}{l}4.14 \pm 0.34 \\
66.1 \pm 5.4 \\
92.7 \pm 5.5\end{array}$ & $\begin{array}{l}4.25 \pm 0.33 \\
67.2 \pm 7.6 \\
92.5 \pm 9.5\end{array}$ & $\begin{array}{lr}4.10 \pm 0.37 \\
65.7 \pm & 8.6 \\
90.2 \pm 13.1\end{array}$ \\
\hline
\end{tabular}

None of the changes over time were statistically significant (Wilcoxon signed-rank).
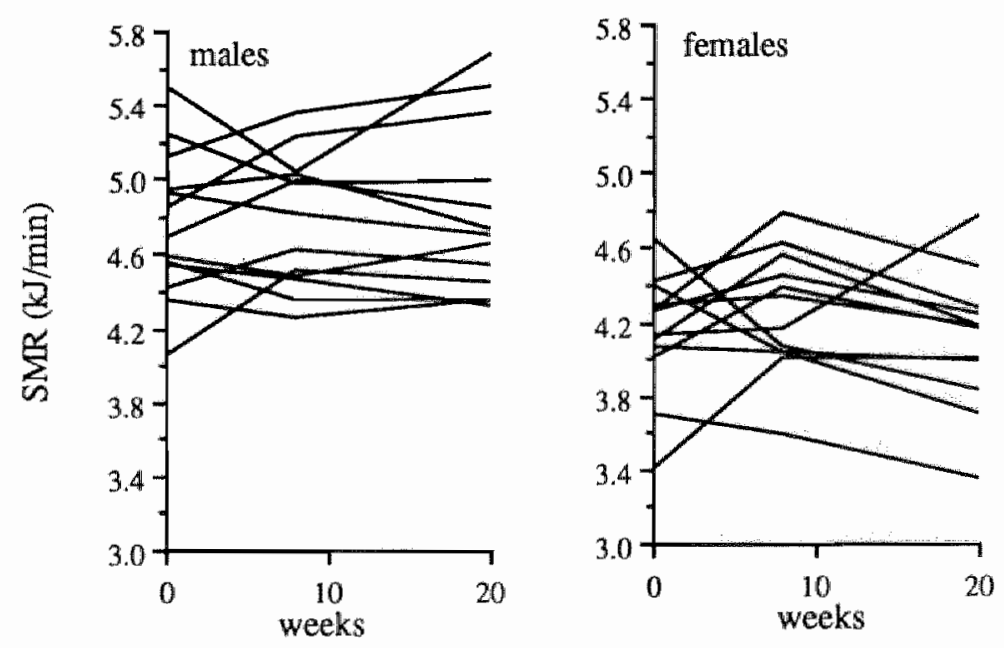

Fig 7.2 Individual changes in sleeping metabolic rate (SMR) in 13 males and 12 females during a 5 -month endurance-training program. 


\section{Discussion}

Compliance to the training schedule was good and both activity level and average daily metabolic rate increased significantly as we showed elsewhere (19). The change in FM in this study is comparable to that reported by Janssen et al. (22). They showed a tendency of decreasing FM of $2.7 \mathrm{~kg}$ in males and $2.2 \mathrm{~kg}$ in females after 1 year during an endurance-training program while we found $2.4 \mathrm{~kg}$ and $0.9 \mathrm{~kg}$ in males and females respectively after 20 weeks. However, Janssen et al. were not able to show any change in FFM which is probably due to the technique used for assessment of body composition (skinfold thickness) in their study. Bingham et al. (18) found a loss of $1.8 \mathrm{~kg}$ body fat (NS) in 5 subjects who participated in a 9 week running program. Exercise has been shown to stimulate lipolysis in adipose tissue (23-27). Després (24) showed adipose tissue to have higher maximal epinephrine stimulated lypolysis in males compared to females, after a 20 week endurance training program. Similarly Leibel (28) and Björntorp (29) showed smaller fat cells which usually occur in the abdominal region (male type fat distribution) to be more sensitive for stimulation. This might explain the sex difference in FM loss during this study $(-2.4 \mathrm{~kg}$ in man $v-0.9 \mathrm{~kg}$ in women, $\mathrm{p}<0.05)$. Simillar findings have been reported by Tremblay et al. (30) and Davis et al. (31). It may be concluded that females show a more conservative response to exercise regarding decrease of energy stores compared to males, as hypothesized by Tremblay (32) and Björntorp (33). These results also correspond with our findings on changes in average daily metabolic rate and habitual physical activity (19).

The most striking result of this study is that $S M R$ was not affected by the endurancetraining program even though FFM increased significantly. This resulted in at tendency of decreasing SMR/kgFFM. This finding is in sharp contrast with studies in which the combination of diet and exercise is evaluated for the treatment of obesity. In these studies mostly an effect of exercise on metabolic rate is found whereas FFM decreases similarly as to treatment with a diet alone $(2,4,5,8,9,11,34)$. Only two studies report preservation of FFM as a result of adding exercise to a slimming diet $(10,35)$, whilst Krotkiewski shows muscle morphology may change in response to endurance training (36) without change in FFM. Yet the contrast of the results of this study with those of diet-exercise studies does not automatically imply contradiction. SMR is usually found to be strongly related to FFM (37-40). In this study FFM increased during the course of the measurements. This implies high protein turnover and synthesis. Protein synthesis and tissue restoration are believed to occur during sleep when ATP-level in cells is high (4143). Therefore one would expect SMR to increase in this study as a result of increased FFM itself and of the biochemical processes necessary for muscle growth. However, no increase in SMR was observed; to the contrary SMR tended to decrease when expressed per $\mathrm{kg}$ lFFM. One can speculate that a mechanism is activated to reduce metabolic rate during sleep in order to compensate for the extra cost of synthesis and maintenance of increasing FFM. This might be virtually the same mechanism as the one responsible for 
the sharp decrease of SMR following caloric restriction. Here it has been shown repeatedly that the decrease in SMR cannot be fully attributed to loss of FFM $(5,8,44)$. This suggests that metabolic rate in some lean tissues may be decreased in response to caloric restriction, although other studies showed SMR $/ \mathrm{kg}$ FFM to sustain on caloric restriction $(2,45,46)$. Verification of this hypothesis however, will be very difficult since no techniques are available to assess different compartments of FFM, and their relative contribution to metabolic rate. Nevertheless the major impact of this study regarding the treatment of obesity is that no long term elevation of SMR could be found after a 20 week endurance training program. Similar results were found by Poehlman et al.(17) and Bingham et al. (18), who showed no effect of exercise on post exercise metabolic rate in longitudinal studies in which sedentary subjects were followed during a training program. Most evidence for elevated post exercise oxygen consumption and increased SMR comes from transversal studies in which subjects with different habitual activity levels are compared $(12-15,47-50)$. The difference between these subjects who are in a steady state and have established a certain activity level, with those in the longitudinal studies who are in a period of constant change may be critical.

\section{References}

1 Björntorp, P, Exercise in the treatment of obesity. Clinics in Endocrinology and Metabolism 5 , $431-453,1976$.

2 Garrow, IS. Effect of exercise on obesity. Acta Med Scand, Suppl. 711, 67-73, 1986.

3 Hanefeld, M, M Zschornack, M Weck, C Hora, and S Fischer. Physical training in obese subjects: selection, motivation, organization and follow-up problems. In P. Bjorntorp, M Cairella, and AN Howard (Eds.): Recent advances in obesity research. Part III. London, J Libbey, 1981, pp. 290-294.

4 Lennon, D, F Nagle, F Stratman, E Shrago, and S Dennis. Diet and exercise training effects on resting metabolic rate. Int J Obes $9,3947,1985$.

5 Dale, D van, and WHM Saris. Repetitive weight loss and weight regain: effects on weight reduction, resting metabolic rase, and lipolyic activity before and after exercise and/or diet treatment. Am J Clin Nutr 49, 409-416, 1989.

6 Mole, PA, JS Stern, CL Schultz, EM Bemauer, and BJ Holcomb. Exercise reverises deprested metabolic rate produced by severe caloric restricion. Med Sci Sports Exerc 21, 29-33, 1989.

7 Warwick. $\mathrm{P}$, and IS Garrow. The effect of an addition of exercise 10 a regime of dietary resiriction on weight loss, nitrogen balance, RMR and spontaneous activity of 30 obese women in a metabolic ward. Int J Obes 5, 25-32, 1981.

8 Henson, LC. DC Poole "CP Donaho, and D Heber. Effects of exercise rraining on resting energy expenditure during caloric restriction. Am J Clin Nutr 46, 893-899, 1987.

9 Hammer, RL, CA Barrier, ES Roundy, JM Bradford, and AG Fisher. Calorie-restricted low-fat diet. and exercise in obese women. Am I Clin Nutr 49, 77-85, 1989.

10 Hill, JO, PB Sparling. TW Shields, PA Heller. Effects of exercise and food restriction on body composition and metabolic rate in obese women. Am J Clin Nutr 46, 622 630, 1987.

11 Dale, D wan, WHM Saris, PFM Schoffelen. F ten Hoor. Does exercise give an addihonal effect in weight reduction regimes. Int J Obes $11,367-375,1987$.

12 Bielinski, R, Y Schutz, and E Jequier. Energy metabolism during the postexercise recovery in man. Am J Clin Nutr 42, 69-82, 1985 . 
13. Machum. S. M Grandmontagne, EA Newsholme, and OM Se jersted. Magnihude and durasion of excess postexercise oxygen consumption in the althy young subjects. Metabolism $35,425-429$, 1986.

14 Tremblay, $A, A$ Nadeaw, C Fournier, and C Bouchard. Effect of a three-day interruption of exercisewaing on resting metabolic rave and glucose-induced thermogenesis in trained individuals. Int I Obes 12, 163168, 1988 .

$15 \mathrm{Bahr}, \mathrm{R}, \mathrm{I}$ Ingres, $\mathrm{O}$ Varge, OM Sejersted, and EA Newsholme Effect of duration of exercise on excess postetercise O2 consumpion. I Appl Physiol 62, 485-490, 1987.

116 Fredman-Akibas, S, E Colt, HR Kissileff, FX Pi-Sunyer Lack of sustained increase in VO2 following exercise in fit and unfir subjects. Am J Clin Nutr 41,545-549, 1985.

17 Poehlmam, ET, A Tremblay, A Nadeau, I Dussault, G Theriault, and C Bouchard. Heredity and changes in hormones and melabolic rates with short-term training. Am J Physiol 250, E 711 E717, 1986.

18 Bingham, SA, GR Goldberg, WA Coward, AM Prentice, and JH Curmmings. The effect of exercise and improved physical funess on basal metabolic rate. Brit J Nutr 61, 155-173, 1989.

19 Mejjer, GAL, GME Jarissen, KR Westerterp, F Verhoeven, WHM Saris, and F ten Hoor. The effect of a 5 -month endurance-training program on physical activity. evidence for a sex-difference in the metabolic response to exercise. this Thesis, Chapter 6.

20 Schoffelen. PFM, WHM Saris, KR Westerterp, and Fi ten Hoor. Evaluation of an automated indirect calorimeter for measurement of energy balance in man. In: Es, AJH van (Ed.) Human energy metabolism: Physical activity and energy expenditure measurements in epidemiological resecurch based upon direct and indirect calorimetry. Wageningen, The Netherlands, Euro-Nut rep. no. 5,1984, pp. $51-54$.

21 Siri, WE. The gross composition of the body. Adv Biol Med Phys 4, 239-280, 1956.

22. Janssen, GME, CJJ de Graef, and WHM Saris. Food intake and body composition in novice alhetes during a training period to run a marathon. Int J Sports Med 10 (Suppl. 1), S17-S21, 1989.

23 Despres, JP, R Savard, A Tremblay, and C Bouchard. Adipocyte diameter and lypolytic activity in marathon runners: Relationship with body fatness. Eur J Appl Physiol 51, 223-230, 1983.

24 Després, JP, C Bouchard, R Savard. A Tremblay, M Marcotte, and G Theriault. The effect of a 20 week endurance training program on Adipose-tissue morphology and lipolysis in men and women. Metalxolism 33, 235-239, 1984.

25 Despres, JP, C Bouchard, R Savard, A Tremblay, M Marcotte, and G Theriault. Level of physical fiumess and adipocyte lipolysis in humans. J Appl Physiol 56,R 11 57-R1161, 1984.

26 Tremblay, A. JP Després, and C Bouchard. Adipose tissue characteristics of ex-obese long distance. runners. Int J Obes 8, 641-648, 1984.

27 Krotkiewski, M, K Mandroukas, L Sjoström, L Sullivan, H Wetterqwist, and P Bjorntorp. Effects of long-term physucal training on body fat, metabolism, and blood pressure in obesity. Metabolism $28,650-658,1979$.

28 Leibel, RL, $\mathbb{J}$ Hirsch, EM Berry, RK Gnen. Alterations in adipocyle free falty acid re-esterification associated with obesity in man. Am J Clin Nutr 42, 198-206, 1985.

29 Bjomtorp, P, G Carlgren, B Isaksson, M Krotkiewski, B Larson, and L Sjoström. Effect of an energy-reduced dietary regimen in relation to adipose tissue cellularily in obese women. Am J Clin Nutr 28, 445 452, 1975 .

30 Tremblay, A, JP Despres, C LeBlanc, and C Bouchard. Sex dimorphism in fat loss in response vo exercise training. J Obes Weight Reg 3, 193-203, 1984 .

31 Davis, JR, AR Tagliaferto, R Kerizer, "T Gerardo, I Nichols, and J Weeler. Vartations in dietaryinduced thermogenesis and body fatmess whith aerobic capacity. Eur J Appl Physiol 50, 319-329, 1983.

32 Tremblay, A, JP Despres, and C Bouchard. The effects of exercise-training on entergy balance and adipose tissue morphology and metabolism. Sports Med 2, 223-233, 1985.

33 Bjomtorp, P. Sex differences in the regulaton of energy balance with exercise. Am J Clin Nutr 49, $958.961,1989$.

34 McKeen PC, BA Franklin, WC Nicholas, and ER Buskitk. Body composition, physical work capacity and physical activity habits at 18 -month follow-up of middle-aged women participating in an exercise intervention progran. Int J Obes $7,61-71,1982$. 
35 Pavlow, KN, WP Steffee, RH Lehman, and BA Burrows. Effects of dienting and evercise on lean body mass, oxygen aptake, and strengah. Med Sci Sports Exerc 17, 466-471, 1985.

36 Krotkiewsiki, M, A-C Bylund-Fallenius, J Holm, P Bjorntorp, G Grimby, and K Mandroukus. Relationstip between muscle morphology and metabolism in obese women: the effects of longlerm physical training. Eur $\mathrm{I}$ Appl Physiol 13, 5-12, 1983.

37 Ravussin, E, B Bumand, Y Schutz, and E Jequier. Twenty-four hour energy expendinure and resting metabolic rate in obese, moderately obese, and control subjects. Am J Clin Nutr 35, 566-573, 1982.

38 Webb, P. Energy expendiure and fou-free mass in men and women. Am J Clin Nutr 34, 1816 1826,1981 .

39 Cunningham, JJ. A reanalysis of the factors influencing basal metabolic rate in normal adults. Am $J$ Clin Nutr 33, 2372-2374, 1980.

40 Owen, OE, JL Holup. DA D'Alessio et al A reappraisal of the caloric requirements of men. Am J Clin Nutr 46, 875-885, 1987.

41 Adam, K. Sleep as a restorative process and a theary to explain why. In: M Comer (Ed.) Progress in brain research. Amsterdam, Elsevier, Vol 53, 289-305, 1980.

42 Oswald, I. Sleep as a restorative process" humant ches. In: M Corner (Ed.) Progress in brain research. Arnsterdam, Elsevier, Vol 53, 279-287, 1980.

43 Shapiro, CM, CG Goll, GR Cohen, and I Oswald. Heal production during sleep. J Appl Physiol; Respirat Eaviron Exercise Physiol 56, 671-677, 1984.

44 Elliot, DL, L Goldberg, KS Kuehl, and WM Bennet. Sustained depression of the resting metabolic rate after massive weighu loss. Am J Clin Nutr 49, 93-96, 1989.

45 Weigle, DS, KJ Sande, PH Iverius, ER Monsen, and JD Brunzell. Weight loss leads to a marked decrease in non-resting energy expenditure in ambulatory tuman subjects. Metabolism 37, 930 $936,1988$.

46 Ravussin, E, B Burnand $\mathrm{Y}$ Schutz, and E Jequier. Energy expenditure before and during energy restriction in obese patients. Am J Clin Nutr 41, 753-759, 1985.

47 Ravussin, E, S Lillioja, WC Knowler, et al. Reduced rate of energy expenditure as a risk factor for body-weight gain. New Engl I Med 318, 467-472, 1988.

48 Ravussin, E, and C Bogardus. Relautionship of genetics, age, and physical fitmess to daily energy expenditure and fuel utilization. Am J Clin Nutr 49,968-975, 1989.

49 Tremblay A, E Fontaine, and A Nadeau. Contribution of postexercise increment in glucose storage to variations in glucose-induced thermogenesis in endurance athietes. Can I Physiol Pharmacol 63 . $1165-1169,1985$.

50 Westerterp, KR, GAL Meijer, WHM Saris, PB Soeters, Y Winants, and F ten Hoor. Physical activity and slecping metabolic rate. (submitted for publication). 



\title{
Chapter 8
}

\section{Sleeping metabolic rate in relation to body composition and the menstrual cycle}

G.A.L. Meijer, K.R. Westerterp, WHM Saris, and F. ten Hoor

to be submitted

\begin{abstract}
The relationship between sleeping metabolic rate (SMR) measured from $3.00-6.00 \mathrm{~h}$ in a respiration chamber and body composition assessed using densitometry was studied in 47 healthy adult subjects ( 23 males and 24 females). Above this the effect of the menstrual cycle on SMR was examined in 16 of the 24 women. SMR was lower in females than in males when expressed in absolute terms $(4.17 \pm 0.50 \times 5.10 \pm 0.82 \mathrm{~kJ} / \mathrm{min}$, $\mathrm{p}<0.0001$ ). However, when expressed per $\mathrm{kg}$ fat free mass (FFM) SMR was higher in females $(92.4 \pm 6.1 \times 88.4 \pm 7.6 \mathrm{~kJ} / \mathrm{min} . \mathrm{kg}$ FFM, $<<0.0001)$. In females SMR increased in the post ovulation phase of the menstrual cycle (estimated as day 18-29 after last menstruation) with $7.7 \%$ on average $(4.33 \pm 0.45 \vee 4.02 \pm 0.43 \mathrm{~kJ} / \mathrm{min}, \mathrm{p}<0.001)$. A stepwise regression showed that both FFM, FM, and the phase of the menstrual cycle contributed significantly to SMR. After adjustment for FFM and FM no sex differences in SMR (males $v$ pre-ovular females) remained. The inclusion of FM in this model is an improvement that eliminates the sex-difference in SMR/kgFFM which is usually found. A prediction equation is given which explains $85 \%$ of the variance in SMR between individuals.
\end{abstract}




\section{Introduction}

Metabolic rate during rest and sleep is generally beliewed to represent the cost of maintenance and restoration of body tissue and energy stores. The contribution of resting metabolic rate (RMR) to total daily energy expenditure is $65-75 \%$ in normal healthy subjects. Therefore, as proposed by the WHO (1), it may be used to estimate the energy requirements of healthy people. Because the assessment of the individual RMR in a large group is labour consuming, predictive equations for RMR may be of use. These equations are based on different measures of body size and/or sex and age. The first equations for predicting basal metabolic rate (BMR) date from 1919 when Harris and Benedict presented their material based on 136 men and 103 women (2). They used sex, age, height, and body mass as independent variables. Since then, many studies have examined the relation between different body size measures and RMR, and nowadays there is large agreement on the fact that RMR is best predicted from fat free mass (FFM) (3-6) as this represents active cell mass. Using FFM as the only denominator, RMR of different subjects (males, females, normal weight, obese) may be estimated with an error of $\sim 10 \%(3,4,6,7)$.

Despite these unequivocal results there are some indications that other factors which can be easily assessed might improve this model. Hoffmans et al. (7) showed that adding fat mass (FM) to the model in a multiple regression improved the explained variance in RMR from FFM from 64 to $74 \%$ in 28 women both of normal weight and overweight. Similar findings have been reported recently by Weststrate et al. ( 8 ). In addition, evidence is now growing that RMR in females fluctuates, as a function of the menstrual cycle $(9,10,11)$. Webb (9) showed that sleeping metabolic rate (SMR) may increase with on average $9 \%$ in the luteal phase.

In this study we analyzed the relationship between body mass (BM), FFM and SMR of 23 men and 24 women, who participated in two studies presented elsewhere $(12,13)$. Furthermore we examined the difference in SMR assessed in the pre-ovulation (pre-O) and post ovulation (post-O) period of the menstrual cycle in 16 women of the 24 mentioned above.

\section{Subjects and Materials}

Subjects from two studies $(12,13)$ were included in the analysis. The total group consisted of 23 men and 24 women, of which 4 and 5 were obese (QI $>27$ ), respectively. Body composition was assessed using hydrostatic weighing, SMR was measured during an overnight sleep in a respiration chamber from 3.00-6.00 h, approximately $1.5 \mathrm{~h}$ before waking up. SMR assessed during a first overnight sleep was used for calculations. 
A regular menstrual cycle with a time period of $28-31$ days was reported by 16 of the 24 women. Data on the last menstruation before the overnight sleep were used to estimate the day of ovulation. First day of menstruation was taken as day 0 in the menstrual cycle. Ovulation was estimated to be on day 15. The pre-ovulation period (pre- $\mathrm{O}$ ) was taken from day 1 to day 12 , and the post ovulation (post-O) period from day 18 to day 30 . Women of study I (12) were remeasured for one night during the opposite phase of the menstrual cycle. The women in study II (13) partitioned in three subsequent measurements, the second and third measurement were after 8 and 20 weeks respectively. Their first SMR value was compared to the first one measured in the opposite phase of the menstrual cycle. Three women reported use of oral contraceptives.

\section{Results}

Mean values of SMR, SMR $/ \mathrm{kgBM}$, and SMR $/ \mathrm{kgFFM}$ for the different groups are presented in Table 8.1. Women had a significant lower SMR than males when expressed in absolute terms $(4.17 \pm 0.50 \vee 5.10 \pm 0.82 \mathrm{~kJ} / \mathrm{min}, \mathrm{p}<0.0001)$. However, when SMR was expressed per $\mathrm{kg}$ FPM, SMR was significantly higher in females. SMR/kgBM did not differ between the sexes $(63.5 \pm 7.2 v 65.8 \pm 6.3 \mathrm{~kJ} / \mathrm{min} . \mathrm{kgBM}, \mathrm{NS})$. In the postovulation period of the menstrual cycle SMR was significantly higher compared to the pre-ovulation period.

Table 8.1 Sleeping metabolic rate (SMR), SMR per $\mathrm{kg}$ body mass (SMR/kgBM) and SMR per $\mathrm{kg}$ fat free mass (SMR/kgFFM) of all subjects, males, females, and females in the pre- and post-ovulation period of the menstrual cycle. All values meantSD.

\begin{tabular}{|c|c|c|c|c|}
\hline & $n$ & $\begin{array}{c}\text { SMA } \\
(\mathrm{kJ} / \mathrm{min})\end{array}$ & $\begin{array}{l}\text { SMR/kgBM } \\
(\mathrm{J} / \mathrm{min} . \mathrm{kgBM})\end{array}$ & $\begin{array}{c}\text { SMR/kgFFM } \\
\text { (d/min.kgFFM) }\end{array}$ \\
\hline all subjects & 47 & $4.62 \pm 0.82$ & $64.6 \pm 6.8$ & $88.4 \pm 7.6$ \\
\hline $\begin{array}{l}\text { malles } \\
\text { femiales }\end{array}$ & $\begin{array}{l}23 \\
24\end{array}$ & $\begin{array}{l}5.10 \pm 0.82 \\
4.17 \pm 0.50\end{array}$ & $\begin{array}{l}65.8 \pm 6.3 \\
63.5 \pm 7.2\end{array}$ & $\begin{array}{l}84.2 \pm 6.8 \\
92.4 \pm 6.1\end{array}$ \\
\hline $\begin{array}{l}\text { pre-ovulation } \\
\text { post-ovulation }\end{array}$ & $\begin{array}{l}16 \\
16\end{array}$ & $\begin{array}{l}4.02 \pm 0.43 \\
4.33 \pm 0.45\end{array}$ & $\begin{array}{l}61.2 \pm 8.2 \\
65.7 \pm 9.8\end{array}$ & $\begin{array}{l}88.3+5.3 \\
94.7 \pm 7.1\end{array}$ \\
\hline $\begin{array}{ll}p<0.0001 \\
p<0.01 \\
& p<0.001\end{array}$ & $\begin{array}{l}\text { diffe } \\
\text { diffe }\end{array}$ & $\begin{array}{l}\text { with pre-ovulat } \\
\text { with pre-ovulat }\end{array}$ & $\begin{array}{l}\text { Wilcoxon sig } \\
\text { (Wilcoxon sig }\end{array}$ & \\
\hline
\end{tabular}




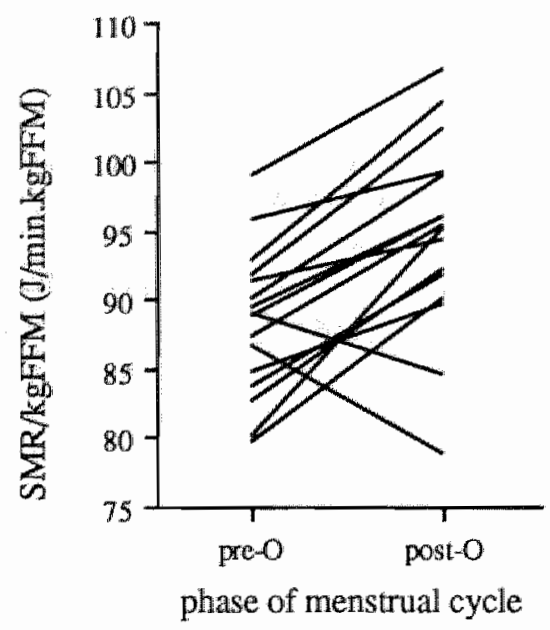

Fig. 8.1 Change in sleeping metabolic rate per $\mathrm{kg}$ fat free mass (SMR/kgFFM) in 16 women from the pre-ovulation (pre-O) to the post-ovulation (post-O) period of the menstrual cycle. $(p<0.01$, Wilcoxon signed rank).

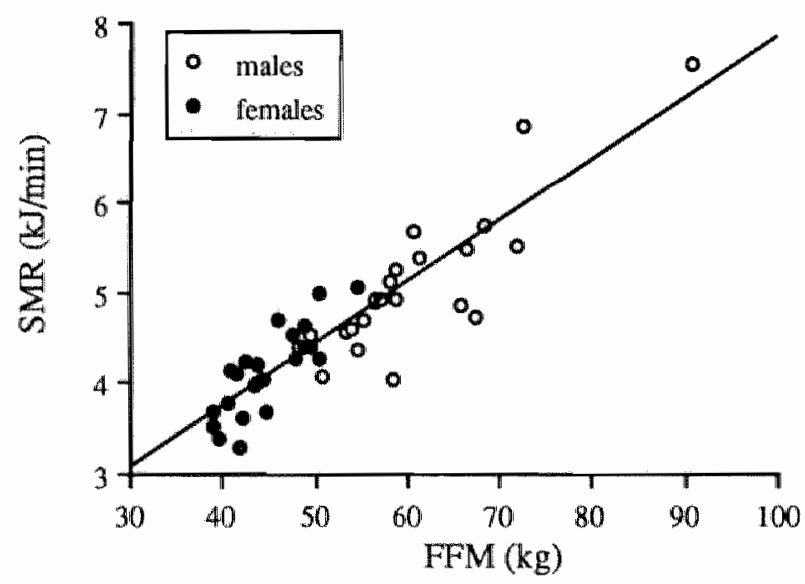

Fig 8.2 Relationship between sleeping metabolic rate (SMR) and fat free mass $(F F M) .\left[S M R(k J / \mathrm{min})=1.018+0.068 * F F M(\mathrm{~kg}) ; n=47, \mathrm{r}^{2}=0.80\right.$, $S_{y, x}=0.37, p<0.00011$. 
In fact, of the 16 females only two showed a fall in SMR from pre-to post-ovulation (Fig. 8.1). They were 2 of the 13 who did not use oral contraceptives.

SMR was strongly related to FFM in our population (Fig. 8.2). A stepwise regression was conducted with FFM, FM, sex and phase of the menstrual cycle (MC) as independent variables to see which other parameters might influence SMR. From this it appeared that both FM and MC improved the model significantly (Table 8.2). After adjustment of SMR for FFM and FM, no significant sex difference in SMR remained. However, females in the post-ovulation period of the menstruation cycle had a significant higher SMR. Thus SMR in our population is best described as:

$$
\begin{aligned}
\operatorname{SMR}(\mathrm{kJ} / \mathrm{min})= & 0.51+0.070 * \mathrm{FFM}+0.016 * \mathrm{FM}+0.253 * \mathrm{MC} \\
& \left(\mathrm{r}^{2}=0.85, \mathrm{~S}_{\mathrm{y}, \mathrm{x}}=0.31, \mathrm{p}<0.0001\right)
\end{aligned}
$$

where FFM and FM are in $\mathrm{kg}_{\text {, }}$ and $\mathrm{MC}$ is 0 for males, and for pre-ovulation females and 1 for post-ovulation females.

Table $\quad 8.2 \quad B$ coefficients, standard error (SE) and p-value, of fat free mass (FFM), fat mass (FM), sex, and phase of the menstrual cycle $(\mathrm{MC})$ in a stepwise regression on sleeping metabolic rate.

\begin{tabular}{lccc}
\hline & $B$ & SE & $\mathrm{p}$ \\
& & & \\
intercept & 0.510 & & \\
FFM & 0.070 & 0.0047 & $<0.0001$ \\
FM & 0.016 & 0.0041 & $<0.001$ \\
MC & 0.253 & 0.101 & $<0.05$ \\
sex not entered & & & NS \\
\hline
\end{tabular}

\section{Discussion}

FFM assessed using hydrostatic weighing is generally believed to represent active cell mass, whereas FM is considered inert in metabolic terms. Nevertheless results fron this analysis as well as from some other studies $(7,8)$ indicate that FM may significantly contribute to SMR or RMR after adjustment for FFM. This means that either fat itself is not completely inert, or that a part of FFM is physiologically related to FM and has a higher metabolic rate than the rest of FFM. The latter suggestion seems more likely. In the study of Ravussin et al. (4) FM had no significant effect on RMR adjusted for FFM. However, in their study body composition was assessed using skinfold thickness which may not be accurate enough to detect the small contribution of FM to RMR. This might 
also explain the difference in explained variance of RMR from FFM in their study (68\%) compared to the $80 \%$ we found. Reanalysis of the data of Ravussin et al. shows that females had a significant higher RMR/kgFFM than males $(89.0 \pm 11.4 v 81.7 \pm 9.4$ $\mathrm{kJ} / \mathrm{min} . \mathrm{kgFFM}, \mathrm{p}<0.05$, Mann-Whitney), as in our study. No data on the phase of the menstrual cycle are reported as this might partially explain the difference. The higher FM in females seems a more likely explanation however.

Women are known to have a higher energy intake and a higher body mass during the post-ovulation period of the menstrual cycle $(14,15,16)$. The increase is thought to be due to increased levels of progesterone during this period. Despite this, the results of different studies on the influence of the menstrual cycle on RMR or SMR are conflicting $(9,10,11,17)$. Webb (9) concludes that methodological factors may be responsible for these different findings. He suggests SMR should be assessed as this measurement may be more reproducible compared to RMR, due to the fact that the subjects are asleep during a whole night, whereas preceding to measurement of RMR different behaviour may have occurred influencing subsequent metabolic rate. Our data which were gathered under this strict protocol confirm his finding that SMR during the post-ovulation period is increased with about $8 \%$ on average. To the contrary Weststrate et al. (17) who measured RMR in the early morning just after waking up were not able to reproduce these findings. In their study 14 women showed increased and 9 decreased post-ovular RMR. However, both in the study of Webb and in ours some females did not show the post-ovular in-crease in SMR, the reason for this being unclear. Webb (9) showed that use of oral contraceptives may inhibit the metabolic response usually found after ovulation. However, this was not the case in our study. The three women who reported use of oral contraceptives showed a similar increase in SMR during the second half of the menstrual cycle as the other women. This may be due to the fact that contraceptives of light oestrogen content are very popular in our country nowadays.

Summarizing we found the variance in SMR -between individuals of both sexes and of normal weight as well as obese- to be explained for $85 \%$ in a model comprising FFM, FM and the phase of the menstrual cycle. SMR adjusted for FFM and FM of females in the pre-ovulation period of the menstrual cycle did not differ from that of males. Postovular SMR was increased with $7.7 \%$ on average $(p<0.001)$. 


\section{References}

1 World Health Organization. Energy and protein requirements report of a joint FAOWWHOWNO expert consultation. Technical Report Series 724, Geneva, $1985: 71-79$.

2 Harris, JA, and FG Benedict. A biometric study of basal metabolism in man. Carnegie Institution of Washington, 1919.

3 Webb, P. Energy expenditure and fat-free mass in men and women. Am J Clin Nutr 34, 1816 $1826,1981$.

4 Rawussin, E, B Burnand, Y Schutz, and E Jequier. Twenty-four hour energy expenditure and resting metabolic rate in obese, moderately obese, and control subjects. Am Y Clin Nutr 35, 566-573. 1982.

5 Owen, OE, $\mathrm{JL}$ Holup, DA D'Alessio et al. A reappraisal of the caloric requirements of men. Am $J$ Clin Nutr 46, 875-885, 1987.

6 Cunningham, JJ. A reanalysis of the factors influencing basal metabolic rate in normal adults. Am J Clin Nutr 33, 2372-2374, 1980.

7 Hoffimans, M, WA Pfeifer, BL Gundlach, HGM Nijkrake, AJM Oude Ophuis, and JGAJ Haunwast. Resting metabolic rate in obese and normal weight women. Int J Obes 3,111-118, 1979.

8 Weststrate, JA, P Deurenberg, and JGAJ Hautvast. Nature and magnitude of inter-individuel differences in resting metabolic rate and diet-induced thermogenesis in lean and obese individuals. PhD. Thesis, Wageningen, The Netherlands, 1989, pp. 140-159.

9 Webb, P. 24-hour energy expenditure and the menstrual cycle. An I Clin Nutr 44, 614-619, 1986.

10 Solomon, SJ, MS Kurzer, and DH Calloway. Menstrual cycle and basal metabolic rate in women. Am $J$ Clin Nutr 36, 611-616, 1982.

11 Bisdee, JT, WPT James, and MA Shaw. Changes in energy expendirure during the menstrual cycle. Brit J Nutr 61, 187-199, 1989.

12 Meijer, GAL, KR Westerterp. AMP van Hulsel, and F ten Hoor. Physical activity and energy expenditure in lean and obese adult human subjects. this Thesis, Chapter 5.

13 Meijer, GAL, GME Janssen, KR Westerterp, F Verhoeven, WHM Saris, and F ten Hoor, The effect of a 5-month endurance-training program on physical activity: evidence for a sex-difference in the metabolic response to exercise. this Thesis, Chapter 6.

14 Dalvit, SP. The effect of the menstrual cycle on patterns of food intake. Am J Clin Nutr 34, 18111815,1981 .

15 Pliner, $\mathrm{P}$, and AS Fleming. Food intake, body weight, and sweetness preferences over the menstrual cycle in humans. Physiol Behavior 30, 663-666, 1983.

16 Gong, EJ, D Garrel, and DH Calloway. Menstrual cycle and voluntary food intake. An J Clin Nutr 49. 252-258, 1989.

17 Weststrate, JA, P Deurenberg, and JGAJ Hautvast. The assessment of resting melabolic rate, die!induced thermogenesis and in wivo fuel whilization using a ventilated hood system: methodological considerations. PhD Thesis. Wageningen, The Netherlands, 1989, pp. 59-104. 



\section{Chapter 9}

\section{General Discussion}

Physical activity is a part of our behaviour. Therefore, studies on the implications of physical activity on different aspects of health should be conducted under natural, free living conditions. The environment of a metabolic ward or a respiration chamber is too restrictive in this respect. Consequently, physical activity under these circumstances is usually low (1-4). However, the assessment of physical activity under free living conditions is cumbersome. In a review on this matter (5) LaPorte et al. show that more than 30 different techniques have been proposed for the assessment of physical activity, and they conclude:" Perhaps with the exception of dietary and nutritional assessments, we know of no other health-related behavior that has been measured in so many ways". Yet the ideal technique has still to be developed. It should be reliable, socially acceptable, and not interfering with the activity pattern of the subject.

In this thesis we presented a newly developed accelerometer, which was applied in a study comparing physical activity in obese and lean subjects, and in an intervention study where subjects who had an initially low activity level were trained for endurance running. The technique as well as the results of both studies mentioned will be evaluated here.

\section{The accelerometer}

Reviewing recent literature on methods for the assessment of physical activity the accelerometer using a piezo-electric sensor turns out to be one of the more promising techniques (2,6-9). However, only few studies examined the reliability of the accelerometer. We tested reproducibility of the accelerometer using a bench test, and subjects during treadmill walking (Chapter 2 and 3). Furthermore accuracy was studied in 7-day field measurements comparing the outcome of the accelerometer with average daily metabolic rate (ADMR) minus sleeping metabolic rate (SMR) assessed with indirect calorimetry (Chapter 4 ). The results of these different approaches are in conflict to some extent. Mean $\mathrm{CV}$ of 10 accelerometers in four subsequent bench-tests during one week was $7.6 \%$. Within each particular device CV was less than $10 \%$. (Table 2.2). Minute to minute readings during each exercise bout on the treadmill varied within $5 \%$ (Table 2.3). However, repeated measurement of accelerometer output (AO) of the same device on the same subject during similar exercise testing varied from $\sim 25 \%$ at $3 \mathrm{~km} / \mathrm{h}$ to $\sim 15 \%$ and $5 \%$ at 5 and $7 \mathrm{~km} / \mathrm{h}$ respectively. (Table 2.4 ). Inter-instrument variation during treadmill tests was about $20 \%$ (Table 2.5). Surprisingly this variation sustained after correction for inter-instrument differences based on bench-test results. Similarly, this correction did not 
improve the relationship between AO and ADMR-SMR in the 7-day field experiment (Table 4.3). Therefore we conclude that although the bench test may be helpful in assessing the reproducibility of the accelerometer on a standardized movement, human movement -even during the strict protocol of a laboratory exercise test- is either not as reproducible or of a different nature. The latter seems most likely as there was correspondence between intra- and inter-individual variation on the treadmill and in the outdoor measurements. The individual correction factor $\mathrm{cc}$ in $\mathrm{kJ} /$ count assessed during the treadmill experiment improved the relationship between $A O$ and energy expenditure due to physical activity in the field experiment (Table 4.3).

In Chapter 4 we focussed on the undividual results of AO compared to energy expenditure. It appeared that 7 of the 11 accelerometers used under free living conditions performed bad whereas the other 4 showed excellent agreement with indirect calorimetry. 77\% of the inter-individual variation in ADMR-SMR was explained from AO (Fig. 4.3). The reason for the poor results of the former instruments is not understood. It may be that the low number of observations made with these instrument plays a role. However, two of these instruments ( 4 and 7 ) also failed in the bench test (Table 2.2) indicating that technical failures may have occurred as well during the production of the instruments. It should be kept in mind that all 14 instruments initially built were in fact hand made prototypes. Pooled results of the five major groups of subjects presented in this thesis are shown in. Fig. 9.1. Differences in physical activity level as determined by indirect calorimetry correlated strongly with average $A O$ of the groups $\left(r^{2}=0.98, p<0.001\right)$. The $\mathrm{X}$-intercept of the regression equation is $1.1(* \mathrm{BMR})$ indicating that the correlation between both techniques makes physiological sense.

Evaluating the accelerometer as a method for assessing physical activity we conclude that despite the technical problems which occurred during this study the underlying principle of the method is good. $77 \%$ of inter-individual variation in ADMR-SMR may be explained from $\mathrm{AO}$, whereas $98 \%$ of differences in physical activity level between small groups of approximately 1.0 subjects is explained from AO. Further development of this accelerometer is needed. Solving the technical problems and reducing size and weight are the first items to be stressed. The rapid evolution of electronic components to smaller size and higher reliability enables such improvement. Next to this, the implications of the intrinsic failure of the instrument in determining static work might be anticipated through computer modeling. A reliable and accurate technique for the assessment of physical activity under free living conditions will thus become available for different kinds of research from epidemiology and pedialrics to treatment and intervention studies. 


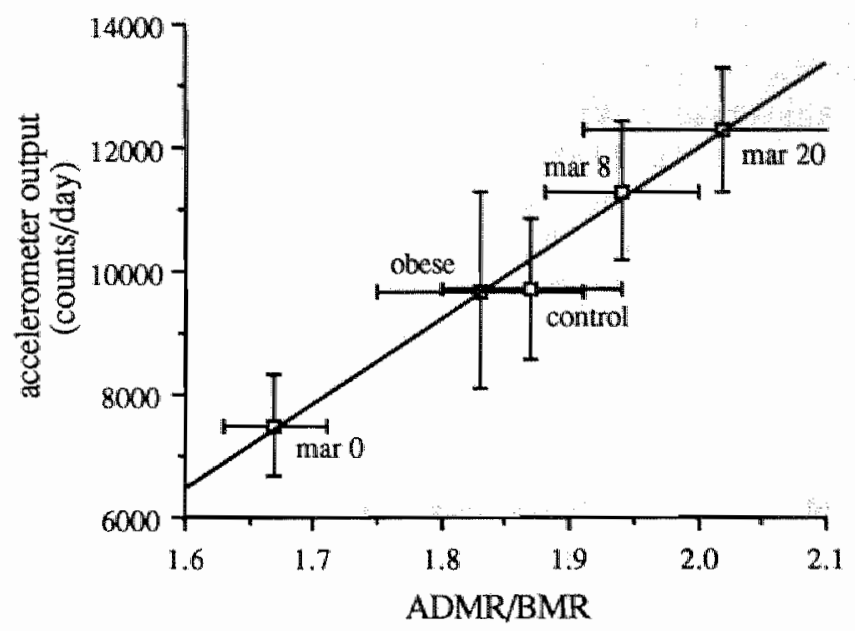

Fig 9.1 Group averages of accelerometer output v average daily metabolic rate $(A D M R)$ as a multiple of basal metabolic rate (BMR). Error bars represent SEM. Data for obese and control from Table 5.2; for intervention study (1/2-marathon; mar 0, initial measurement, mar 8 and mar 20 after 8 and 20 weeks of training) from Table 6.3.( $r^{2}=0.98, X$-intercept $\left.=1.1\right)$

Physical activity

Looking at Fig. 9.1 some major conclusions can be drawn. Firstly, we did not find any difference in activity between lean and obese subjects, neither with the accelerometer nor with the doubly labeled water technique. Secondly, we succeeded in selecting a group of relatively inactive subjects (mar 0 ) for our intervention study. This was the only group of subjects which significantly differed from the others in activity level. Intervention increased the activity level significantly after 8 weeks, after which the increase slowed down. The implications of these findings will be discussed here in greater detail.

Physical activity in the obese

In Chapter 5 we examined the question whether different activity levels may exist between obese and lean subjects. Obesity is thought to arise from an imbalance between energy input and energy output of the human body. Differences in energy intake between obese subjects and lean controls are almost never reported (10-16). Therefore a deficit in energy output may be suspected in the obese $(17,18,68)$. From studies on resting metabolic rate (RMR) and diet-induced thermogenesis (DIT) it is generally concluded that obese subjects do not differ from lean controls regarding these two aspects of energy metabolism, after adjustment for body mass or FFM. However, results on physical activity of the obese are 
inconsistent. Numerous studies show the obese to be less active than lean controls (24,25), while others report similar activity levels in both groups (26-30). We suggest that these different findings may be due to the techniques used to assess physical activity. Observational studies are more likely to show a difference, while in studies using more objective methods differences are found less frequently. This discrepancy might be explained from the higher cost attributed to -observed- activity with increasing body mass. In our study we measured body movement itself regardless of the concurring expenditure and found no difference between obese people and lean controls (obese: AO $=9687 \pm 2753 v$ lean: $\mathrm{AO}=9712 \pm 3557$ counts/day, NS / Table 5.2, see also Fig. 9.1). Energy expenditure due to physical activity tended to be higher in the obese probably as a result of their larger body size (ADMR-SMR: $6.9 \pm 2.1 v 5.9 \pm 2.1$ MJ/day, NS / Table 5.2). After adjustment for FFM no difference between the groups was found (116 $\pm 0.11 v 114 \pm 31 \mathrm{~kJ} / \mathrm{kgFFM}$.day, NS / Table 5.2). Similar results have been reported by Prentice et al. (10) who also used the doubly labeled water technique for measuring free living energy expenditure. Furthermore we did not find any evidence for a lower RMR in the obese as sleeping metabolic rate (SMR) was equal in both groups when adjusted for FFM.

We conclude no metabolic disorder appears in the obese. Difficulties in the measurement of energy intake and the possibility of systematic under-reporting of obese subjects seems more likely $(10,11)$. Two final remarks should be made regarding these results. Firstly, our population was very small and may not be representative for the population at large. For instance, most of our obese and lean subjects had a full time job which may mask differences in spontaneous activity. Secondly, one may question whether energy expenditure due to activity should be adjusted to FFM or body mass. Considering the weight bearing aspects during activity in the obese, adjustment for body mass might seem better. However, in this study their was no significant difference using either factor as denominator for metabolic rate. The choice of adjustment factors will be addressed later on in this discussion.

\section{Physical activity: implications for energy metabolism}

The 1/2-marathon-project was a study which aimed at increasing physical activity and examined changes in metabolic rate and body composition. Food intake data from the study of Janssen et al. (31) suggested that at least in females the added cost of running exercise might be compensated for. The nature of this compensation was unclear thus it might appear in one or all compartments contributing to energy expenditure. Other studies show that RMR -the largest energy compartment-, if responding, increases (32-38). Results of again other studies suggest that sex-differences appear in response to added exercise (39-42). Understanding the nature of metabolic responses to added exercise is of particular importance in the treatment of obesity. In an attempt to unravel any change in metabolic rate we therefore measured habitual physical activity, ADMR, SMR, body 
composition and exercise performance in 16 males and 16 females of normal health and weight before and after 8 and 20 weeks during an endurance-training program.

In males energy expenditure increased to a much larger extent compared to that in females ( $+3.3 \mathrm{MJ} /$ day $v+1.3 \mathrm{MJ} /$ day in females, Table 6.4). Correspondingly, loss of fat mass (FM) was significantly higher in males $(-2.4 \mathrm{~kg} v-0.9 \mathrm{~kg}$ in females, $\mathrm{p}<0.05)$. Although in both sexes the increase in ADMR outlived the net cost of the added exercise, in females this discrepancy (1.1 MJ/day) could be easily explained from an increase in RMR during the non-sleeping part of the day, and assuming an increase of $10 \%$ in DIT due to increased food intake. However, applying the same assumptions in males after 20 weeks a discrepancy of $1.7 \mathrm{MJ} /$ day remained which could not be accounted for (Table 6.7). Excluding running exercise, habitual physical activity showed no significant change in either sex, although in men there was a tendency of a $15 \%$ increase (Fig. 6.2). Summarizing we conclude that all results point at the same direction. When confronted with a stress on energy metabolism females seem to show a much more conservative response than males. Similar findings have been recently published by Bingham et al. (38). These results correspond with experience from studies on treatment of obesity and metabolism of adipose tissue $(43,44,45)$. It may be argued that women seem to be biologically determined to preserve their fat storage, which is localized mainly in the femoral region, for pregnancy and lactation.

SMR measured at least $36 \mathrm{~h}$ after the last exercise bout showed no response to the increased activity level in our study. Similar findings have been reported in other intervention studies on physical activity $(37,38)$. However, most cross-sectional studies show increased RMR or SMR after exercise that may last for even $24 \mathrm{~h}$ in subjects with a high habitual physical activity level $(33,35)$. This raises the question whether intensity and duration of this intervention have been large enough to evoke a response in SMR, or whether metabolic rate and body composition are mainly genetically determined (37, 46-50,68) and resistant to relatively short term shifts in for instance activity level. Nevertheless, regarding treatment of obesity, 20 weeks of controlled exercise training implies quite an effort for the patient and will ask a lot of motivation. Together with the increased risk for injuries in these people the benefits of such a program may be small, and perhaps only of significance in supporting the motivation to keep to the diet and, afterwards, in maintaining a lower body mass. Reminding the fact that we found no difference in habitual activity level between lean and obese, one might ask the reason for choosing activity as a tool for treatment. In contrast with the findings of Lennon (51) our data suggest that exercise added to a diet will be of more help for men than for women.

\section{Body composition and metabolic rate}

If one wants to compare the metabolic rate of a mouse with that of an elephant it is clear that some adjustment has to be made for the different appearance of these animals. Analyzing data on metabolic rate of different species in correspondence to their body size 
and-mass, Kleiber found that body surface area in combination with body mass explains inter-species differences in metabolic rate (52). A physiological explanation for this can be found in the observation that heat loss is relatively high when body surface area is large compared to body mass, which is the case in small animals. Differences in metabolic rate between species ranging in body mass from a few grams up to $1000 \mathrm{~kg}$ or more may be best described from $\mathrm{BM}^{3 / 4}$ (Fig 9.2).

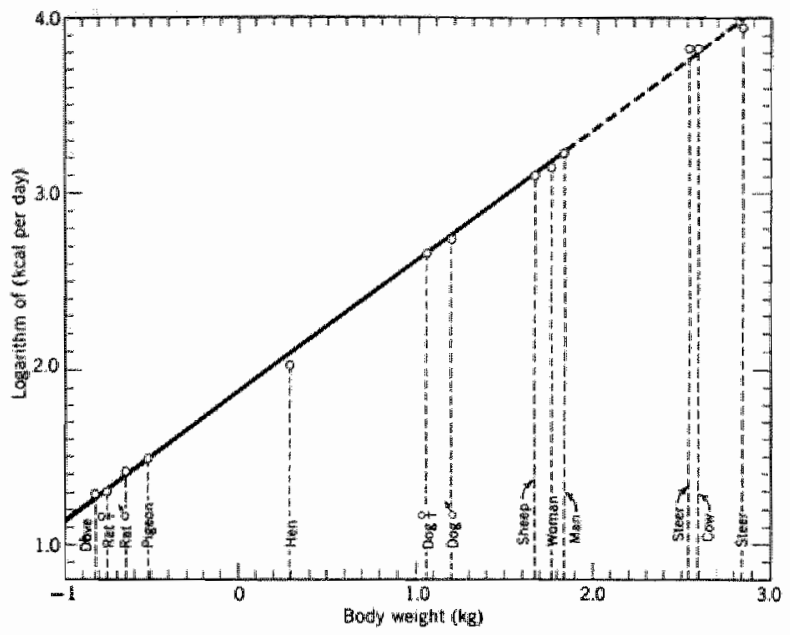

Fig 9.2 The linear interspecies relationship between the logarithms of body weight $(B W)$ and metabolic rate $(M R)$. MR (kcal/day) $=70 * B W 3 / 4$. From: Kleiber, 1961 .

Problems may arise when we want to know whether a flying bird is as active as a running athlete. In such cases metabolic rate during that specific activity is usually expressed as a multiple of BMR. The flying bird and the long distance runner both spend about 10 times more energy than at rest and may be considered equally active in metabolic terms. This multiple of BMR -also called the physical activity index- is without dimension and has little physiological meaning. It does not explain why at this particular activity expenditure is raised by a factor 10 , and not 8 or 20 for instance.

Similarly, problems occur when trying to compare metabolic rate within one species, as in this thesis in man. Body surface area is sometimes used for this adjustment but seems of little relevance within the much smaller weight range within one species, and particularly in man who dresses himself in order to regulate body temperature. However, it is obvious that for a proper comparison of metabolic rate in different subjects some adjustment has to be made for differences in body size, -mass, and -composition. Harris and Benedict presented their predictive equations for BMR in man in 1919 (53). These 
equations were based on measurements in 239 adults. The regression analysis was done by hand. They adjusted BMR for sex, age, height and body mass. After the introduction of computers there has been an exponential growth of prediction equations for metabolic rate in man, either at rest or during specific activities $(21,54-59)$. However, true physiological relationships are not implicit to these models $(52,60,61)$. It is for this reason (amongst others) that the WHO decided to estimate energy requirements using the physical activity index: ADMR/BMR (62). As we suggested in Chapter 6 this index may be prone to error when BMR covaries with activity. Data from cross sectional studies support this suggestion $(56,63)$. More appealing models are the ones that use a single predictor like fat free mass (FFM) to explain differences in metabolic rate. Here a clear physiological relation with active cell mass of the body seems to exist. Several authors reported FFM to be the best single predictor for RMR or SMR in man $(3,4,19-21,64)$. In our study FFM explained $80 \%$ of the inter-individual variation in SMR (Fig. 8.2). However, a sex difference in SMR adjusted for FFM remained (males: $92.4 \pm 6.1 \mathrm{v}$ $88.4 \pm 7.5 \mathrm{~kJ} / \mathrm{min} . \mathrm{kg}$ FFM in females, $\mathrm{p}<0.0001$ ). Reanalysis of the data of Ravussin (4) shows a similar sex difference $(89.0 \pm 11.4 \vee 81.7 \pm 9.4, \mathrm{p}<0.05)$. Recently, Ravussin recognized this difference using a larger data set and he suggests to add FM to the model (68). In our study a stepwise multiple regression analysis showed that FM contributed significantly to SMR and added about $5 \%$ to the $80 \%$ explained variation. After this adjustment the sex difference disappeared except for females in the post-ovular phase of the menstruation cycle who had a 7.7\% increased SMR ( $\mathrm{p}<0.01 /$ Table 8.1). Although the increase in metabolic rate during the post-ovular phase is not fully understood, evidence on this phenomena is growing (65-67). The contribution of FM to SMR in our model is more puzzling as FM is generally considered to be metabolically inert. Furthermore FM covaries with FFM. An explanation may be found in the composition of FFM itself. FFM can be schematically divided into two types of tissue, muscle and organs. Muscle probably adds very little to SMR whereas the largest contribution may be expected from the organs, particularly the liver and the central nervous system. A muscular body composition usually correlates with a low fat mass, whereas a high fat mass may be associated with larger organs. Thus FM may give an indication of the composition of FFM and thereby explain some of the remaining variance in SMR after adjustment for FFM. Other studies also show that FM may contribute to variance in SMR or RMR after adjustment for FFM $(19,20,64)$.

Comparing metabolic rate due to specific activities in lean and obese, as for instance in treadmill walking, it usually correlates best with body mass. In this thesis this also appeared to be true. The extra cost of these activities in obese subjects are thought to be due to the extra weight they have to bear, which explains the best fitting to be found between BM and metabolic rate. Yet in our study on habitual activity level we adjusted ADMR-SMR for FFM. The reason behind this is that ADMR-SMR is not metabolic rate due to a specific activity but a compilation of metabolic rate due to all kinds of activities which occur during the day. Most of these activities are sedentary or at a sedentary level, 
the weight bearing aspects of higher activity levels adding very little to ADMR-SMR. Severall authors have shown that $24 \mathrm{~h}$ energy expenditure at sedentary activity levels are best explained from FFM $(3,4)$. A true physiological adjustment should perhaps contain both FFM and BM according to time spent at higher activity levels. For the results of the comparison of physical activity between obese and lean subjects in our study either adjustment (FFM or BM) led to the same conclusion; no significant difference was found.

\section{Conclusions}

1. The accelerometer using a three directional sensor as developed in our department proves to be a reliable technique for the assessment of physical activity under free living conditions.

2 Physical activity of obese subjects in this study equalled that of lean controls. Similarly there was no difference in SMR adjusted for FFM. Thus no metabolic disorder was found in the obese. A strong negative correlation between energy intake minus expenditure on the one hand and body mass on the other hand together with only minor indications of dieting suggests systematic underrecording of food intake (either wilful or unaware) in the obese.

3 Increase of physical activity by following an endurance training program increases ADMR to a further extent than may be expected from the net cost of running itself. Activity thus stimulates other components of metabolic rate, possibly through activation of the sympathetic nervous system. The effect is larger in males than in females. Correspondingly, loss of FM is significantly higher in males. Females seem to be more conservative in preserving their energy balance.

4 FM as assessed by hydrostatic weighing makes a significant contribution to SMR adjusted for FFM.

5 The menstrual cycle affects SMR. During the post-ovular phase SMR is increased with on average $7.7 \%$. Therefore in females the phase of the menstrual cycle should be taken into account in future studies which include assessment of RMR. 


\section{References}

1 Garby, L, O Lammert, and E Nielsen. Energy expendinure over 24 howrs on low phystcal acrivity programmes in human subjects. Hum Nutr: Clin Nutr $40 \mathrm{C}, 141-150,1985$.

2 Schutz, $Y, F$ Froidevaux, and $\mathrm{E}$ Jéquier. Estimation of 24 h energy expenditure by a portable accelerometer. Proc Nutr Soc 47, 23A, 1988.

3 Webb, P. Energy expenditure and fat-free mass in men and women. Am J Clin Nutr 34, 1816$1826,1981$.

4 Ravussin, E, B Burnand, Y Schutz, and E Jequier. Twenty-four hour energy enpenditure and resting metabolic rate in obese, moderately obese, and control subjects. Am J Clin Nutr 35, 566-573, 1982.

5 LaPorte, RE, HJ Montoye, and CJ Caspersen. Assessment of physical activity in epidemiological research : problems and prospects. Publ Health Rep 100, 131-146, 1985.

6 Montoye, HJ, and HL Taylor. Measurement of physical activity in population studies: A review. Hum Biol 56, 195-216, 1984.

7 Saris, WHM. Habitual physical activiny in children: methodology and findings in health and disease. Med Sci Sports Exerc 18, 253-263, 1986.

8 Groves, D. Beyond the pedometer: New tools for monitoring activity. The Physician and Sportsmedicine 16, 160-166, 1988 .

9 Meijer, GA, KR Westerterp, H Koper, and $\mathrm{F}$ ten Hoor. Assessment of energy expenditure by recording heart rate and body acceleration. Med Sci Sports Exerc 21, 343-347, 1989 (this Thesis: Chapter 3).

10 Prentice, AM, AE Black, WA Coward, et al. High levels of energy expenditure in abese women. Brit Med J 292, 983-987, 1986.

12 Lissner, L, J-P Habicht BI Sirupp, DA Levitsky, ID Haas, and DA Roe. Body composition and energy intake: do overweight women overeat and underreport? Am J Clin Nutr 49, 320-325, 1989.

13 George, V. A Tremblay, JP Despres, C LeBlanc, L Perusse, and C Bouchard. Evidence for the existence of small eaters and large eaters of similar far-free mass and activity level. Int J Obes 13 , $43-53,1989$.

14 Ohlson, MA, and $\mathrm{U}$ Harper. Longitudinal studies of food intake and weight of women from ages 18 to 56 years. I Am Diet Assoc 69, 626-631, 1976.

15 Kulesza, W. Dietary intakes in obese women. Appetite 3, 61-68, 1982.

16 Kromhout, D. Energy and macronutrient intake in lean and obese middle aged men the Zuphen study). Am J Clin Nutr 37, 295-299, 1983.

17 Sims, EAH, E Danforth. Expenditure and storage of energy in man. J Clin Invest 79, 1019-1025, 1987.

18 Thompson, JK, GJ Jarvie, BB Lahey, and KJ Cureton. Exercise and obesity: Etiology, physiology, and interwention. Psychol Bull 91, 55-79, 1982.

19 Weststrate, JA, P Deurenberg, and JGAJ Hautvast. Nature and magnitude of inter-individuel differences in resting metabolic rate and diet-induced thermogenesis in lean and obese indwiduals. PhD. Thesis, Wageningen, The Netherlands, 1989, pp. 140-159.

20 Hofmans, M, WA Pfeifer, BL Gundlach et al. Resting metabolic rate in obese and normal weight women. Int J Obes 3, 111-118, 1979.

21 Owen, OE, JL Holup. DA D'Alessio et al. A reappraisal of the caloric requirements of men. Am J Clin Nutr 46, 875-885, 1987.

22 D'Alessio, DA. EC Kavle, MA Mozzoli et al. Thermic effect of food in lean and obese men. J Clin Invest $81,1781-1789,1988$.

23 Felig, P, J Cunningham, M Lewith, R Hendler, E Nadel. Energy expendiure in obesity in fasting and postprandial state. Am J Physiol 244, E4S 51, 1983.

24 Dorris, RJ, AJ Stunkard. Physical activity: performance and atitudes of a group of obese women. Am J Med Sci 223, 622-628, 1957.

25 Chirico, AM, AJ Stunkard Physical activity and human obesity. N Engl I Med 263, 935-940, 1960.

26 Stunkard, AJ, and J Pestka. The physical activity of abese girls. Am J Diseases Childh 103 812 $817,1962$. 
27 Wikinson, PW, JM Parkin, G Pearison, H Strong, and P Sykes. Energy intake and physical activity in obese children. Brit Med I $1,756,1977$.

28 Gremfield, NS, and CH Itellner. Resting level of physical activity in obese females. Am J Clin Nut 22, 1418-1419, 1969 .

29. Maxfield, $E$, and Fonishi. Patterns of food intake and physical activity in obesity. I Am Diet Assoc 49, 406 408, 1966 .

30 Tryon, WW. Activity ar a function of body weight Am J Clin Nutr 46, 451 -455, 1987.

31 Janssen, GME, CJ de Graef, and WHM Saris. Food intake and body composition in novice ahletes during a training periad to run a marathon. In I Sports Med 10 (Suppl. 1), S17-S21. 1989.

32 Bielinski, $\mathrm{R}, \mathrm{Y}$ Schut, and E Jequier. Energy metabolism during the postexercise recovery in man. Am I Clin Nutr $42,69-82,1985$.

33 Maehlum, S, M Grandmontagne, EA Newsholme, and OM Sejersted. Magnitude and duration of excess postexercise oxygen consumption in heallhy young subjects. Metabolism 35, 425-429, 1986.

34 Tremblay, A, A Nadeati, G Fournier, and C Bouchard. Effect of a thee-day interruption of exercisetraining on resting metabolic rate and glucose-induced thermogenesis in trained individuals. Int I Obes $12,163-168,1988$.

35 Bahr, R, I Ingnes, O Vaage, OM Sejersted, and EA Newsholme. Effect of duration of exercise on excess postexercise O2 consumption. J Appl Physiol 62, 485-490, 1987.

36 Freedman-Akabas, S, E Colt, HR Kissileff, FX Pi-Sunyer. Lack of sustained increase in VO2 following exercise in fit and unfit subjects. Am J Clin Nutr 41, 545-549, 1985.

37 Poehlman, ET, A Tremblay, A Nadeau, I Dussault, Gi Thériault, and C Bouchard. Heredity and changes in hormones and metabolic rates with short-term training. Am J Physiol 250, E 711E717, 1986.

38 Bingham, SA, GR Goldberg, WA Coward, AM Prentice, and JH Cummings. The effect of exercise and improved physical fitness on basal metabolic rate. Brit J Nutr 61, 155-173, 1989.

39 Tremblay, A, JP Després, C LeBlanc, and C Bouchard. Sex dimorphism in fal loss in response to exercise sraining. J Obes Weight Reg 3, 193-203, 1984.

40 Bjorntorp, P. Sex differences in the regulation of energy balance with exercise. Am J Clin Nutr 49, $958-961,1989$.

41 Chen, JD, and C Bouchard. Discussion from the session: Sex differences in metabolic adaptation to exercine. In: B Saltin (Ed). Biochemistry of exercise. Vol VI, Champaign, Illinois, Human Kinetics Publ , 1986, pp.227-238.

42 Friedmann, B, and W Kindermann. Energy metabolism and regulatory hormones in women and men during endurance exercise. Eur J Appl Physiol 59, 1-9, 1989.

43 Saris, WHM. Physiological aspects of exercise in weight cycling. Am J Clin Nutr 49, 1099-1104, 1989.

44 Davis, JR, AR Tagliaferro, R Kertzer, T Gerardo, J Nichols, and J Weeler. Variations in dietaryinduced thermogenesis and body faness with aerobic capaciry. Eur J Appl Physiol 50, 319-329, 1983.

45 Despres, JP, C Bouchard, R Savard, A Tremblay, M Marcolte, and G Thériault. The effecr of a 20 week endurance training program on Adipose-tisue morphology and lipolysis in men and women. Metabolism 33, 235-239, 1984.

46 Bogardus, $\mathrm{C}, \mathrm{S}$ Lillioja, E Ravussin et al. Familial dependence of the resting metabolic rate. $\mathrm{N}$ Engl J Med 315, 96-100, 1986.

47 James, WPT, and P Trayhum. An insegrated view of the metabolic and genetic basis for obesity. Lancel' $2,770-773,1976$.

48 Ravussin, E, SL Lillioja, WC Knowler et al. Reduced rate of energy expenditure as a risk factor for body-weight gain. New Eng J Med 318, 467-472, 1988.

49 Giriffiths, $M$ and PR Payne. Energy expenditure in small children of obese and non-obese parents. Nature 260, 698-700, 1976.

50 Roberts, SB, J Sawage, WA Coward, B Chew, and A Lucas. Energy expenditure and innake in infants born to lean and overweight mothers. New Eng I Med 318, 461-466, 1988. 
51 Lennon, D, F Nagle, F Stratman, E Shrago, and S Dennis. Diet and exercise training effects on resting metabolic rate. Int J Obes $9,39-47,1985$.

52 Kleiber, M. Body size and metabolic rate. In: Kleiber, M. The fire of live: an introduction to animal energetics. New York, London, Wiley, 1961, pp. 177-216.

53 Harris, JA, and FG Benedict. A biometric study of basal metabolism in mam. Camegie Instiution of Washington, 1919.

54 Roza, AM, and HM Shizgal. The Harris Benedict equation reevaluated: resting energy requirements and the body cell mass. Am J Clin Nutr 40, 168-182, 1984.

55 Schofield, WN. Predicting basal metabolic rate, new standards and review of previous work. Hum Nutr: Clin Nutr. 39C, Suppl 1,5-41, 1985.

56 Owen, OE, E Kavle, RS Owen et al. A reappraisal of caloric requirements in healthy women. Am J Clin Nutr 44, 1-19, 1986.

57 Lawrence. M. Predicting energy requirements: is energy expenditure proportion al to the BMR or to body weight. Eur J Clin Nutr 42, 919-927, 1988.

58 Swain, DP, JR Coast, PS Clifford, MC Milliken, and J Stray-Gundersen. Influence of body size on oxygen consumption during cycling. J Appl Physiol 62, 668-672, 1987.

59. Montoye, HJ, T Ayen, F Nagle, and ET Howley. The oxygen requirement for horizontal and grade walking on a motor-driven treadmill. Med Sci Sports Exerc 17, 640-645, 1985.

60 Waterlow, JC. Notes on the new international estimater of energy requirements. Proc Nutr Soc 45 , $351-360,1986$.

61 Lawrence, M, K Thongprasert, and JVGA Dumin. Berween-group differences in basal metabolic rates: An analysis of data collected in Scorland, The Gambia and Thalland. Eur J Clin Nutr 42 , $877-891,1988$.

62 World Health Organization. Energy and protein requirements, report of a joint FAO/WHO/UNO expert consultation. Technical Report Series 724, Geneva, 1985, pp. 71-79.

63 Westerterp, KR, GAL Meijer, WHM Saris, PB Soeters, Y Winants, and F ten Hoor. Physical activity and sleeping metabolic rate. (submitted for publication).

64 Cunningham, JI. A reanalysis of the factors influencing basal melabolic rate in normal adults. Am J Clin Nutr 33, 2372-2374, 1980.

65 Webb, P. 24-how energy expenditure and the menstrual cycle. Am J Clin Nutr 44, 61.44619. 1986.

66 Solomon, SJ, MS Kurzer, and DH Calloway. Menstrual cycle and basal metabolic rate in womien. An J Clin Nutr 36,611-616, 1982 .

67 Bisdee, JT, WPT James, and MA Shaw. Changes in energy expenditure during the menstrual cycle. Brit J Nutr 61, 187-199, 1989.

68 Ravussin, E, and C Bogardus. Relationships of genetics, age, and physical fintess to daily energy expenditure. Am J Clin Nutr 49, 968-975, 1989. 


\section{Summary}

One of the problems in clarifying the possible relationship between physical activity and health is the lack of a standardized method for the assessment of physical activity under free living conditions. Methods used for this purpose range from job classification, questionnaires and observation, to assessment of physiological parameters like heart rate and maximal oxygen uptake. Recently accelerometers have been added to this spectrum. These instruments allow measurement of body accelerations resulting from movement. Most of the accelerometers available are uni-directional i.e. accelerations are assessed in one direction only. This thesis describes a newly developed three directional accelerometer. Experiments were conducted to test validity and accuracy of the instrument both in the laboratory and under free living conditions. Furthermore two outdoor studies are described using the accelerometer for the assessment of physical activity.

Reviewing literature on different motion sensor techniques, their validity and accuracy, it is concluded that from all motion sensors the accelerometer looks most promising, yet, little is known on its reliability (Chapter 2). Subsequently, the reliability of the three-directional accelerometer is tested during treadmill experiments and with the aid of a device delivering a standardized movement (the bench test). Variation between accelerometers during treadmill walking was on average $22 \%$, and was not improved by adjustment for differences found in the bench test. Reproducibility of the instruments in four bench tests performed within a week was higher than $92 \%$, and in the treadmill experiments on average $85 \%$. We conclude that the the accelerometer is superior to other motion sensors; yet, the technique should be further improved. Possible steps to achieve this improvement are discussed.

In Chapter 3 the relationship between accelerometer output $(A O)$ and heart rate - which was recorded synchronously - one the one hand and energy expenditure on the other hand, is presented. In the laboratory, $A O$ showed a linear relationship with energy expenditure measured by indirect calorimetry during 7 different activities covering most of the range of energy expenditure expected during normal daily life. In a field study, AO showed a strong correlation with energy intake in 4 healthy subjects. In both studies the accelerometer was superior to heart rate recording in this respect.

The validity and accuracy of the accelerometer under free living conditions is described in Chapter 4. Accelerometer output was compared with measurements of physical activity using indirect calotimetry (doubly labeled water and respiration chamber) in 52 subjects. It appeared that from the 11 accelerometers used only 4 showed a strong correlation with energy expenditure due to physical activity. Possible reasons for the malfunctioning of the other 7 are discussed. The pooled data of the former mentioned instruments explain $77 \%$ of the variation in energy expenditure, providing corrections are 
made for individual differences in energy expenditure assessed in the laboratory during similar activities. Without the latter correction the accelerometer may still be a powerful instrument in epidemiological research.

Summarizing these regults it is concluded that the accelerometer using a three directional sensor is a useful instrument for the assessment of physical activity under free living conditions. The accuracy of the method is superior to that of heart rate recording and of all other motion sensor techniques described in literature. Yet, they also show that the accelerometer technique needs further improvement.

Physical activity has been suggested several times to be a potential causal factor for obesity. We found no difference in physical activity between 9 obese and 13 control subjects, either measured with the accelerometer $(9712 \pm 3557$ v $9687 \pm 2753$ counts/day), or with indirect calorimetry and adjusted for differences in fat free mass (116 $\pm 23 \vee 114 \pm 31 \mathrm{~kJ} / \mathrm{kg}$ day) (Chapter 5). Energy intake assessed with a 7-day food diary showed a large discrepancy with energy expenditure in the obese (on average -4.5 $\mathrm{MJ} /$ day). As there were no clear indications of dieting in this group we conclude that underrecording of food intake is the major factor responsible for this discrepancy.

A low physical activity level, quite common in our society, may be increased by participating in (recreational) sports. However, little is known about the effects of such an increase on energy metabolism. We studied metabolic changes and changes in body composition in 32 subjects ( 16 males, 16 females) with an initial low activity level during a 5-month endurance-training program which aimed at running a 1/2 marathon after 9 months (Chapter $6 \& 7$ ). Physical activity assessed with the accelerometer increased with 62 and $63 \%$ after 20 weeks in males and females respectively. This increase was mainly due to the increase in training. Energy expenditure increased significantly in males and outlived expenditure for endurance-training 3 to 4 times. In fermales changes in energy expenditure could be largely attributed to the net cost of training itself and to a small increase in resting metabolic rate. Furthermore, no long-term effect of exercise on sleeping metabolic rate was observed. The results suggest that exercise stimulates physical activity and diet-induced thermogenesis in males, but not in females.

After 20 weeks of training there was no significant change in body mass. However, body composition changed significantly. Loss of fat mass was 2.4 and $0.9 \mathrm{~kg}$ in men and women respectively, while fat free mass increased with 1.7 and $1.0 \mathrm{~kg}$ respectively.

In an analysis of the relationship between body composition and the menstrual cycle on the one hand and sleeping metabolic rate on the other hand, fat free mass was the best single predictor of sleeping metabolic rate, as in most literature on this subject (Chapter 8). However, in our data fat mass made a significant contribution to the model. Possible explanations are discussed. Apart from this the menstrual cycle appears to influence sleeping metabolic rate significantly. Of 16 women, 14 showed increased sleeping metabolic rate in the post-ovular phase of the menstrual cycle. We suggest to include both fat mass and the menstrual cycle in future analyses of sleeping metabolic rate. 


\section{Samenvatting}

Een van de problemen bij het onderzoek naar de mogelijke relatie tussen lichamelijke aktiviteit en gezondheid is het ontbreken van een gestandaardiseerde methode voor het bepalen van lichamelijke aktiviteit van mensen in hun dagelijkse leven. Methoden die hiervoor in het verleden gebruikt zijn lopen uiteen van het indelen naar beroepen, vragenlijsten en directe observatie, tot het meten van fysiologische parameters als hartfrekwentie en maximale zuurstofopnamecapaciteit. De ontwikkeling van versnellingsopnemers voegt een nieuwe methode aan dit spectrum toe. Deze instrumenten meten de versnellingen van het lichaam die ontstaan ten gevolge van bewegingen die gemaakt worden. De meeste versnellingsopnemers zijn slechts gevoelig voor versnellingen in én richting. In dit proefschrift wordt een nieuw ontwikkelde versnellingsopnemer gepresenteerd, die versnellingen in drie richtingen waarneemt. Zowel de validiteit van deze nieuwe methode als de nauwkeurigheid zijn onderzocht, enerzijds in het laboratorium, anderzijds bij mensen onder dagelijkse leefomstandigheden. Daarnaast worden twee experimenten beschreven waarin deze nieuwe methode gebruikt is voor het meten van lichamelijke aktiviteit.

Naar aanleiding van een uitgebreid literateratuuronderzoek met betrekking tot de betrouwbaarheid van verschillende methoden om beweging van het menselijk lichaam te meten, kan geconcludeerd worden dat de versnellingsopnemer de meest veelbelovende techniek is. Tegelijkertijd moet echter geconstateerd worden dat er nog maar weinig bekend is over de nauwkeurigheid van deze techniek (Hoofdstuk 2). De betrouwbaarheid van de hier ontwikkelde versnellingsopnemer is bepaald met behulp van een apparat dat een gestandaardiseerde beweging uitvoert (calibratieproeven), en tijdens proeven op de loopband. Bij de loopbandproeven was de gemiddelde variatie tussen de verschillende versnellingsopnemers $22 \%$. Deze variatie kon niet worden verkleind door te corrigeren voor verschillen die in de calibratieproeven werden gevonden. De reproduceerbaarheid van de instrumenten in vier calibratieproeven die binnen een week werden uitgevoerd was hoger dan $92 \%$; de reproduceerbaarheid tijdens de loopbandproeven was gemiddeld $85 \%$. Hieruit concluderen we dat de hier gepresenteerde versnellingsopnemer beter is dan andere "bewegingsmeters". De techniek blijft echter voor verbeteringen vatbaar; enkele suggesties hiervoor worden besproken.

In Hoofdstuk 3 is de relatie tussen de gemeten versnelling (AO, accelerometer output) en de -gelijktijdig opgenomen- hartfrekwentie en het energiegebruik beschreven. Er werd een lineair verband aangetoond tussen $\mathrm{AO}$ en het energiegebruik -gemeten in het laboratorium met behulp van indirecte calorimetrie-tijdens 7 vormen van aktiviteit met verschillende intensiteit. De intensiteit van deze aktiviteiten kwam overeen met die welke in het normale dagelijkse leven verwacht mogen worden. In een veldonderzoek bij 4 
gezonde proefpersonen bleek $\mathrm{AO}$ sterk gecorreleerd te zijn met de energieopname. In beide onderzoekingen waren de resultaten van de versnellingsopnemer beter dan die op basis van de hartfrekwentiemetingen.

De nauwkeurigheid van de versnellingsopnemer bij meting van lichamelijke aktiviteit onder normale dagelijkse omstandigheden is verder onder de loep genomen in Hoofdstuk 4. Van 52 proefpersonen is $A O$ vergeleken met verschillende maten voor lichamelijke aktiviteit op basis van indirecte calorimetrie (tweevoudig gemerkt water en respiratiekamers). Het bleek dat van de 11 gebruikte versnellingsopnemers slechts 4 een sterk verband tussen $A O$ en het energiegebruik ten gevolge van lichamelijke aktiviteit te zien gaven. Mogelijke oorzaken voor het slecht functioneren van de andere 7 worden beschreven. De gegevens verzameld met de 4 genoemde meters verklaren $77 \%$ van de variatie in energiegebruik, mits gecorrigeerd wordt voor individuele verschillen in energiegebruik zoals die in het laboratorium bij vergelijkbare aktiviteiten worden vastgesteld. Ook zonder deze laatste correctie is de versnellingsopnemer echter een bruikbaar instrument voor epidemiologisch onderzoek.

Samenvattend kan gesteld worden dat de hier gepresenteerde in drie richtingen gevoelige versnellingsopnemer, een bruikbaar instrument is voor het bepalen van de lichamelijke aktiviteit van mensen onder normale dagelijkse omstandigheden. De nauwkeurigheid van de methode is groter dan die van metingen op basis van hartfrekwentie, en van alle andere bekende "bewegingsmeters". Het is echter duidelijk dat de methode verder verbeterd dient te worden.

Regelmatig wordt er gesuggereerd dat lichamelijke aktiviteit een rol zou spelen bij het ontstaan van overgewicht. In een onderzoek naar de lichamelijke aktiviteit van 9 mensen met - en 13 mensen zonder overgewicht vonden wij geen verschil, noch op basis van de metingen met de versnellingsopnemer (AO: $9712 \pm 3557$ v $9687 \pm 2753$ counts/dag), noch op basis van metingen met tweevoudig gemerkt water en gecorrigeerd voor verschillen in vetvrije massa (116 $23 \mathrm{~kJ} / \mathrm{kg}$.dag $v 114 \pm 31 \mathrm{~kJ} / \mathrm{kg}$.dag) (Hoofdstuk 5). De energieopname gemeten met een 7-daags voedingsdagboek bleek vooral bij de mensen met overgewicht veel lager dan het energiegebruik (gemiddeld $-4.5 \mathrm{MJ} / \mathrm{dag}$ ). Aangezien er geen duidelijke indicaties waren voor lijngedrag in deze groep, concluderen we dat deze discrepantie vooral moet worden toegeschreven aan onderrapportage van de voedselopname.

In onze maatschappij hebben veel mensen weinig lichaamsbeweging. Door aan sport te gaan doen kan de lichamelijke aktiviteit verhoogd worden. Er is echter weinig bekend over de effecten van een dergelijke aktiviteitsverhoging op de energiewisseling. Bij 32 ongetrainde mensen (16 mannen, 16 vrouwen) met een laag aktiviteitsniveau bestudeerden wij de veranderingen in energiewisseling en in lichaamssamenstelling, gedurende de eerste 5 maanden van een trainingsprogramma dat gericht was op het lopen van een halve marathon na 9 maanden (Hoofdstuk $6 \& 7$ ). Na 20 weken was de lichamelijke aktiviteit zoals die gemeten werd met de versnellingsopnemer bij mannen en vrouwen met respectievelijk 62 en $63 \%$ toegenomen. Deze toename was vrijwel geheel toe te schrijven 
aan het trainingsprogramma zelf. Bij mannen nam het energiegebruik significant toe; deze toename was 3 tot 4 maal zo hoog dan op basis van de training verwacht mocht worden. Bij de vrouwen kon de toename in het energiegebruik vrijwel geheel worden toegeschreven aan de training en aan een lichte stijging van de ruststofwisseling. Daarnaast werd geen lange termijn effect van de stijging in aktiviteit op de slaapstofwisseling gevonden. Deze resultaten suggereren dat inspanning bij mannen een stimulerend effect heeft op lichamelijke aktiviteit in het algemeen en mogelijk op de dieetgeinduceerde thermogenese, terwijl dit bij vrouwen niet zo is.

Er werden geen veranderingen in lichaamsgewicht gevonden na 20 weken training. De lichaamssamenstelling was echter wel significant veranderd. Bij mannen en vrouwen nam de vetrmassa af met 2.4 respectievelijk $0.9 \mathrm{~kg}$, terwijl de vetwrije massa met 1.7 respectievelijk $1.0 \mathrm{~kg}$ toenam.

$\mathrm{Na}$ analyse van het verband tussen de lichaamssamenstelling en de menstruele cyclus enerzijds, en de slaapstofwisseling anderzijds, bleek dat de vetvrije massa de beste voorspeller is voor de slaapstofwisseling (Hoofdstuk 8), zoals vaker is beschreven in de literatuur. Uitgaande van onze gegevens bleek echter dat toevoeging van de vetmassa aan dit model tot een significante verbetering van dit model leidt. Mogelijke verklaringen hiervoor worden besproken. Daarnaast bleek dat de menstruele cyclus van invloed is op de slaapstofwisseling. Van 16 vrouwen vertoonden 14 een duidelijk verhoogde slaapstofwisseling tijdens de post-ovulaire fase van de menstruele cyclus. Het lijkt daarom aan te bevelen om bij toekomstig onderzoek naar de slaapstofwisseling, naast de vetvrije massa ook rekening te houden met de vetmassa en, bij vrouwen, tevens met de fase van de menstruele cyclus. 


\section{Dankwoord}

Tijdens het onderzoek dat ik de afgelopen vier jaar verrichtte heb ik met veel mensen samengewerkt. Al deze mensen wil ik hartelijk bedanken voor hun bijdrage aan dit werk. Enkelen van hen zou ik hier graag noemen.

In de eerste plaats Rika, het is ook jou doorzettingsvermogen dat doorklinkt in dit proefschrift. Sander en Tomas, jullie enthousiasme voor alles wat papa doet hoop ik ook op dit werk te mogen betrekken, we zullen dat later uitvechten.

Van mijn begeleiders gaat mijn dank allereerst uit naar Dr. K. R. Westerterp. Klaas, je inhoudelijke en praktische inbreng zijn onontbeerlijk geweest voor de totstandkoming van dit proefschrift. Je gaf me de ruimte om zelf beslissingen te nemen. We hebben goed en met plezier samengewerkt. Ik heb veel van je geleerd.

Prof. Dr. F. ten Hoor en Prof. Dr. Ir. W.H.M. Saris, mijn promotoren, toonden een warme belangstelling voor de opzet en het verloop van de diverse eksperimenten. Foppe en Wim, het proefschrift heeft veel aan kracht gewonnen door de diskussies die we gevoerd hebben, waarvoor mijn hartelijke dank.

Prof. Dr. Ir. J.D. Janssen, Prof. Dr. R.A. Binkhorst, Prof. Dr. A. Tremblay en Prof. Dr. P. Webb wil ik bedanken voor hun opmerkingen, die tot een verdere verbetering van het manuscript hebben geleid.

Hans Koper, je hebt de versnellingsmeters ontworpen en gebouwd. Ik wil je bedanken voor de inzet en het geduld dat je bij dit werk hebt getoond en voor de het feit dat je op de onmogelijkste momenten klaar stond voor reparaties en onderhoud.

Uiteraard gaat mijn dank ook uit naar de proefpersonen zonder wiens vrijwillige inzet en bewonderenswaardige doorzettingsvermogen onze ideeën nooit van de grond gekomen waren.

Gène Janssen die betrokken was bij de opzet van het "halve marathon projekt", en zorg droeg voor de training van de proefpersonen.

Harm Kuipers, Hans Keizer en de andere mensen van het sportlaboratorium, die hun ruimte beschikbaar stelden voor de loopbandproeven. 
Het onderzoek dat tot dit proefschrift heeft geleid was onmogelijk geweest zonder de helpende handen van Astrid van Hulsel, Gerard Seyts, Francois Verhoeven, Syska Walgemoet, Heleen Verdonk, Ellen van den Heuvel, Judith Kalksma, Elly Ermens en Suzan Diender, die als stagiares bij de direkte uitvoering van de proeven betrokken waren.

Loek Wouters, die het programma schreef om de meters uit te kumen lezen en de urinemonsters analyseerde.

Paul Schoffelen die alle problemen met computers wist op te lossen en de respiratiekamers draaiende hield.

Margriet Westerterp, je hebt het voor elkaar gekregen dat de versnellingsmeter op de televisie te zien was.

Ed Beckers en Annemie Gijssen voor de verwerking van de urinemonsters.

Truus Dickhaut en Mary Peters voor de secretariële werkzaamheden.

Trudy Mullers en Elly Brouwer voor de hulp in de keuken.

Nancy Rehrer, je was het beste kamermaatje dat ik me kon wensen. Vele malen heb je mijn gewroet met het Engels verbeterd. Het doet me goed dat we, hoewel we inhoudelijk op een heel ander terrein bezig zijn, een proef hebben kunnen opzetten, waarvan de publicatie binnenkort verschijnt.

Tenslotte wil ik alle collega's van de vakgoep Humane Biologie bedanken voor de goede sfeer waarin ik heb kunnen werken.

Jannes en Inge, het schijnt dat $\mathrm{ik}$ gezegd heb professor van het bos te zullen worden. Of dat lukt weet ik niet, ik geloof dat ik wat afgedwaald ben. Maar ik weet wel dat als ik het door de bomen niet meer zie, ik altijd op jullie terug kan vallen. 
Gerwin Alexander Leo Meijer werd geboren op 12 augustus 1959 te Emmen. Na het behalen van het Atheneum-B diploma in 1977, begon hij in datzelfde jaar aan de studie Biologie te Groningen. Hij legde twee kandidaatsexamens af. In 1981 het kandidaatsexamen Biologie (B1), en in 1982 het kandidaatsexamen Biochemie (B4). Voor het eerste doctoraalhoofdvak (Ethologie; Dr. J. Veen en Prof. Dr. G.P. Baerends) verbleef hij vijf maanden op het eiland Griend, als stagiaire bij de Vereniging tot behoud van Natuurmonumenten. Het doctoraalexamen omvatte verder het tweede hoofdvak Oecologie (Dr. D. Masman en Dr. S. Daan), en het bijvak Didaktiek (Drs. R. Delhaas). In 1985 behaalde hij het doctoraalexamen (cum laude; Prof. Dr. R.H. Drent). Sindsdien was hij werkzaam als wetenschappelijk assistent aan de Rijksuniversiteit Limburg, Faculteit der Gezondheidswetenschappen, bij de vakgroep Humane Biologie (Dr. K.R. Westerterp, Prof. Dr. F. ten Hoor en Prof. Dr. Ir. W.H.M. Saris). Het onderzoek dat hij daar verrichtte naar de effecten van lichamelijke aktiviteit op de energiewisseling is beschreven in dit proefschrift. 


\section{Publications}

Meijer, G.A.L. and K.R. Westerterp. Assessment of physical activity using synchronous recording of heart rate and body acceleration. Proc. Nutr. Soc., Vol. 47, 25A, 1988 .

Meijer, G.A.L., K.R. Westerterp. H. Koper, and F. ten Hoor. Assessment of energy expenditure by recording heart rate and body acceleration. Med. Sci. Sports Exerc., Vol. 21, No. 3, pp. 343-347, 1989.

Meijer, G.A.L. Energy requirements of the obese: the effect of body mass on energy expendinure. Int. J. Obes, Vol. 13, Suppl. 1, 7, 1989.

Meijer, G.A.L., K.R. Westerterp, F. Verhoeven, H. Koper, and F, ten Hoor. Methods to assess physical actiwity with special reference to motion sensors and accelerometers.

(rubmitred for publication).

Meijer, G.A.L., K.R. Westerterp, L. Wouters, and F, ten Hoor. Validity of the accelerometer in the field; a comparison with the doubly labeled water technique. (submitted for publication).

Meijer, G.A.L., K.R. Westenterp, A.M.P. van Hulsel, and F. ten Hoor. Physical activity and energy expenditure in lean and obese adult thuman subjects. (submitted for publication)

Meijer, G.A.L., G.M.E. Janssen, K.R. Westerterp, F "Verhoeven, W.H.M. Saris, and F, ten Hoor. The effect of a 5 -month endurance-training program on physical activity: evidence for a sexdifference in the melabolic response to exercise. (to be submitted).

Meijer, G.A.L., K.R. Westerterp, G.H.P. Seyts, G.M.E. Janssen, W.H.M. Saris, and F. ten Hoor, Body composition and sleeping metabolic rate in response to a 5 -month endurance training program. (to be submitted).

Meijer, G.A.L., K.R. Westerterp. W.H.M. Saris, and F. ten Hoor. Sleeping metabolic rate in relation to body composition and the menstrual cycle. (to be submitsed).

Westerterp, K.R. G.A.L. Meijer, W.H.M. Saris, P.B. Soeters, Y. Winants, and F. Hen Hoor. Physical activity and slecping metabolic rate. (subminted for publication).

Westerterp, K.R., G.A.L. Meijer, L. Wouters, and F, ten Hoor. Fat-free mass as a function of fat mass and habitual activity level. (submitted for publication).

Rehrer, N.J., and G.A.L. Meijer. Biomechanical vibration of the abdominal region during running and bicycling. J. Sports Med. , 1990 (in pressi). 